\title{
Influence of fire suppression on combustion products in tunnel fires
}

Ying Zhen Li, Lotta Vylund, Haukur Ingason, Glenn Appel

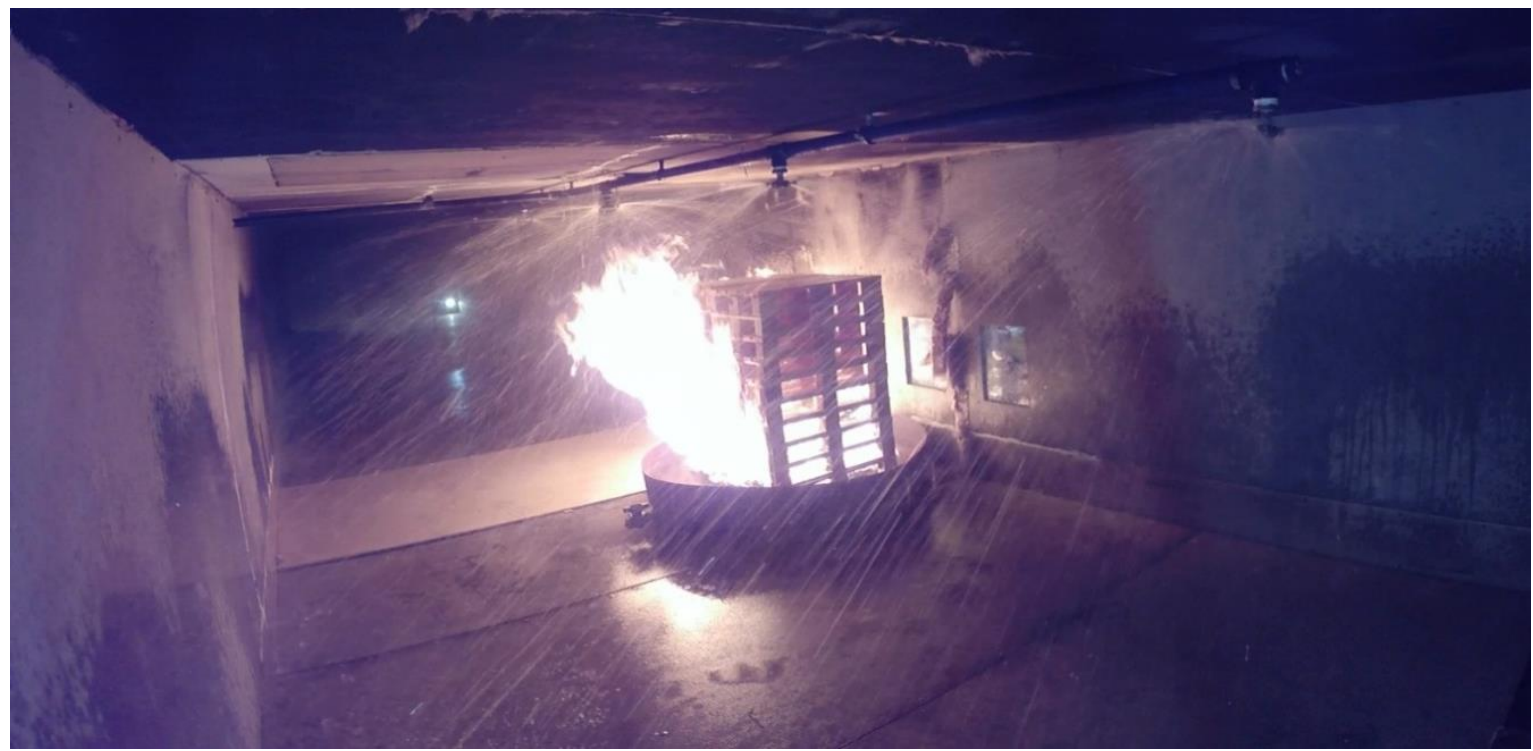




\section{Influence of fire suppression on combustion products in tunnel fires}

Ying Zhen Li, Lotta Vylund, Haukur Ingason, Glenn Appel 


\section{Abstract \\ Influence of fire suppression on combustion products in tunnel fires}

A series of pre-tests and tunnel fire model scale tests with and without fire suppression were carried out to investigate effects of fire suppression on production of key combustion products including $\mathrm{CO}$ and soot. The key parameters accounted for in the tests include fuel type, ventilation velocity and activation time. The results show that fire suppression indeed has influence on production of combustion products especially for cellulous fires. In case that the fire is not effectively suppressed, e.g. when the water density is too low or activation is too late, the CO concentration and visibility could be worse than in the free-burn test. From the point of view of production of combustion products, only fire suppression systems with sufficient capability and early activation are recommended to be used in tunnels.

Key words: tunnel fire, fire suppression, ventilation, activation, $\mathrm{CO}$ yield, soot yield, visibility

\section{SP Sveriges Tekniska Forskningsinstitut}

SP Technical Research Institute of Sweden

SP Report 2015:09

ISBN 978-91-88001-39-9

ISSN 0284-5172

Borås 2015 


\section{Contents}

$\begin{array}{lr}\text { Abstract } & 3\end{array}$

$\begin{array}{lr}\text { Contents } & 4\end{array}$

Preface 6

$\begin{array}{ll}\text { Summary } & 7\end{array}$

1 Introduction $\quad 10$

2 Theory $\quad 12$

$\begin{array}{lll}2.1 & \text { Scaling theory } & 12\end{array}$

$2.2 \quad$ Heat release rate 14

$\begin{array}{lll}2.3 & \text { CO production } & 14\end{array}$

2.4 Soot yield 15

2.5 Visibility 15

$\begin{array}{lll}2.6 & \text { A short discussion } & 15\end{array}$

$3 \quad$ Experimental Setup 17

3.1 Pre-tests 17

3.2 Model tunnel fire tests 19

3.2.1 Model scale tunnel 19

$\begin{array}{lll}3.2 .2 & \text { Water spray system } & 20\end{array}$

$\begin{array}{lll}3.2 .3 & \text { Ventilation system } & 21\end{array}$

3.2.4 Fire load 21

$\begin{array}{lll}3.2 .5 & \text { Measurement } & 22\end{array}$

$4 \quad$ Test procedure $\quad 24$

4.1 Pre-tests 24

$\begin{array}{lll}4.2 & \text { Tunnel fire tests } & 24\end{array}$

$5 \quad$ Results and discussion $\quad 26$

5.1 Pre-tests 26

$\begin{array}{lll}5.1 .1 & \text { Tyre fires } & 26\end{array}$

$\begin{array}{lll}5.1 .2 & \text { Wood pallet fires } & 27\end{array}$

5.1.3 PE slab fires 28

$\begin{array}{lll}\text { 5.1.4 PUR slab fires } & 29\end{array}$

5.1.5 A discussion for the pre-tests 31

$\begin{array}{lll}5.2 & \text { Wood pallet fires in tunnel tests } & 31\end{array}$

5.2.1 Heat release rates in wood pallet fires 31

5.2.2 CO production in wood pallet fires 33

$\begin{array}{lll}\text { 5.2.3 Soot production in wood pallet fires } & 37\end{array}$

5.2.4 Visibility at mid tunnel height in wood pallet fires 40

5.2.5 Discussion of wood pallet fires 41

5.3 PE crib fires in tunnel tests 42

5.3.1 Heat release rates in PE crib fires 42

5.3.2 CO production in PE crib fires 45 
5.3.3 Soot production in PE crib fires 51

5.3.4 Visibility at mid tunnel height in PE crib fires 54

5.3.5 Discussion of PE crib fires 56

5.4 PUR crib fires in tunnel tests 57

5.4.1 Heat release rate in PUR crib fires $\quad 57$

5.4.2 CO production in PUR crib fires 58

5.4.3 Soot production in PUR crib fires $\quad 62$

5.4.4 Visibility at mid tunnel height in PUR crib fires 64

5.4.5 Discussion of PUR crib fires 64

5.5 HCN production in tunnel tests $\quad 65$

$\begin{array}{lll}5.6 & \text { Summary of test data } & 65\end{array}$

$6 \quad$ Summary and conclusions $\quad 66$

$\begin{array}{lll}7 & \text { References } & 68\end{array}$ 


\section{Preface}

The Stockholm bypass project was granted co-funding for research, including testing, from the European Union (EU) through the Trans-European Transport Network (TEN-T). The model scale tests presented in this report were performed within the framework of this EU project. Special thanks to Ulf Lundström and Henric Modigh for their support and encouragement during the performance of the tests.

The technicians Sven-Gunnar Gustafsson, Tarmo Karjalainen and Michael Magnusson at SP Fire Research are acknowledged for the construction of the test rig and the valuable assistance during performance of the tests. We would also like to thank Oskar Bialas for the assistance in carrying out some of the tests.

The sole responsibility of this publication lies with the authors. The European Union is not responsible for any use that may be made of the information contained therein. 


\section{Summary}

A series of pre-tests and a series of model scale tunnel fire tests with and without fire suppression were carried out to investigate the effect of fire suppression on production of key combustion products. The key parameters accounted for in the tests include fuel type, ventilation velocity and activation time.

The focus of the study was to investigate the effects of water-based suppression systems on production of $\mathrm{CO}$, visibility and soot production and put it into the context of corresponding free burning fire load without any interaction of fire suppression. The main concern is whether the suppression system can cause adverse effects on the conditions inside the tunnel. Pre-tests were carried out in a fire laboratory under a large industrial calorimeter measuring heat release rates and gas flows. This was followed by tests carried out in a $15 \mathrm{~m}$ long, $2.8 \mathrm{~m}$ wide and $1.4 \mathrm{~m}$ high model scale tunnel.

The parameters focused on are the yield and production rate of the key combustion products, i.e. CO and soot. The yield of one combustion product, $Y(\mathrm{~kg} / \mathrm{kg})$, is defined as the amount of the combustion product produced by consuming $1 \mathrm{~kg}$ of fuel. The production rate of one combustion product is defined as the mass of the combustion product produced per second.

\section{- Pre-tests}

For the tyre fire, the soot yield is mainly in a range of 0.05 to 0.08 and it is as high as 0.16 at the ignition stage, and the $\mathrm{CO}$ yield is in a range of 0.04 to 0.08 . For wood pallet fires, the soot yield in the free burn test increases with time up to approximately 0.02 before $2.5 \mathrm{~min}$ after ignition and decreases to approx. 0.001 after $5 \mathrm{~min}$. For PE slab fires, the CO yield is mainly in a range of 0.02 to 0.06 , and the soot yield in the free-burn test increases continuously to around 0.11 at $13 \mathrm{~min}$. For PUR slab fires, the CO yield is around 0.08 during most of the burning period and the soot yields in both tests are in a range of 0.03 to 0.06 .

The fires were not effectively suppressed except the PE slab fire. The effect of fire suppression on the $\mathrm{CO}$ yield and soot yield is not significant with the only exception of that they may rise during a short period. However, it should be kept in mind that the water flow rate delivered by the nozzle was only around $1.5 \mathrm{~mm} / \mathrm{min}$ at the floor level, much lower than the one used in tunnel fire tests, as the main objective of the pre-tests was to obtain burning rates of the fuels planned for use in the tunnel fire tests.

\section{- Tunnel fire tests}

For the fires of all the three types of fuel, i.e. wood pallet, PE crib and PUR crib, the effect of ventilation velocity on the maximum heat release rate is insignificant. The fire appears to grow more rapidly at a higher ventilation velocity. After activation of the fire suppression system with a water density of $5 \mathrm{~mm} / \mathrm{min}(10 \mathrm{~mm} / \mathrm{min}$ at full scale), the fires were effectively 
suppressed under all the velocities tested, with or without coverage. The wood crib fires take slightly longer time to decay compared to the plastic fires. The fire with coverage both develops and decays more slowly but the maximum heat release rate is approximately the same.

The $\mathrm{CO}$ yields in the free burn tests tend to decrease slightly with the ventilation velocity and the time. In tests with fire suppression, the $\mathrm{CO}$ yields generally increase with the decreasing heat release rates. In tests with later activation after the heat release rate decreases to around $100 \mathrm{~kW}$ to $200 \mathrm{~kW}$ (3 MW to $6 \mathrm{MW}$ at full scale), significant increase (3.5 to 4.5 times increase) in $\mathrm{CO}$ yield could be observed, especially for wood pallet fires. Note that without activation of the water spray system the fires could develop up to $1800 \mathrm{~kW}$ (57 MW) to 3200 $\mathrm{kW}$ (100 MW). In other words, production of CO mainly occurs when the fire is close to the extinguishment. However in most tests with suppression, the contribution of the high $\mathrm{CO}$ yield to the $\mathrm{CO}$ production rate is limited as the corresponding heat release rates are at a low level. Given that the maximum CO concentration at mid tunnel height (10.6 m downstream, corresponding to $42 \mathrm{~m}$ at full scale) in the free burn test is still the highest for all the fuels and velocities tested, the free burn tests could still represent the worst scenarios from the point of view of $\mathrm{CO}$ concentration and evacuation. Further, early activation reduces the $\mathrm{CO}$ concentration significantly.

Concerning soot it should be kept in mind that the estimated soot production or soot yield after activation of fire suppression become higher than real values and can only be used as indications of upper limits. The reason for this is that the attenuation of light intensity accounts for effects of both soot and water droplets. The soot yields in the free burn test tend to decrease with the ventilation velocity and increase with time. The soot yields in free burn tests and fire suppression tests approximately lie at the same level but after activation when the heat release rate is lower than a certain value, e.g. $150 \mathrm{~kW}-200 \mathrm{~kW}$, the soot yields increase significantly with time. Fortunately this period is very short and also corresponds to very small heat release rates. Therefore the contribution to the smoke production rate is limited even if the soot yield is high. In all the tests the maximum soot production rate in the free-burn test is the highest. Consequently, during the whole period, it can be concluded that the free-burn test can be considered as the worst case in terms of visibility.

The visibility in the free burn tests for all the fuels is generally the lowest compared to fire suppression tests due to that the heat release rate decreased immediately after activation of the fire suppression system.

Note that data of $\mathrm{CO}$ and visibility are reliable but not for data of the soot. In summary, test results of $\mathrm{CO}$ concentration at the early stage indicate that in most cases, the free burn test corresponds to the worst scenario despite that in the decay period of a fire with late activation the $\mathrm{CO}$ concentration could be higher. Further, test results of visibility show that that the free burn test corresponds to the minimum value. 
It is observed that wood pallet fires behave differently compared to the plastic crib fires. In the wood crib tests with late activation, the $\mathrm{CO}$ concentration in the decay period is slightly higher than that in the free-burn test. The difference in the $\mathrm{CO}$ yield is, however, much larger. The $\mathrm{CO}$ yield of a wood pallet fire after fire suppression is generally 3.5 to 4.5 times that in a free-burn test while generally the $\mathrm{CO}$ yield in the plastic fires increases slightly after suppression and only in tests 11 and 25 significant increase is observed. The high CO yield for wood pallet fires after suppression indicates strong interaction between the water droplets, the produced water vapours and the combustion gases for wood pallet fires, which results in incomplete combustion. There could be two reasons for this. One reason could be that the cellulose materials, e.g. wood, absorb water into the material, which to some extent behaves as a water sink. During fire suppression, the unburnt fuels can be pre-wetted while part of the fuels could be extinguished and then absorbs water. During the fire, a large amount of water vapours could be produced from these extra water sources and interact strongly with the combustion gases. Another reason could be that for a same maximum heat release rate, a wood pallet fire corresponds to a larger exposed fuel surface area and more fuel surfaces could be pre-wetted, compared to a plastic crib fire.

Based on the test data and the above analysis, it can be concluded for the fires tested that lowpressure fire suppression does not cause significant adverse effect in case that the fire can be effectively suppressed after activation, that is, the fire size has been reduced to less than $40 \%$ of that in the free-burn test. To achieve this goal, early activation and high water density is required. In case that the fire is not effectively suppressed, e.g. when the water density is too low or activation is too late, the $\mathrm{CO}$ concentration and visibility could be much worse than in the free-burn test.

Therefore, from the point of view of production of combustion products, only fire suppression systems with sufficient capability and early activation are recommended to be used in tunnels. 


\section{$1 \quad$ Introduction}

Nowadays use of water-based fire suppression systems in tunnels has attracted much attention and the regulations and standards are also changing with regard to its use. Despite this, there are still numerous issues needed to be clarified before quantitative guidelines can be made.

The Swedish Transport Administration (STA) plans to construct a new highway connection through the western part of Stockholm called the Stockholm bypass, due for completion in 2025. A new type of water based fire suppression system will be installed in the tunnel. In earlier studies within the frame of the EU co-funded project (TEN-T) a concern was raised that if the system activates late, an increase of toxic substances and smoke could be produced. The impact of this effect could be mitigated by activating the system early. Further research was needed to investigate the implication of this observation in future testing [1]. The work presented here is directly related to the research question raised.

Other related studies show that the design fires can be reduced if tested water-based fire suppression systems are used. This leads to so-called technical trade-offs on protection of the tunnel structure, ventilation systems and evacuation [2]. The gas temperature in the ceiling near the fire may be reduced from $1350{ }^{\circ} \mathrm{C}$ to lower than $1000{ }^{\circ} \mathrm{C}$ in a tunnel with a waterbased fire suppression system and thus less fire protection for the tunnel structure could be required. The possibly lowered design fire size results in decrease in ventilation design and may also facilitate the evacuation. Therefore by introducing these technical trade-offs, a costeffective system is possible. The main problem is the uncertainty of these technical changes as they are very sensitive to the specific water-based fire suppression systems.

There was a concern raised by STA about using water spray suppression systems in tunnels and the risk for negative effects of it in combination with transporting water-reactive dangerous goods through road tunnels. As a part of this study this was investigated in a separate report where it was found that as water reactive chemicals are transported in liquid form, liquid pool will be formed upon release. In most cases the pool will react exothermically with ground water, water from the substrate and in several cases water from the atmosphere. One could expect therefore that water-reactive chemicals will find plenty of water in tunnel environments so that further application of water from a sprinkler system will mainly cool any exothermic reactions including fire. This is unlikely a worse situation than a release on roads above ground, which may be an issue of minor relevance, given that these substances are allowed for road transportation [3].

There have been many full scale fire suppression tests carried out in tunnels [4-12]. These tests have been mainly concerned about the design fires in tunnels with focus on specific fire suppression systems. Model scale tests have also been performed to systematically investigate the design fires with different fire suppression systems [13]. Tests with automatic suppression systems in tunnels have also been carried out in model scale [14]. 
At present it is clear that by equipping a tunnel with a deluge water-based fire suppression system of enough capacity, e.g. greater than $10 \mathrm{~mm} / \mathrm{min}$ for a water spray system, the design fire can be reduced to a lower level [2]. It is, however, not clear how the combustion products are released in such cases. As the fire is suppressed due to the intervention of the water sprays, strong interaction between the combustion and water sprays exist. This results in changes in the production of combustion products, which in turn changes the environment in the tunnel. Therefore this issue is very important for analysis of evacuation in a tunnel fire after activation of a suppression system. A scenario similar to the use of water-based fire suppressions is the fire-fighting operation in a tunnel fire. Note that the fire fighters uses fire hoses to suppress and extinguish the fire. The agent used can be water, foam, or mixture of water and foam, but for attacking solid fuel fires water is mostly used. In such cases, the same adverse effect as that using a fixed water-based fire suppression system exists. Clearly, this issue has to be clearly addressed from the point of view of both tunnel safety designs and firefighting operations.

The main objective of the work is therefore to investigate effects of a deluge water-based fire suppression systems on combustion products in tunnel fires. The focuses are on CO concentration, $\mathrm{CO}$ yield, soot yield and visibility. 


\section{Theory}

\subsection{Scaling theory}

The Froude scaling technique has been applied in this project. Although it is impossible and in most cases not necessary to preserve all the terms obtained by scaling theory simultaneously, the terms that are most important and most related to the study are preserved. The thermal inertia of the involved material, turbulence intensity and radiation are not explicitly scaled, and the uncertainty due to the scaling is difficult to estimate. However, the Froude scaling has been used widely in enclosure fires. Our experience of model tunnel fire tests shows there is a good agreement between model scale and large scale test results on many focused issues [15-20].

The model tunnel was built in a scale of 1:4, which means that the size of the tunnel is scaled geometrically according to this ratio. The scaling of other variables such as the heat release rate, flow rates and the water flow rate can be seen in Table 1.

Previously one series of tunnel tests with a similar fire suppression system was carried out to investigate the effects of ventilation velocity, different suppression systems and other parameters on the performance of fire suppression systems, and to study the design fires for tunnels with fire suppression [13].

Wood pallets are used as one main fuel type. Scaling of wood pallet fires is applied in this work, see reference [21].

Visibility, $V_{i s}(\mathrm{~m})$, can be directly estimated using the extinction coefficient:

$$
V_{i s} \propto \frac{1}{C}
$$

The extinction coefficient, $C(1 / \mathrm{m})$, can be obtained by the following:

$$
C=\frac{1}{L} \log \left(\frac{I_{o}}{I}\right)
$$

where $L$ is the light path length, $I_{o}$ is the intensity of the incident light and $I$ is the intensity of light through the smoke.

The average extinction coefficient can also be estimated using:

$$
C=\frac{\dot{m}_{f} Y_{s} \sigma_{s}}{\dot{V}_{g}}
$$

where $\dot{m}_{f}$ is fuel mass loss rate $(\mathrm{kg} / \mathrm{s}), Y_{s}$ is soot yield $(\mathrm{kg} / \mathrm{kg}), \sigma_{s}$ is a specific mass extinction 
coefficient $\left(\mathrm{m}^{2} / \mathrm{kg}\right)$, which can be considered as a constant, $\dot{V}_{g}$ is volume flow rate of the tunnel flow $\left(\mathrm{m}^{3} / \mathrm{s}\right)$. The specific mass extinction coefficient, $\sigma_{s}$, is considered as a constant $3300 \mathrm{~m}^{2} / \mathrm{kg}$ for flaming combustion [22].

It is assumed that the same fuel type is used in model scales. Also, note that that the fuel mass burning rate and smoke mass flow rate scales as $5 / 2$ power of the length scale. Therefore the average extinction coefficient scales as:

$$
C \propto Y_{s} \propto l^{0}
$$

This suggests that the average extinction coefficient and the visibility scales as the soot yield. Note that in most cases the soot yield is insensitive to the scale, that is, the average extinction coefficient and the visibility scales as zero order of the length scale. In other words, they are approximately the same in all scales.

Table 1 A list of scaling correlations for the model tunnel.

\begin{tabular}{|c|c|c|}
\hline Type of unit & Scaling model $^{*}$ & Eq. number \\
\hline $\begin{array}{l}\text { Heat Release Rate Q } \\
(\mathrm{HRR})(\mathrm{kW})\end{array}$ & $\frac{Q_{F}}{Q_{M}}=\left(\frac{L_{F}}{L_{M}}\right)^{5 / 2}$ & Eq. (5) \\
\hline Volume flow $\dot{V}\left(\mathrm{~m}^{3} / \mathrm{s}\right)$ & $\frac{\dot{V}_{F}}{\dot{V}_{M}}=\left(\frac{L_{F}}{L_{M}}\right)^{5 / 2}$ & Eq. (6) \\
\hline Velocity $u(\mathrm{~m} / \mathrm{s})$ & $\frac{u_{F}}{u_{M}}=\left(\frac{u_{F}}{u_{M}}\right)^{1 / 2}$ & Eq. (7) \\
\hline Time $t(\mathrm{~s})$ & $\frac{t_{F}}{t_{M}}=\left(\frac{L_{F}}{L_{M}}\right)^{1 / 2}$ & Eq. (8) \\
\hline Energy $E(\mathrm{~kJ})$ & $\frac{E_{F}}{E_{M}}=\left(\frac{L_{F}}{L_{M}}\right)^{3}$ & Eq. (9) \\
\hline Mass $m(\mathrm{~kg})$ & $\frac{m_{F}}{m_{M}}=\left(\frac{L_{F}}{L_{M}}\right)^{3}$ & Eq. (10) \\
\hline Temperature $T(\mathrm{~K})$ & $T_{F}=T_{M}$ & Eq. (11) \\
\hline Water flow rate $\dot{q}_{w}(\mathrm{~L} / \mathrm{min})$ & $\frac{\dot{q}_{w, F}}{\dot{q}_{w, M}}=\left(\frac{L_{F}}{L_{M}}\right)^{5 / 2}$ & Eq. (12) \\
\hline Water density $\dot{q}^{\prime \prime}(\mathrm{mm} / \mathrm{min})$ & $\frac{\dot{q}_{w, F}^{\prime \prime}}{\dot{q}_{w, M}^{\prime \prime}}=\left(\frac{L_{F}}{L_{M}}\right)^{1 / 2}$ & Eq. (13) \\
\hline $\begin{array}{l}\text { Pressure difference } P \\
(\mathrm{~Pa})\end{array}$ & $\frac{P_{F}}{P_{M}}=\frac{L_{F}}{L_{M}}$ & Eq. (14) \\
\hline Water droplet $d(\mu \mathrm{m})$ & $\frac{d_{F}}{d_{M}}=\left(\frac{L_{F}}{L_{M}}\right)^{1 / 2}$ & Eq. (15) \\
\hline
\end{tabular}

*Assume the ratio of heat of combustion $\Delta H_{c, M} / \Delta H_{c, F}=1 . L$ is the length scale (m). Index $M$ is related to the model scale and index $F$ to full scale. 


\subsection{Heat release rate}

The heat release rates could be estimated using the oxygen consumption method [23, 24]:

$$
\dot{Q}=14330 \sum \dot{m}_{i}\left[\frac{X_{0, O_{2}}\left(1-X_{\mathrm{CO}_{2}, i}\right)-X_{O_{2}, i}\left(1-X_{0, \mathrm{CO}_{2}}\right)}{1-X_{\mathrm{O}_{2}, i}-X_{\mathrm{CO}_{2}, i}}\right]
$$

where $\dot{Q}$ is the heat release rate $(\mathrm{kW}), \dot{m}_{i}$ is the mass flow rate of the $i$ th layer, $X_{0, O_{2}}$ is the volume fraction of oxygen in the incoming air (ambient) or 0.2095, $\mathrm{X}_{0, \mathrm{CO}_{2}}$ is the volume fraction of carbon dioxide in the incoming air (ambient) or $X_{0, \mathrm{CO}_{2}} \approx 0.00033, \mathrm{X}_{\mathrm{O}_{2}}$ and $\mathrm{X}_{\mathrm{CO}_{2}}$ are the volume fractions of oxygen and carbon dioxide measured by a gas analyser (dry) at the measuring station downstream of the fire. Since the gas temperatures at the measurement station were not very high in the tests with fire suppression, the humidity was considered to have quite limited influence on the estimation of the heat release rates and thus ignored. Note that the tunnel is divided into several horizontal layers in order to estimate the heat release rate and other parameters. At each layer the properties are assumed to be uniform.

Alternatively, the heat release rates can be estimated using the mass loss method:

$$
\dot{Q}=\dot{m}_{f} \Delta H_{c, e f f}
$$

where $\dot{m}_{f}$ is fuel mass loss rate and $\Delta H_{c, \text { eff }}$ is effective heat of combustion.

Therefore the fuel mass loss rate, $\dot{m}_{f}$, can be estimated using:

$$
\dot{m}_{f}=\frac{\dot{Q}}{\Delta H_{c, e f f}}
$$

Note that the fuel mass loss cannot be directly measured by a weighing platform after a fire suppression system is activated as the water droplets affect the weight measurement significantly. Instead, the heat release rate in Eq. (18) should be estimated using the oxygen consumption method, i.e. Eq. (16).

\subsection{CO production}

The $\mathrm{CO}$ production rate $(\mathrm{kg} / \mathrm{s})$ can be calculated by:

$$
\dot{m}_{C O}=\frac{M_{C O}}{M} \dot{m}_{g} X_{C O}
$$

where $\dot{m}_{g}$ is mass flow rate of the tunnel flow $(\mathrm{kg} / \mathrm{s}), M$ is molecular weight $(\mathrm{kg} / \mathrm{kmol})$. Note that the tunnel is divided into several horizontal layers in order to estimate the CO production rate. 
The CO yield $(\mathrm{kg} / \mathrm{kg})$ is defined as:

$$
Y_{C O}=\frac{\dot{m}_{C O}}{\dot{m}_{f}}
$$

\subsection{Soot yield}

The soot yield, $Y_{s}(\mathrm{~kg} / \mathrm{kg})$, is defined as:

$$
Y_{s}=\frac{\dot{m}_{s}}{\dot{m}_{f}}
$$

It should be pointed out that after a fire suppression system is activated, a laser/photocell in fact measures the obscuration due to the combined effect of both soot produced by the fire and water vapor produced and introduced by the fire suppression system. Generally the assumption is reasonable that a fire suppression system does not cause significant soot deposition (the amount of soot washed away by fire suppression is negligible), especially for nozzles producing large droplets, e.g. T-Rex nozzles. Therefore after a fire suppression system is activated, the measured soot concentration could be considered as upper limits for soot production. Note that the tunnel is divided into several horizontal layers in order to estimate the soot yield.

\subsection{Visibility}

Visibility, $V_{i s}(\mathrm{~m})$, can be directly estimated using the extinction coefficient:

$$
V_{i s}=\frac{a}{C_{s}}
$$

The parameter $a$ is a constant related to the characteristics of the evacuation sign and the smoke. The value of a is in a range of 5 to $10 \mathrm{~m}$ for a light-emitting sign and 2 to 4 for a reflecting sign. As light-emitting signs along the tunnels are required, a conservative value of 5 is chosen for calculation of the visibility in this work.

The extinction coefficient, $C_{s}(1 / \mathrm{m})$, in Eq. (22) can be obtained by the following:

$$
C_{s}=\frac{1}{L} \ln \left(\frac{I_{o}}{I}\right)
$$

where $L$ is the light path length, $I_{o}$ is the intensity of the incident light and $I$ is the intensity of light through the smoke.

\subsection{A short discussion}

There exist data from free burn tests in small laboratory tests measuring the $\mathrm{CO}$ and soot yields for the materials tested in this project $[25,26]$. For later comparison of the 
experimental data these values are presented in Table 2. Although these values were obtained in totally different environment compared to here, they can be used as indicator of what to expect for each material without interaction of water.

Table 2 Data obtained from other reports on CO and soot yield [25, 26].

\begin{tabular}{|l|c|c|}
\hline Fuel & $\mathrm{Y}_{\mathrm{co}}(\mathrm{kg} / \mathrm{kg})$ & $\mathrm{Y}_{\mathrm{s}}(\mathrm{kg} / \mathrm{kg})$ \\
\hline Tire & $0.048-0.060$ & $0.001^{* *}-0.015$ \\
\hline Wood & 0.005 & 0.060 \\
\hline PE & 0.024 & 0.13 \\
\hline PUR & 0.031 & \\
\hline
\end{tabular}

${ }^{*}$ not measured. ${ }^{* *}$ Measured under furniture calorimeter at SP.

Note that the visibility is affected by fire suppression systems in the tests as would be the case in real fire situation inside a tunnel. The analysis in Section 2.1 using scale models are assumed to work in both large and small scales. In other words, the average extinction coefficient and the visibility are approximately the same in all scales.

The measured data for $\mathrm{CO}$ are not directly affected by water spray and therefore deemed as reliable criteria while investigating the effect of fire suppression system on combustion products.

However, in the case of visibility measurement, after a fire suppression system is activated, the laser/photocell measures the obscuration due to the combined effect of both soot produced by the fire and water vapor originated from the fire suppression system. Therefore after a fire suppression system is activated, the measured soot concentration, soot production rate, and soot yield are all not factual values. They should be considered as upper limits.

In conclusion, data for $\mathrm{CO}$ and visibility is assumed to be reliable information from the free burn tests. After fire suppression system is activated, data for soot are higher than real values but could be considered as upper limits for the relevant parameters. 


\section{Experimental Setup}

A series of pre-tests were carried out in a fire laboratory placed under a large fire collector called the SP industry calorimeter [27]. Later, tests were carried out inside a 1:4 model scale tunnel. The tests were carried out both with and without water-based fire suppression system. In the following a description of the tests is given.

\subsection{Pre-tests}

A series of pre-tests with and without fire suppression was carried out under an industry calorimeter consisting of a fire collector system equipped with analysing instrumentation used for determination of the heat release rate and measurement of production of gas and soot. Different fuel types and arrangements were used in the tests, see Figure 1. The fuels tested include 6 half car tyres without wheel rims, two piles of wood pallets, a row of plastic slabs (EPS, PE or PUR), and cribs (PE or PUR).

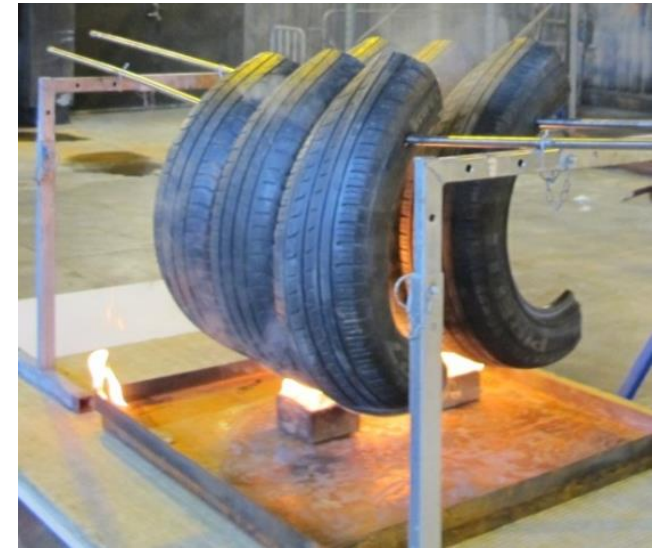

(a) tyre

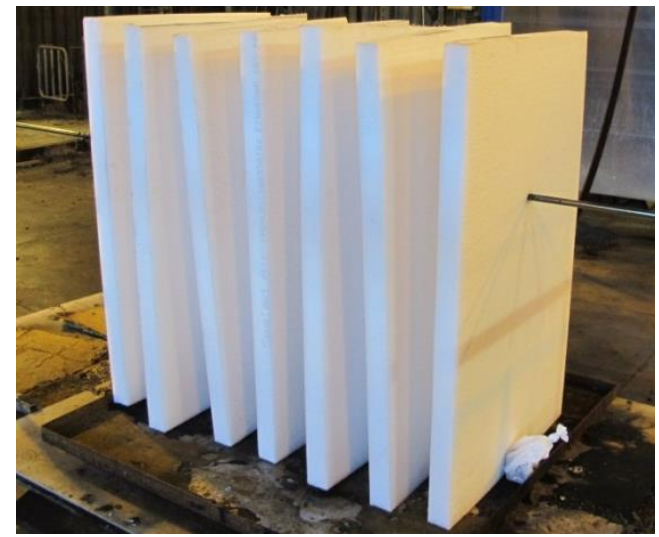

(c) EPS/PE/PUR slabs

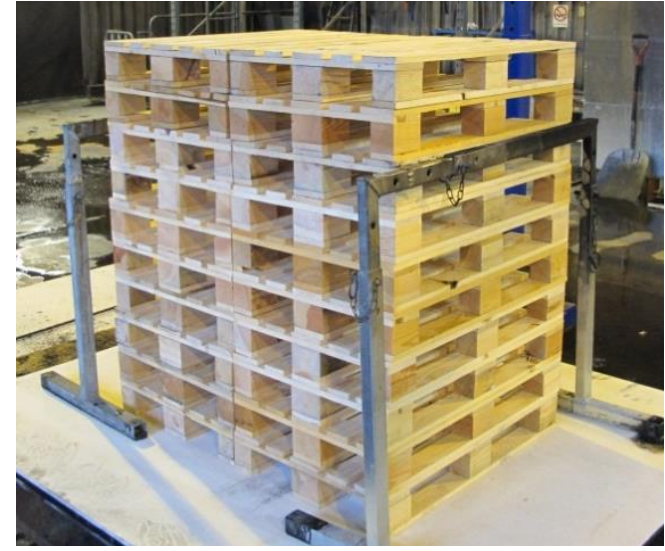

(b) wood pallet

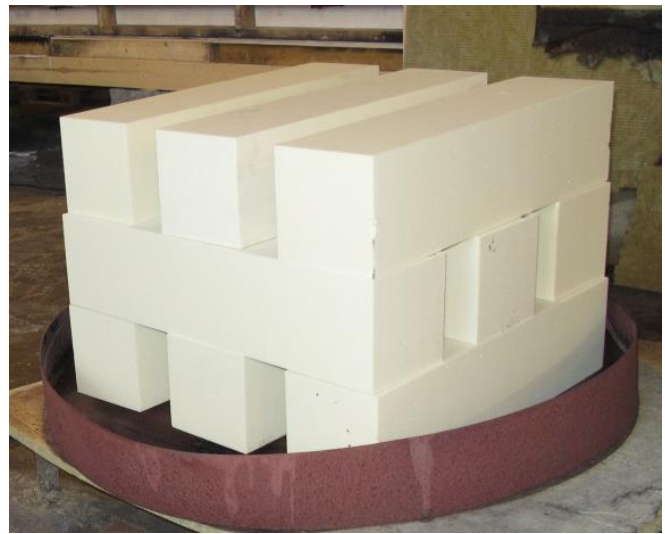

(d) PE/PUR cribs

Figure 1 Fuel arrangement for different fuel types in the pre-tests.

In the wood pallet tests, the fuel consisted of two piles each having 10 pallets. Geometry for the pallet is shown in Figure 2. In tyre tests, a total of six half tyres were hanged over the 
ignition source. Two rectangular pool fire with a side length of $10 \mathrm{~cm}$ were placed at the bottom as the ignition source. The arrangement of the PE/PUR cribs is presented in Figure 4. The cribs were placed in a pan of $1.25 \mathrm{~m}$ diameter. In all these tests, two rectangular pool fire with a side length of $10 \mathrm{~cm}$ were placed at the bottom as the ignition source.

In the plastic pre-tests, small ignition sources were placed between the slabs at the floor level with each having a cube of fibreboard soaked with $100 \mathrm{ml}$ heptane and placed in a small plastic bag.

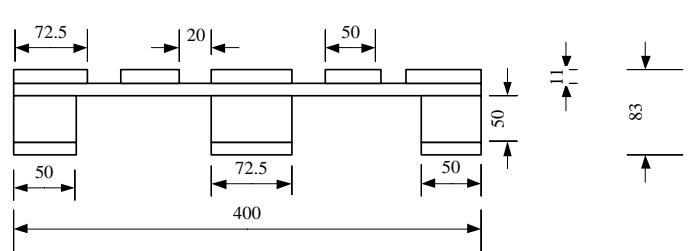

(a) side view

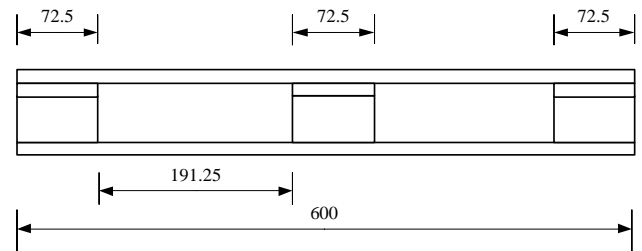

(b) front view

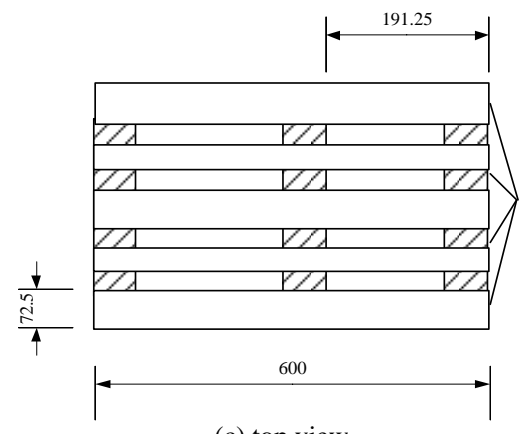

(c) top view

Figure 2 Detailed drawing for one wood pallet.

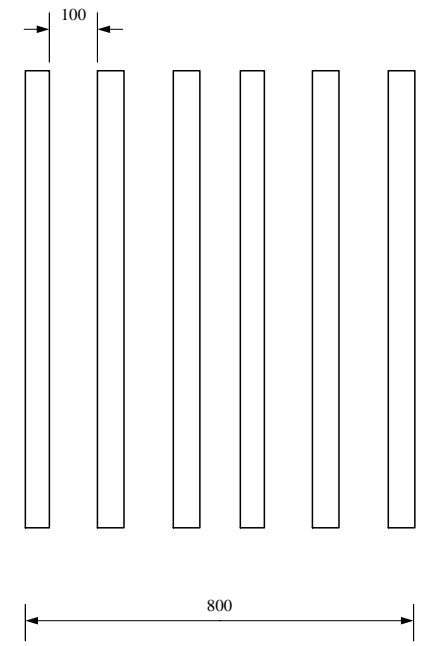

(a) front view
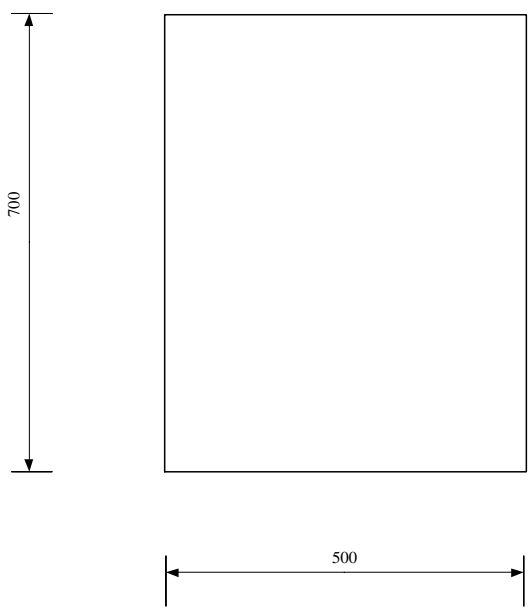

(b) side view

Figure 3 Detailed drawing for plastic slabs. 


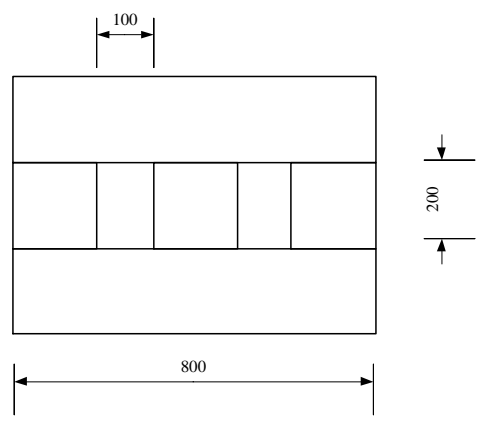

(a) front view

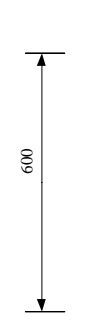

Figure 4 Detailed drawing for plastic cribs.

In the fire suppression tests, a Lechler nozzle called Lechler 460.726 with a $\mathrm{K}$ factor of 4.77 and a cone angle of $90^{\circ}$ was placed right above the fire source. The vertical distance between the nozzle and the floor is $1 \mathrm{~m}$. The water delivered is set to be $4.77 \mathrm{l} / \mathrm{min}$ at an operation pressure of $1 \mathrm{~atm}$. The nozzle delivers a water flow rate of around $5 \mathrm{~mm} / \mathrm{min}$ at $55 \mathrm{~cm}$ below the nozzle and $1.5 \mathrm{~mm} / \mathrm{min}$ at the floor level.

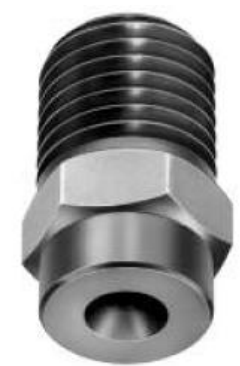

Series 460

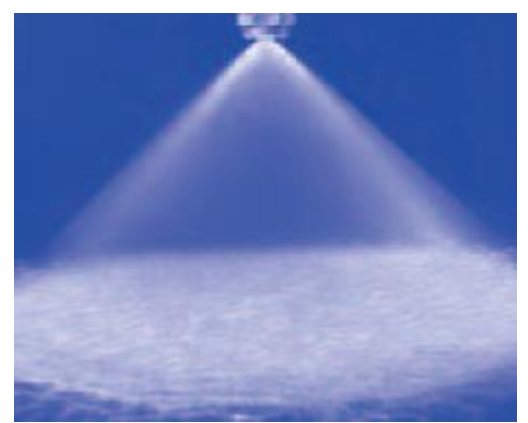

Figure 5 Lechler 460.726 used in the pre-tests.

The fire source was placed on a weighing platform to measure the fuel loss rate. The industry calorimeter right above the fire source was used to measure the flow rate, gas concentration, gas temperature, smoke extinction coefficient, and heat release rate.

\subsection{Model tunnel fire tests}

\subsubsection{Model scale tunnel}

The model scale tunnel was $15 \mathrm{~m}$ long, $2.8 \mathrm{~m}$ wide and $1.4 \mathrm{~m}$ high. The scaling ratio is 1:4 compared to a normal sized road tunnel. This suggests that the corresponding full scale dimensions were $60 \mathrm{~m}$ long, $11.2 \mathrm{~m}$ wide and $5.6 \mathrm{~m}$ high, respectively.

The model tunnel, including the floor, ceiling and one of the side walls, was constructed using non-combustible, $15 \mathrm{~mm}$ thick Promatect $\mathrm{H}$ boards. Several windows $(300 \mathrm{~mm} \times 300 \mathrm{~mm}$ ) are 
placed on one side of the tunnel. The model tunnel was built on a platform and the tunnel floor was $0.8 \mathrm{~m}$ above the floor level of the lab. An axial fan was used to produce the flows inside the tunnel. The end of the tunnel was set below a smoke hood through which the smoke was exhausted to the central system.

\subsubsection{Water spray system}

In most of the tests, the water spray system was designed to cover a region of $7.5 \mathrm{~m}$, corresponding to $30 \mathrm{~m}$ in full scale.

In the tunnel fire tests, the T-Rex nozzles were used. Three-dimensional geometry of the full scale T-Rex nozzle was obtained using a laser scan. The corresponding geometry of the TRex nozzles in 1:4 scale is shown in Figure 6. The T-Rex nozzles in model scale have a $\mathrm{K}$ factor of 22.5, corresponding to 360 in full scale.
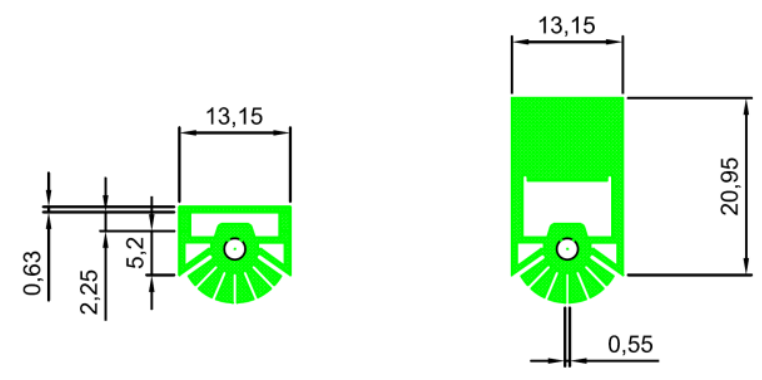

(a) Front of outlet
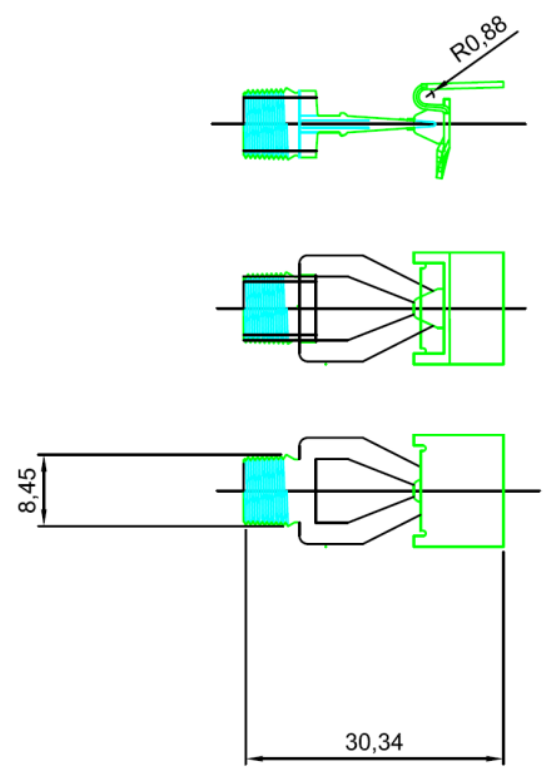

(b) Normal to the outlet (side view)

Figure 6 Geometry of the model scale T-Rex nozzles (Dimensions in mm).

After the geometry was obtained by the laser scan, a powerful 3D printer was used to print out the steel T-Rex nozzles used in the tests, see Figure 7. 


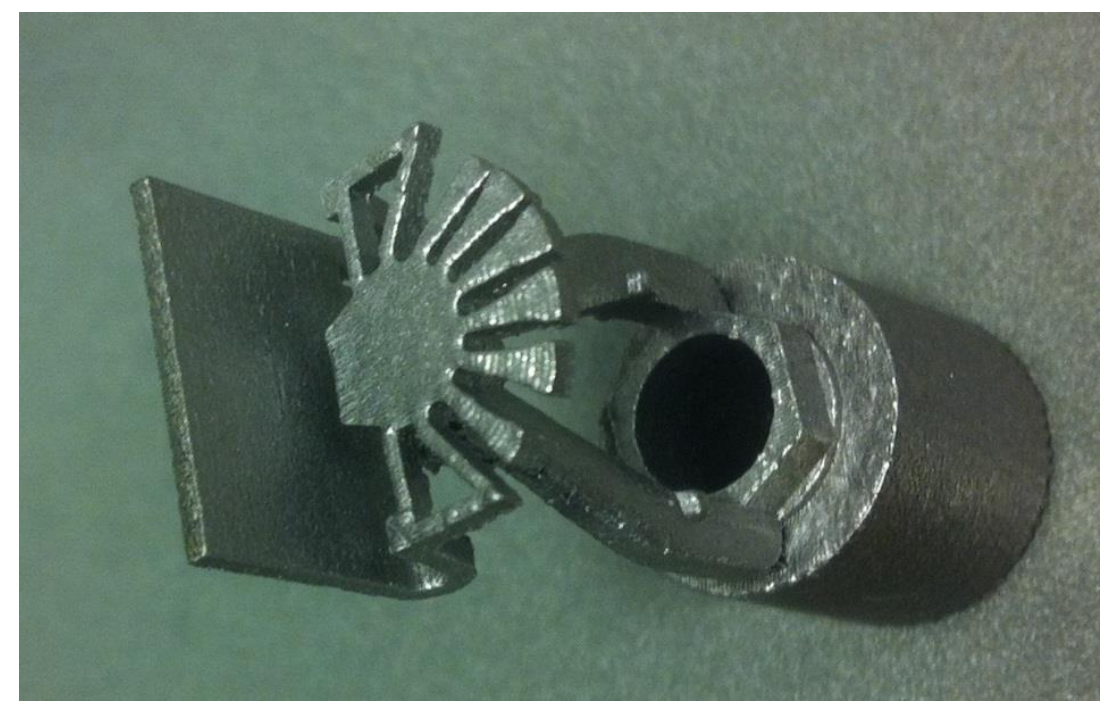

Figure 7 A photo of a 1:4 T-Rex nozzle that is made of steel.

A total of 6 couples of T-Rex nozzles, were placed along the centre line of the tunnel, see Figure 9. All the T-Rex nozzles were placed approximately $100 \mathrm{~mm}$ below the ceiling. Note that at each position, one couple of T-Rex nozzle was placed.

The water spray system with the T-Rex nozzles is shown in Figure 9. The pipes have a diameter of $30 \mathrm{~mm}$. The interval between the nozzles are $1.25 \mathrm{~m}$, corresponding to $5 \mathrm{~m}$ in full scale.

The fire suppression system delivers a water flow rate of $5 \mathrm{~mm} / \mathrm{min}$ on the floor level. Compared to the system used in the pre-tests, the applied water flow rate in the tunnel tests is higher.

\subsubsection{Ventilation system}

Two axial fans were attached to the upstream end of the tunnels to produce a longitudinal flow in the tunnel. The fans were BRV 710 with a diameter of approx. $0.71 \mathrm{~m}$. Together they can produce a maximum longitudinal flow of over $3 \mathrm{~m} / \mathrm{s}$ in the model tunnel, corresponding to $6 \mathrm{~m} / \mathrm{s}$ in full scale. In the model scale tunnel tests, the longitudinal ventilation velocity in the tunnel was set to be $0.75 \mathrm{~m} / \mathrm{s}, 1.5 \mathrm{~m} / \mathrm{s}$, or $3 \mathrm{~m} / \mathrm{s}$.

\subsubsection{Fire load}

The Heavy Goods Vehicle (HGV) mock-up was simulated using three different types of fuels. The fuels were placed in a $1 \mathrm{~m}$ diameter steel pan with approximately $80 \mathrm{~mm}$ high rims. The steel pan was placed on a weighing platform for measurement of the fuel mass loss rate.

In some test, two piles of wood pallets were used as the fire source, as shown in Figure 8. 1/2 standard Europe wood pallets (pine) were used as fuels, see Figure 2. 
PE cribs and PUR cribs were also used as the fire source in some tests. The geometry is the same as that in the pre-tests.

In some tests the front, the back side and top of the fire load were covered by steel plates.

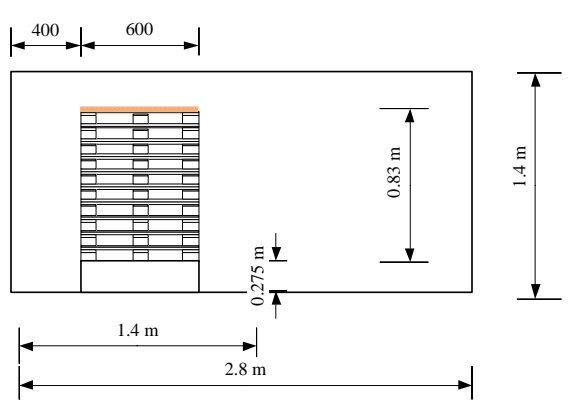

Figure 8 Fuel arrangement.

\subsubsection{Measurement}

In total, 12 thermocouples, 1 plate thermometers, 6 bi-directional pressure tubes, and 3 gas analyses were placed in the tunnel, see Figure 9.

All ceiling thermocouples were placed $100 \mathrm{~mm}$ below the ceiling, except at Pile A. One plate thermometer was attached to the ceiling right above the fire source. At Pile A, the bidirectional tubes were placed at the center, and the gas analysis and thermocouples were placed horizontally $50 \mathrm{~mm}$ from the gas analysis. Two laser/photocells were installed at Pile A. The distance between the emitter and receiver is $0.4 \mathrm{~m}$.

Measurements at pile A are used to estimate the flow rate, heat release rate, $\mathrm{CO}$ production and soot production.

In the tunnel tests, superposition of individual horizontal cross sections are applied for all the parameters. 


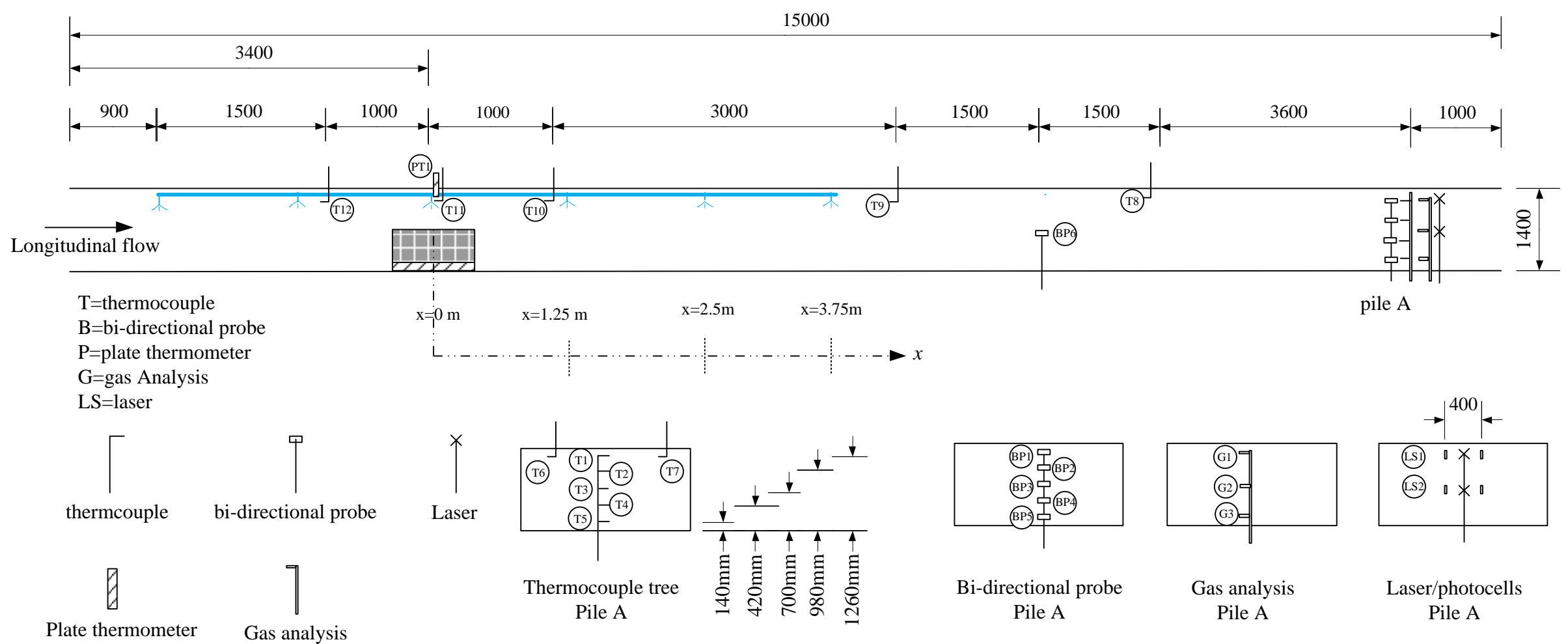

Figure 9 The layout and identification of instruments in the series of tunnel fire tests (dimensions in mm). 


\section{$4 \quad$ Test procedure}

\subsection{Pre-tests}

A series of pre-tests with and without fire suppression was carried out first. A summary of these pre-tests is presented in Table 3. Different activation time was tested. The main objective is to obtain burning rates of the fuels planned for use in the tunnel fire tests.

Table 3 Summary of free-burn pre-tests.

\begin{tabular}{|c|c|c|c|}
\hline Test no. & Fuel & type & Activation time \\
\hline & & & (min:s) \\
\hline 1 & Tires & Free-burn & - \\
\hline 2 & Wood pallet & Free-burn & - \\
\hline 3 & EPS & Free-burn & - \\
\hline 4 & EPS & & \\
\hline 5 & Tires & Suppression & $03: 43$ \\
\hline 6 & Wood pallet & Suppression & $07: 53$ \\
\hline 7 & EPS & & \\
\hline 8 & PE & Free-burn & - \\
\hline 9 & PUR & Free-burn & - \\
\hline 10 & PE & Suppression & $02: 27$ \\
\hline 11 & PUR & Suppression & $01: 18$ \\
\hline
\end{tabular}

\subsection{Tunnel fire tests}

A series of tunnel fire tests with and without fire suppression was carried out. A summary of these tests is presented in Table 4. By default there was no coverage of the fuel used in the test. At a given velocity, the free-burn test was carried out followed by fire suppression tests with different activation time (after ignition).

In all the wood pallet fire tests, the measured humidity was approximately $10 \%$.

Two cameras were used to record the tests with one placed inside the tunnel close to the fan and another outside the window beside fuel.

Table 4 Summary of tunnel fire tests.

\begin{tabular}{|c|c|c|c|c|c|}
\hline Test no. & Fuel type & Type & $\begin{array}{c}\text { Ventilation } \\
\text { velocity }\end{array}$ & $\begin{array}{c}\text { Activation time } \\
\text { (after ignition) }\end{array}$ & coverage \\
\hline & & & $\mathrm{m} / \mathrm{s}$ & $\mathrm{min}$ & \\
\hline 1 & Wood & Free-burn & 1.5 & & \\
\hline 2 & PUR & Free-burn & 1.5 & & \\
\hline 3 & PE & Free-burn & 1.5 & & \\
\hline 4 & PUR & Free-burn & 1.5 & & \\
\hline 5 & Wood & Suppression & 1.5 & $04: 24$ & \\
\hline 6 & PUR & Suppression & 1.5 & $03: 08$ & \\
\hline 7 & Wood & Suppression & 1.5 & $05: 27$ & \\
\hline 8 & PE & Suppression & 1.5 & $03: 17$ & \\
\hline 9 & PUR & Suppression & 1.5 & $01: 36$ & \\
\hline
\end{tabular}




\begin{tabular}{|c|c|c|c|c|c|}
\hline 10 & PE & Suppression & 1.5 & $03: 51$ & \\
\hline 11 & PUR & Suppression & 1.5 & $00: 59$ & \\
\hline 12 & PE & Free-burn & 3 & - & \\
\hline 13 & PE & Free-burn & 0.75 & - & \\
\hline 14 & Wood & Free-burn & 3 & - & \\
\hline $15^{*}$ & PE & Suppression & 3 & $03: 01$ & \\
\hline 16 & PUR & Suppression & 1.5 & $00: 30$ & \\
\hline 17 & Wood & Suppression & 3 & $01: 12$ & \\
\hline 18 & PE & Suppression & 0.75 & $02: 50$ & \\
\hline 19 & Wood & Suppression & 3 & $03: 18$ & \\
\hline 20 & PUR & Free-burn & 3 & - & \\
\hline 21 & PE & Free-burn & 1.5 & - & Yes \\
\hline 22 & PUR & Suppression & 3 & $00: 41$ & \\
\hline 23 & Wood & Suppression & 0.75 & $04: 45$ & \\
\hline 24 & PE & Suppression & 3 & $03: 26$ & \\
\hline 25 & PE & Suppression & 1.5 & $03: 40$ & Yes \\
\hline 26 & PE & Suppression & 0.75 & $03: 14$ & \\
\hline
\end{tabular}




\section{$5 \quad$ Results and discussion}

\subsection{Pre-tests}

\subsubsection{Tyre fires}

The measurement in the tyre fire test using the fire suppression system did not work properly. Therefore only results from the free-burn test are presented. The heat of combustion for the tyre is estimated to be $28 \mathrm{MJ} / \mathrm{kg}$ based on comparison of the two different heat release rate measurements.

Figure 10 shows the heat release rate in the free-burn tyre fire test. The maximum heat release rate is approximately $1.5 \mathrm{MW}$.

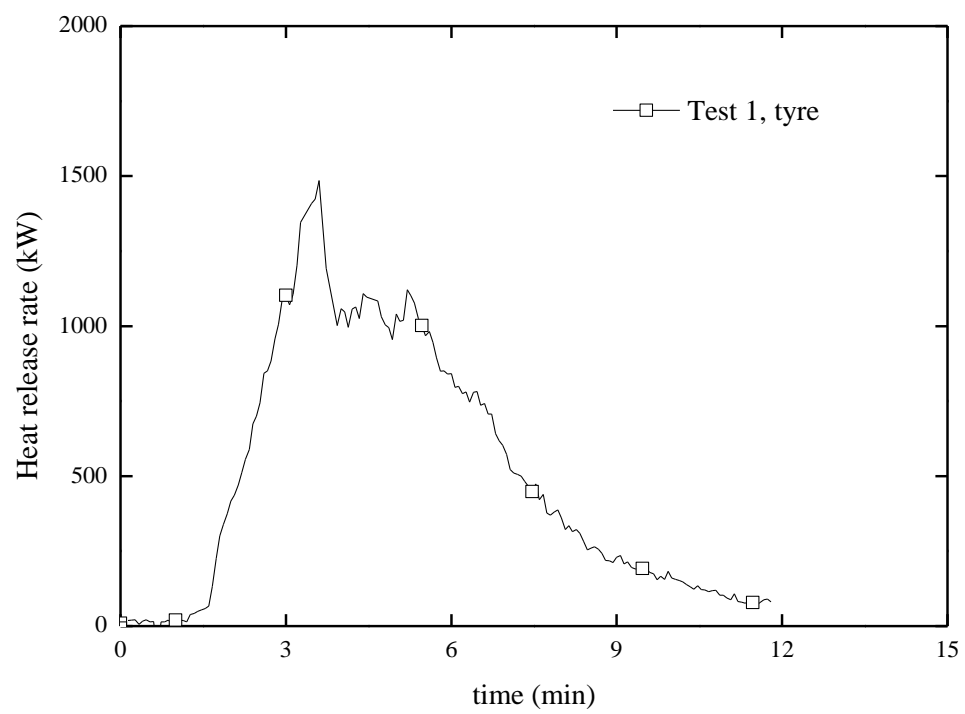

Figure 10 Heat release rate in the free-burn tyre test.

Figure 11 shows the $\mathrm{CO}$ yield in the free-burn tyre fire test. The $\mathrm{CO}$ yield is mainly in a range of 0.04 to 0.08 . The $\mathrm{CO}$ yield increases with time and it maintains at the level of roughly 0.06 during the whole test.

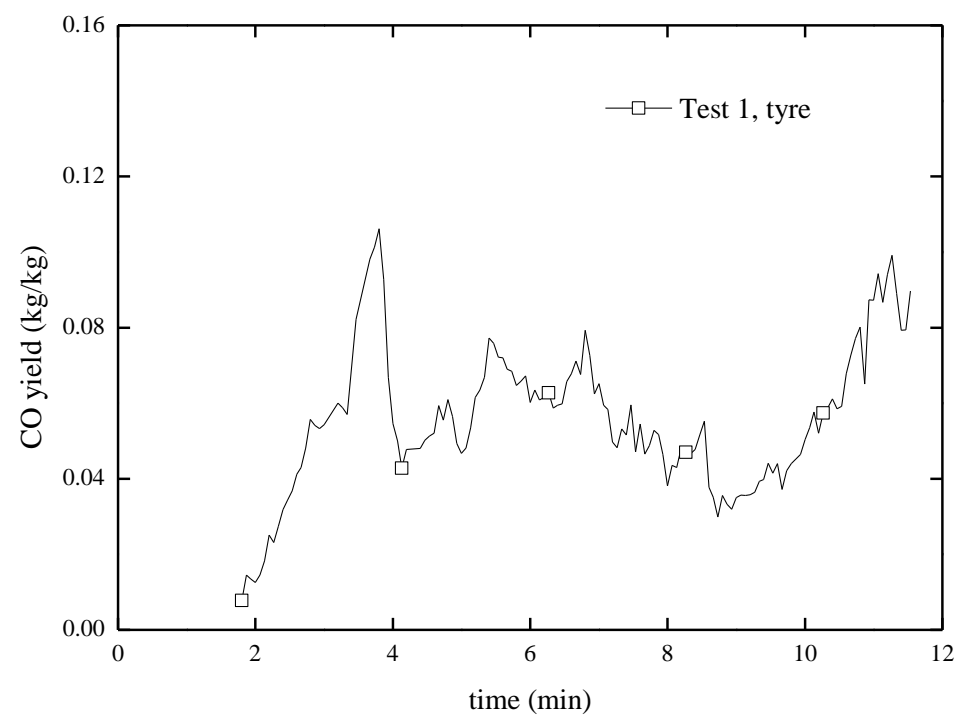

Figure 11 CO yield in the free-burn tyre test. 
Figure 12 shows the soot yield in the free-burn tyre fire test. The soot yield is mainly in a range of 0.05 to 0.08 . However, at the ignition stage, the soot yield is as high as 0.16. However, the absolute soot production rate at this stage is not so high compared to the other stage as the heat release rate is at a lower level.

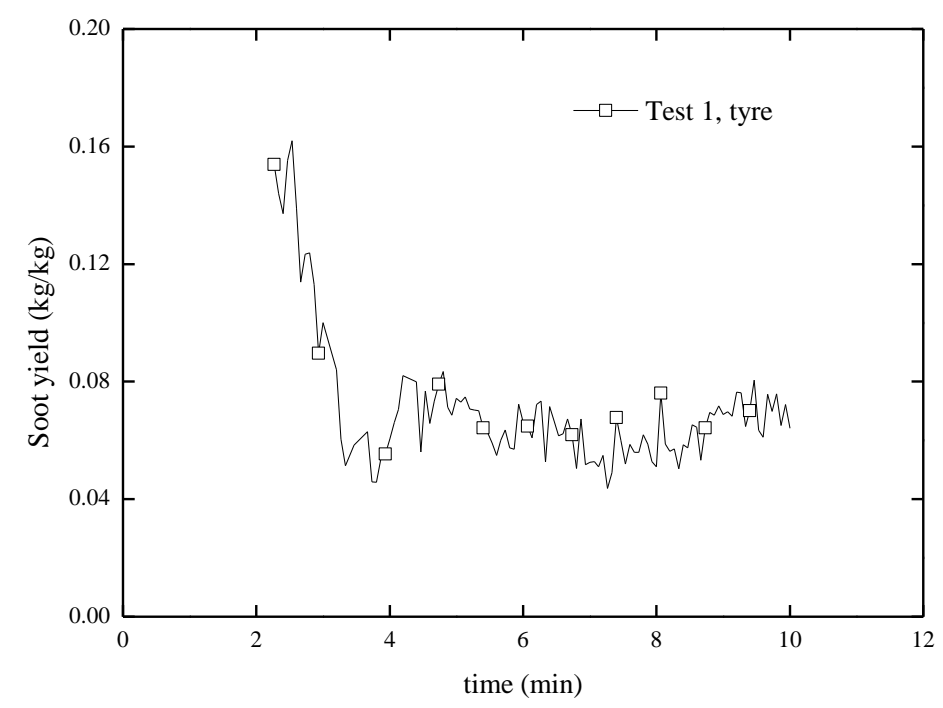

Figure 12 Soot yield in the free-burn tyre test.

\subsubsection{Wood pallet fires}

Figure 13 shows the comparison of heat release rates in the free burn and fire suppression tests with wood pallet fires. The maximum heat release rate in the free burn wood pallet fire test is $1084 \mathrm{~kW}$. In test 6 the heat release rate is approximately $850 \mathrm{~kW}$ at the activation. It can be seen that the heat release rate is still at a very high level after fire suppression although immediate drop in the heat release rate can be observed. This is mainly related to the late activation.

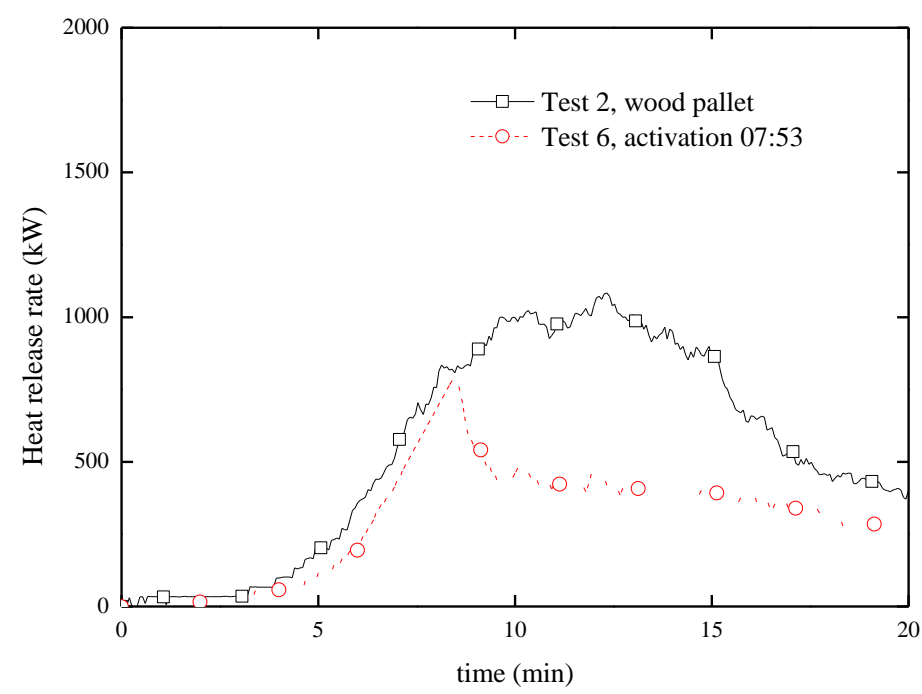

Figure 13 Comparison of heat release rates in the free burn and fire suppression tests with wood pallet fires. 
The $\mathrm{CO}$ and soot measurements in the fire suppression test and the $\mathrm{CO}$ measurement in the free-burn test did not work. The results are therefore not presented here except the soot yield in the free-burn test.

Figure 14 shows the soot yield in the free-burn wood pallet fire test. The soot yield of wood pallet in the free burn test increases with time up to approximately 0.02 before 2.5 min after ignition and decreases to approx. 0.001 after 5 min.

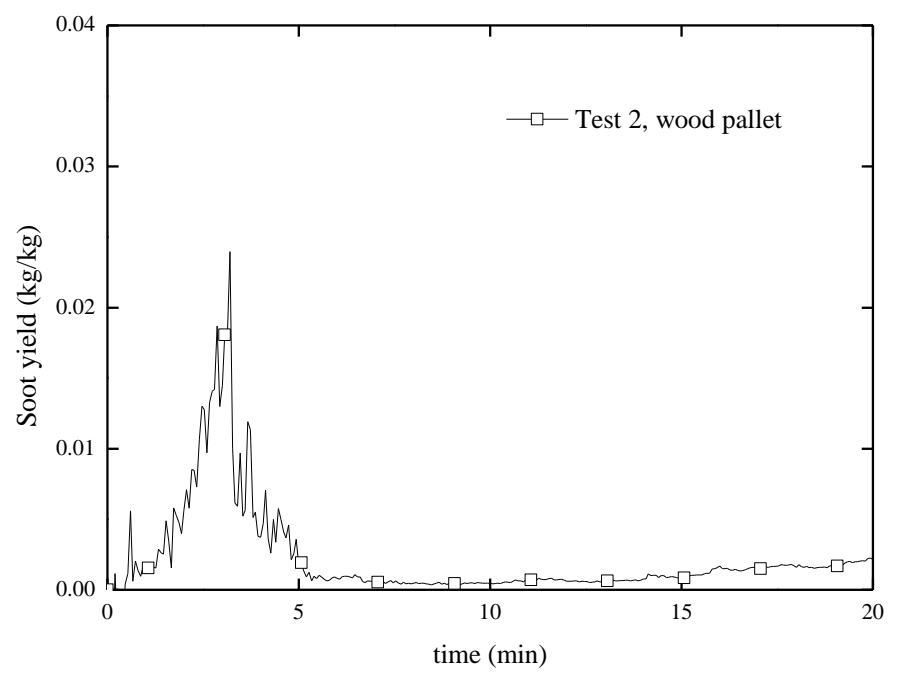

Figure $14 \quad$ Soot yield in the free-burn wood pallet test.

\subsubsection{PE slab fires}

Figure 15 shows comparison of heat release rates in the free burn and fire suppression tests with PE slab fires. Clearly the fire was suppressed effectively after activation. In these PE pre-tests the PE slabs were melted very early which could explain the first drop in the heat release rate in Figure 15. Afterwards the fire in the free-burn test behaved as a pool fire.

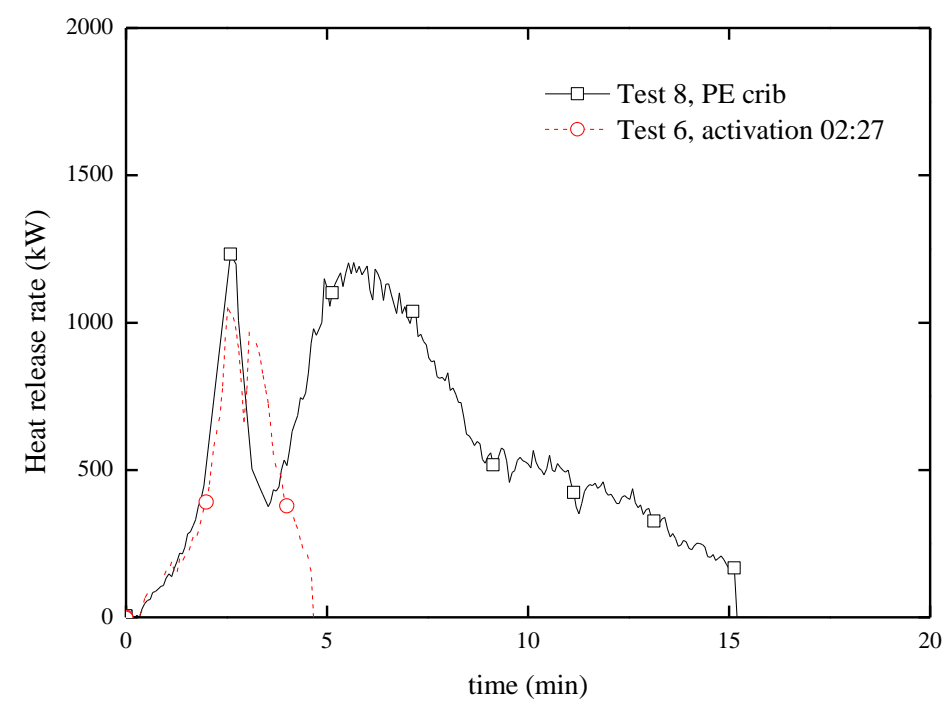

Figure 15 Comparison of heat release rates in the free burn and fire suppression tests with PE slab fires. 
Figure 16 shows comparison of $\mathrm{CO}$ yield in the free burn and fire suppression tests with $\mathrm{PE}$ slab fires. The $\mathrm{CO}$ yield is mainly in a range of 0.02 to 0.06 . The $\mathrm{CO}$ yield after $5 \mathrm{~min}$ shows a slightly increasing trend.

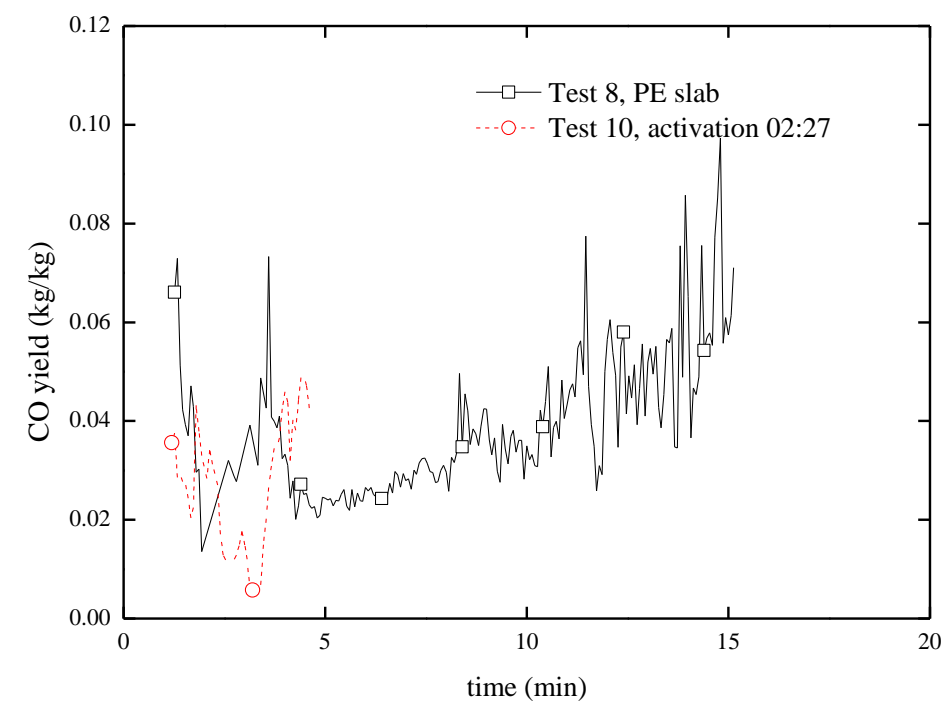

Figure 16 Comparison of CO yield in the free burn and fire suppression tests with PE slab fires.

Figure 17 shows comparison of soot yield in the free burn and fire suppression tests with PE slabs. The soot yield in the free-burn test increases continuously to around 0.11 at 13 min.

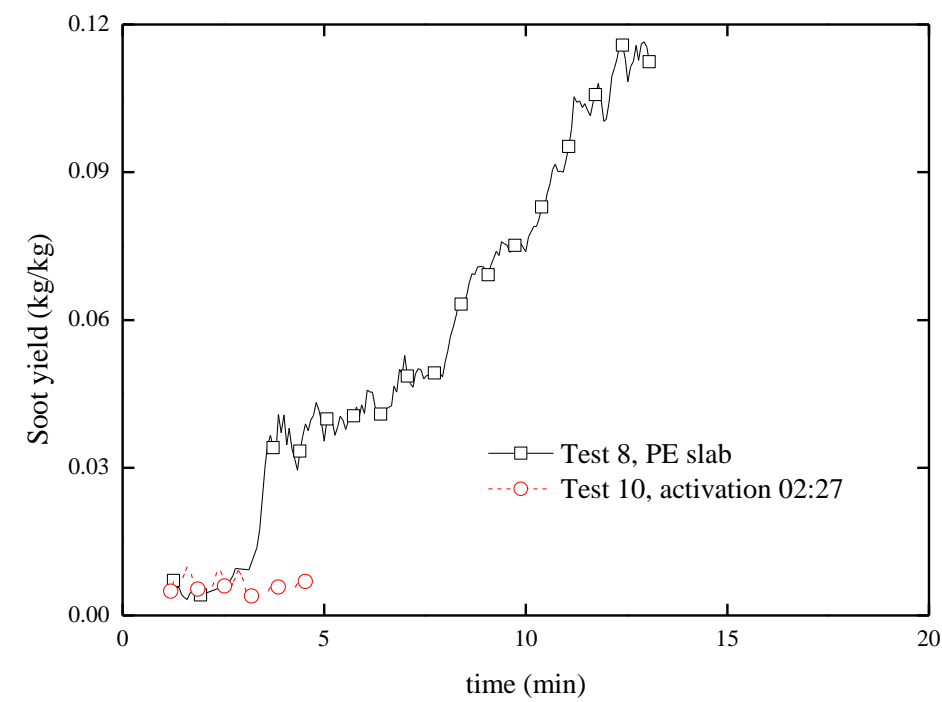

Figure 17 Comparison of soot yield in the free burn and fire suppression tests with PE slab fires.

\subsubsection{PUR slab fires}

Figure 18 shows comparison of heat release rates in the free burn and fire suppression tests with PUR slab fires. The PUR slabs burn very quickly and reaches the peak values at approximately $1 \mathrm{~min}$. The PUR slabs were also melted and some solid leftover still 
existed after the tests. In the suppression test 11 the suppression system was activation $1: 18$ and thus the fire had already reached its peak value. The effect of fire suppression system on the burning is limited mainly due to the late activation.

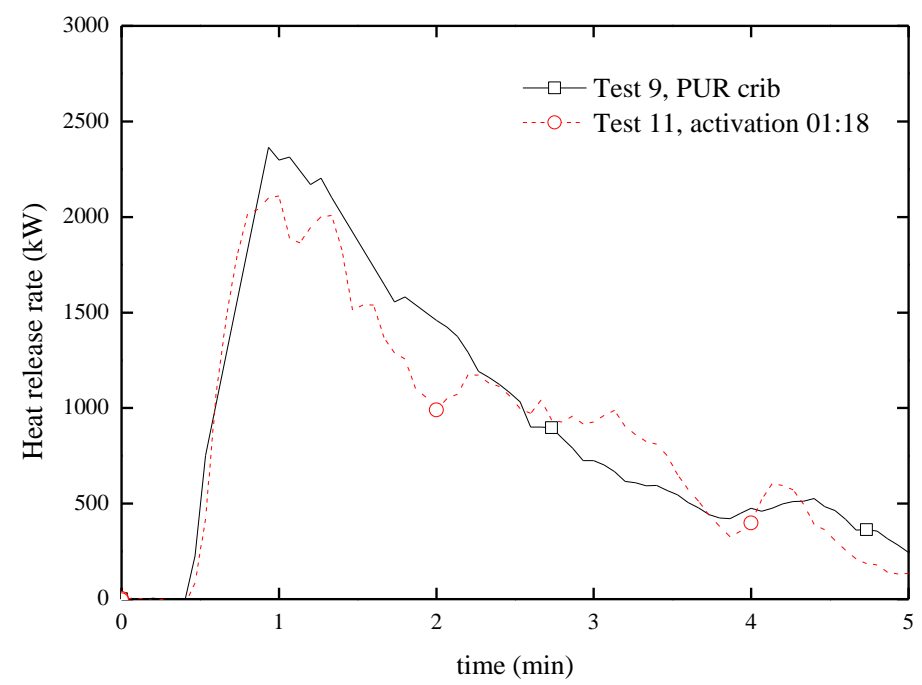

Figure 18 Comparison of heat release rates in the free burn and fire suppression tests with PUR slab fires.

Figure 19 shows comparison of $\mathrm{CO}$ yields in the free burn and fire suppression tests with PUR slab fires. The $\mathrm{CO}$ yield is around 0.08 during most of the burning period. In the suppression test 11 the $\mathrm{CO}$ yield reaches its peak value of 0.16 at around $4 \mathrm{~min}$.

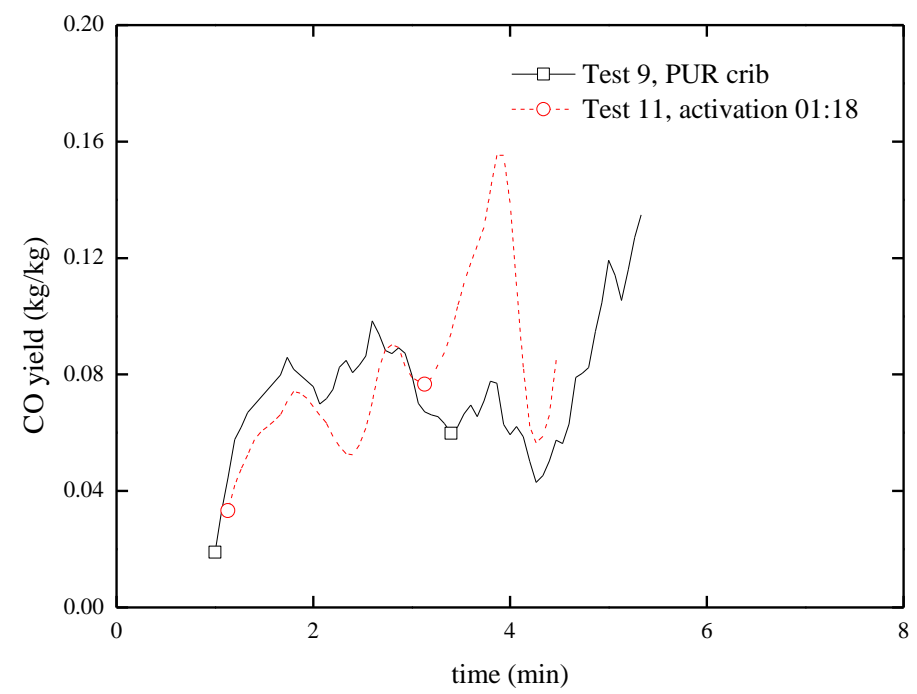

Figure 19 Comparison of CO yields in the free burn and fire suppression tests with PUR slab fires.

Figure 20 shows comparison of soot yields in the free burn and fire suppression tests with PUR slab fires. The soot yields in both tests are in a range of 0.03 to 0.06 . The effect of fire suppression on the soot yield is insignificant. 


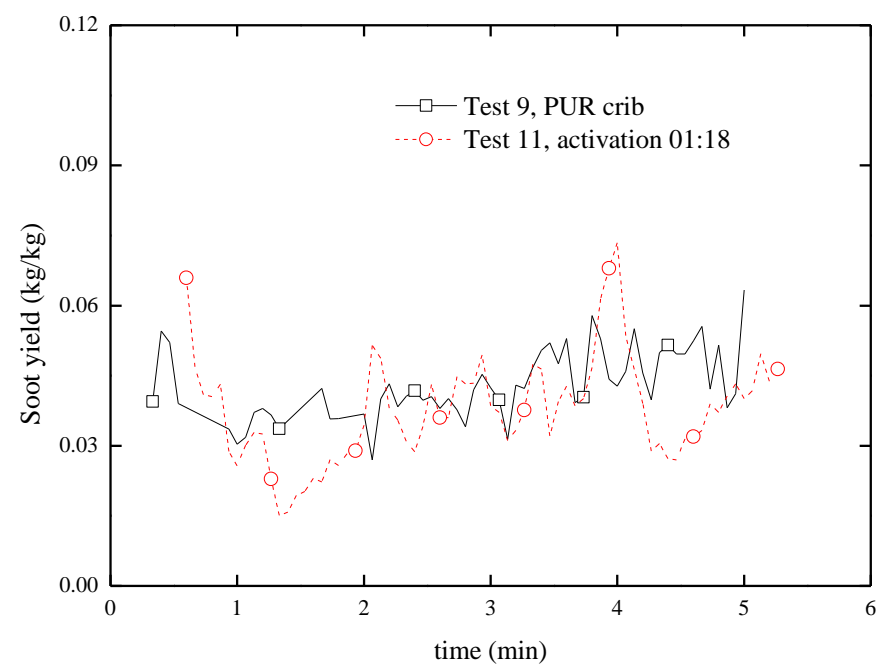

Figure 20 Comparison of soot yields in the free burn and fire suppression tests with PUR slab fires.

\subsubsection{A discussion for the pre-tests}

For the tyre fire, the soot yield is mainly in a range of 0.05 to 0.08 but it is as high as 0.16 at the ignition stage, and the $\mathrm{CO}$ yield is in a range of 0.04 to 0.08 . For wood pallet fires, the soot yield in the free burn test increases with time up to approximately 0.02 before 2.5 min after ignition and decreases to approx. 0.001 after 5 min. For PE slab fires, the CO yield is mainly in a range of 0.02 to 0.06 , and the soot yield in the free-burn test increases continuously to around 0.11 at $13 \mathrm{~min}$. For PUR slab fires, the $\mathrm{CO}$ yield is around 0.08 during most of the burning period and the soot yields in both tests are in a range of 0.03 to 0.06 .

The fires were not effectively suppressed except the PE slab fire. The effect of fire suppression on the CO yield and soot yield is not significant with the only exception of that they may rise during a short period. However, it should be kept in mind that the water flow rate delivered by the nozzle is only around $1.5 \mathrm{~mm} / \mathrm{min}$ at the floor level.

\subsection{Wood pallet fires in tunnel tests}

\subsubsection{Heat release rates in wood pallet fires}

\subsubsection{Effect of ventilation velocity in free-burn tests}

Figure 21 shows the effect of ventilation velocity on heat release rate in the free-burn tunnel fire tests. The maximum heat release rate for both $1.5 \mathrm{~m} / \mathrm{s}$ and $3 \mathrm{~m} / \mathrm{s}$ is approximately $1.9 \mathrm{MW}$. In test 1 with $1.4 \mathrm{~m} / \mathrm{s}$, the value is around $1.7 \mathrm{MW}$ before the collapse of the wood pallet that results in the rise of the heat release rate to $1.9 \mathrm{MW}$. Clearly it shows that the effect of ventilation velocity on the maximum heat release rate is insignificant despite that a small increase could be observed. The main difference is that the fire in test 14 with $3 \mathrm{~m} / \mathrm{s}$ grows up more rapidly, that is, the fire growth rate is greater due to higher ventilation velocity. 


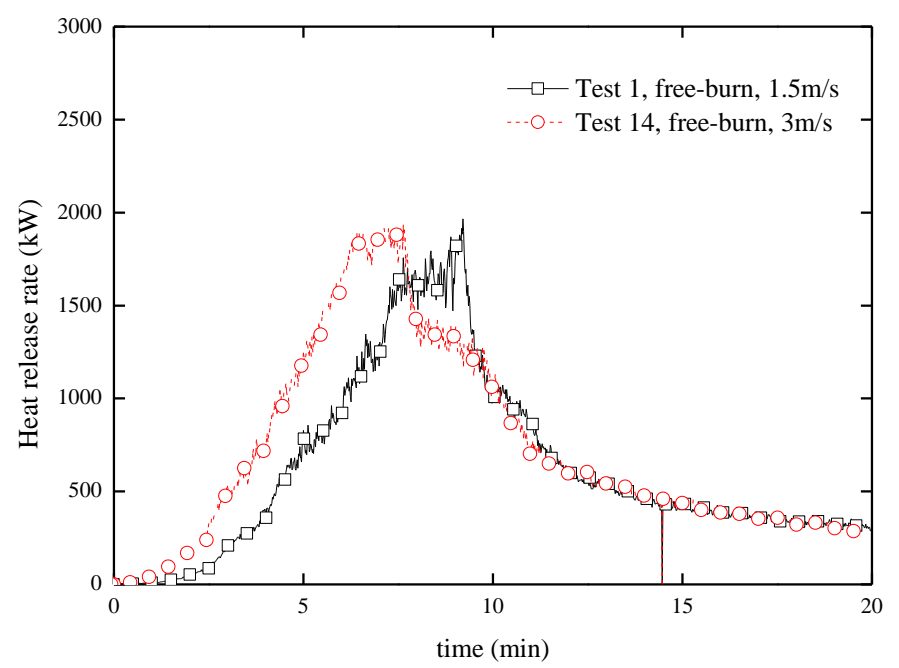

Figure 21 Heat release rate in the free-burn tests at different velocities (Wood pallet fires).

\subsubsection{Effect of fire suppression}

Figure 22 and Figure 23 show comparisons of heat release rates in the free burn tests and fire suppression tests for a velocity of $1.5 \mathrm{~m} / \mathrm{s}$ and $3 \mathrm{~m} / \mathrm{s}$, respectively. The heat release rate at the activation time was $550 \mathrm{~kW}$ in test 5 and $750 \mathrm{~kW}$ in test 7 , as shown in Figure 22. The heat release rate at the activation time was $100 \mathrm{~kW}$ in test 17 and $850 \mathrm{~kW}$ in test 19, as shown in Figure 23. Clearly, for a given velocity, the heat release rates approximately follow the same curve, indicating good repeatability. It can also be seen that for both velocities, the heat release rate decreased immediately after the fire suppression system was activated. In other words, the wood crib fire was effectively suppressed at both velocities.

It appears that the fire exposed to higher ventilation is easier to extinguish. The reason could be that the flame is highly inclined under $3 \mathrm{~m} / \mathrm{s}$ which facilitates the water to reach the fuel surfaces.

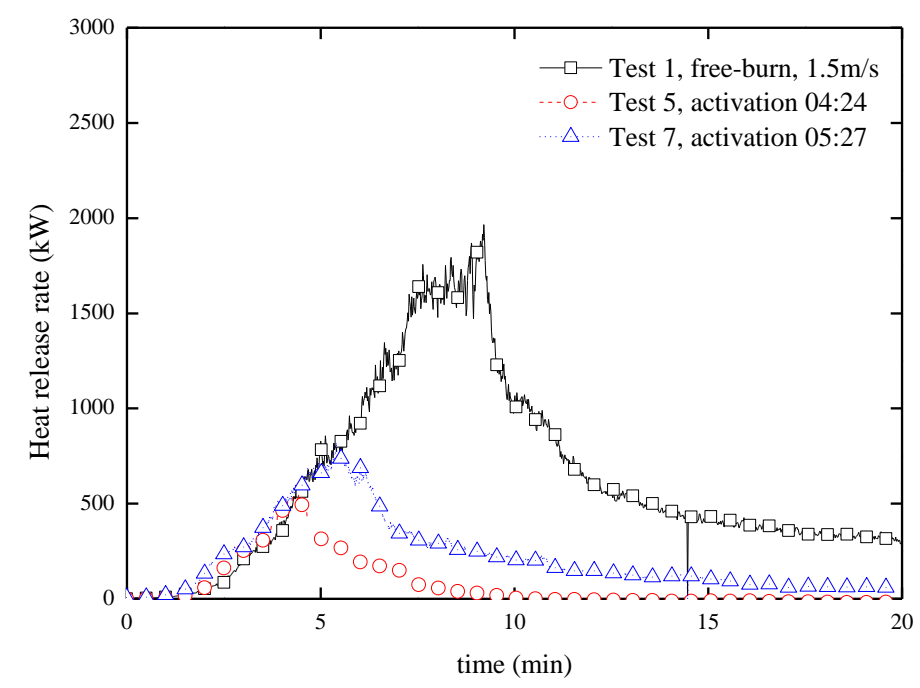

Figure 22 Comparison of heat release rates in the free burn test and fire suppression tests for velocity of $1.5 \mathrm{~m} / \mathrm{s}$ (Wood pallet fires). 


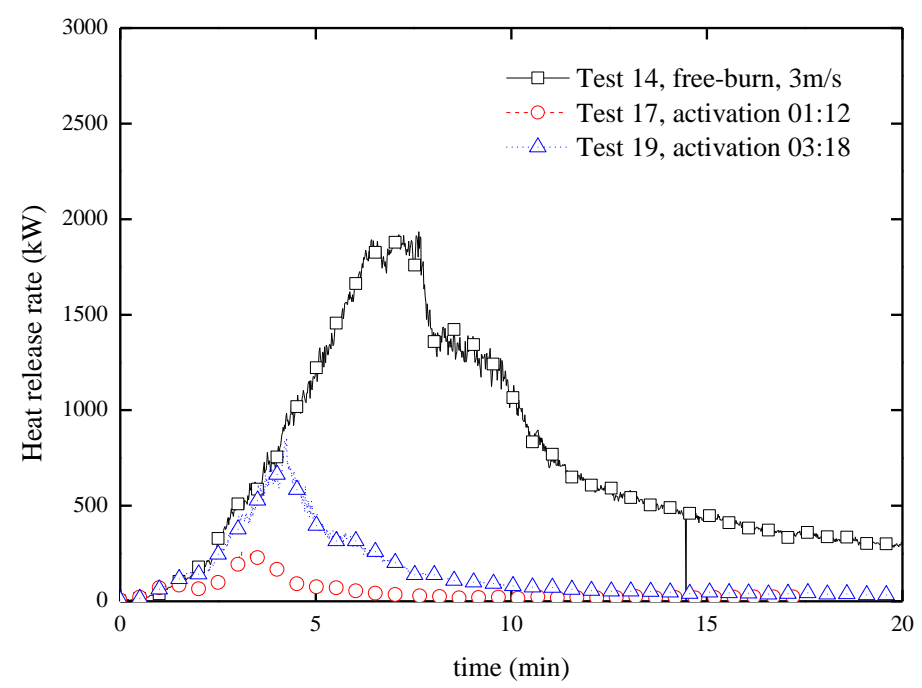

Figure 23 Comparison of heat release rates in the free burn test and fire suppression tests for velocity of $3 \mathrm{~m} / \mathrm{s}$ (Wood pallet fires).

\subsubsection{CO production in wood pallet fires}

\subsubsection{CO concentration at mid tunnel height}

Figure 24 and Figure 25 show comparisons of $\mathrm{CO}$ concentration at mid tunnel height (measured at G2 in Figure 9) in the free burn tests and fire suppression tests for a velocity of $1.5 \mathrm{~m} / \mathrm{s}$ and $3 \mathrm{~m} / \mathrm{s}$, respectively. The location is $10.6 \mathrm{~m}$ downstream of the fire, corresponding to $42.4 \mathrm{~m}$ at full scale.

To be on the safe side, the $\mathrm{CO}$ concentration at mid tunnel height $(0.7 \mathrm{~m}$ in model scale and $2.8 \mathrm{~m}$ in full scale above tunnel floor) could be used to represent the situation at the human level.

The CO concentration at mid tunnel height in the free burn test obtained the highest value for both $1.5 \mathrm{~m} / \mathrm{s}$ and $3 \mathrm{~m} / \mathrm{s}$. The CO concentration curve in the free-burn test approximately follows the heat release rate curve. Note also that during the decay period the $\mathrm{CO}$ concentration in a fire suppression test with late activation is higher than that in the free-burn test, especially in the tests at a velocity of $3 \mathrm{~m} / \mathrm{s}$. Note that there could be two reasons for the increase in the $\mathrm{CO}$ concentration in a fire suppression test. One reason is the possible increase in $\mathrm{CO}$ production rate due to strong interaction of the combustion gas with the water droplets. This effect will be shown in the following section. Another possible reason is that the water droplets cool down the gas and also entrain the upperlayer gas into the lower layer. Both the cooling and the entrainment effects results in destratification of the smoke layer.

However, the free burn tests still represent the worst scenario from the point of view of CO concentration in this test series, as the early $10 \mathrm{~min}$ (20 min at full scale) could be regarded as the key period for evacuation.

Further, comparing the two suppression tests shows that early activation reduces the $\mathrm{CO}$ concentration significantly. 


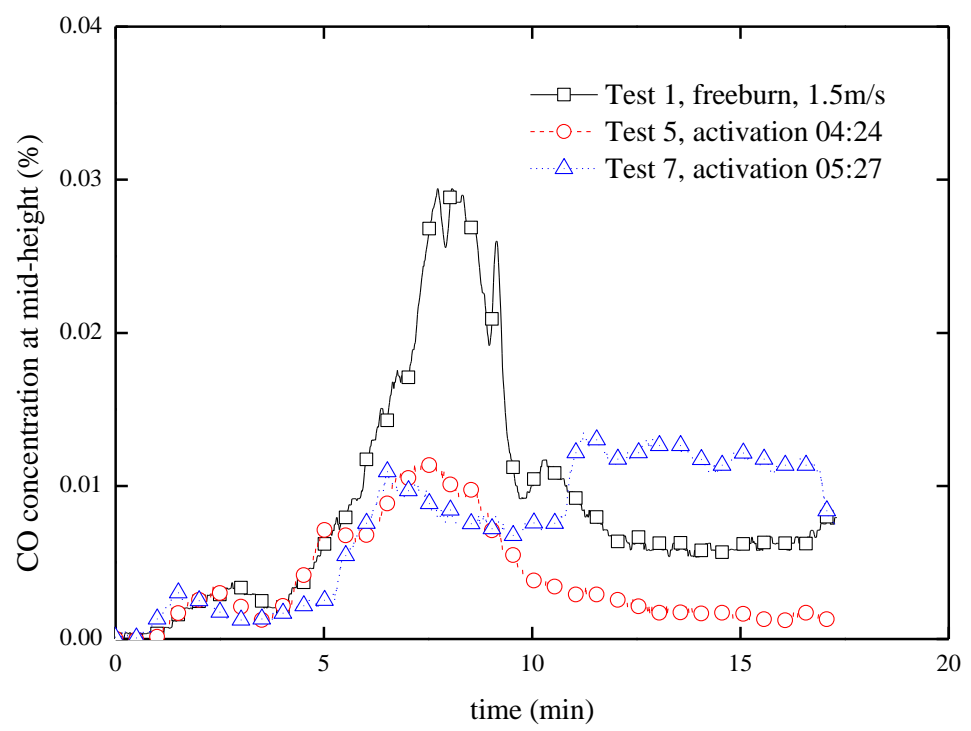

Figure 24 Comparison of $\mathrm{CO}$ concentration in the free burn test and fire suppression tests for velocity of $1.5 \mathrm{~m} / \mathrm{s}$ (Wood pallet fires).

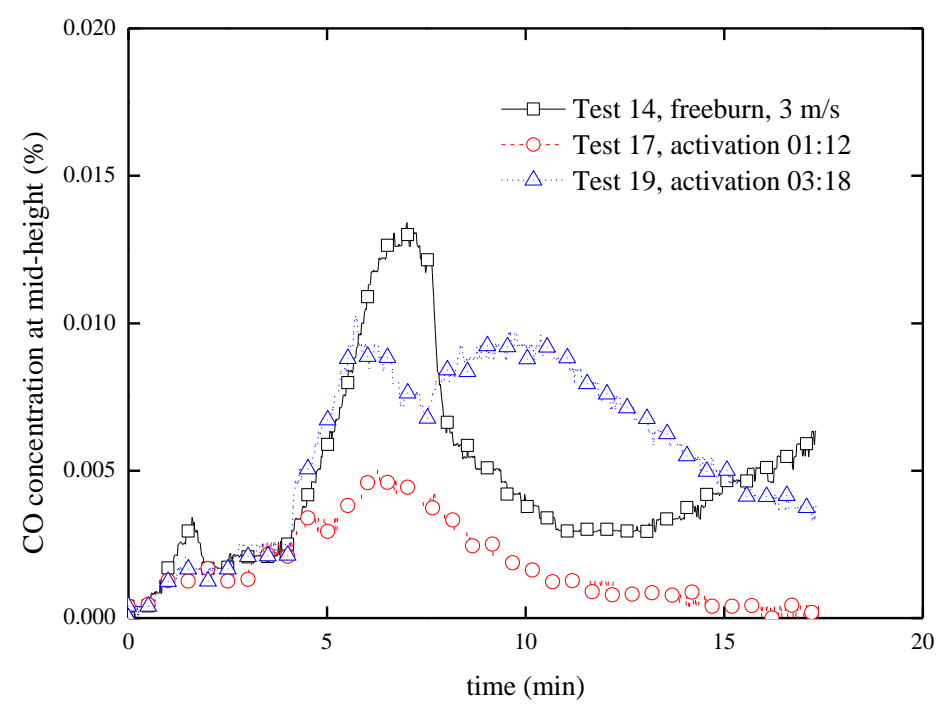

Figure 25 Comparison of $\mathrm{CO}$ concentration in the free burn test and fire suppression tests for velocity of $3 \mathrm{~m} / \mathrm{s}$ (Wood pallet fires).

\subsubsection{CO production rate}

Figure 26 and Figure 27 show comparisons of $\mathrm{CO}$ production rates in the free burn tests and fire suppression tests for a velocity of $1.5 \mathrm{~m} / \mathrm{s}$ and $3 \mathrm{~m} / \mathrm{s}$, respectively.

Clearly, it shows in Figure 26 that the maximum CO production rates in the fire suppression test 7 is even higher than that in the free-burn test, although they are approximately at the same level. However, given that the heat release rate in the fire suppression test is much lower than that in the free-burn test, the CO yield in test 7 should be much higher than in the free-burn test. After around $9 \mathrm{~min}$, the $\mathrm{CO}$ production rate in the fire suppression test 7 is much higher than that in free-burn test 1 . 


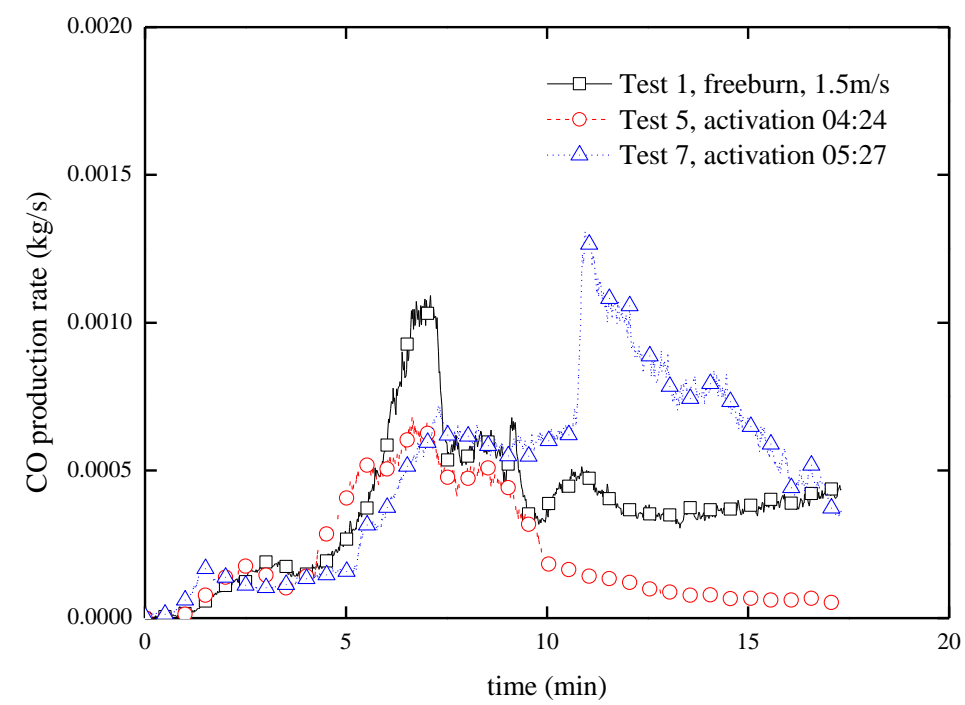

Figure 26 Comparison of $C O$ production rates in the free burn test and fire suppression tests for velocity of $1.5 \mathrm{~m} / \mathrm{s}$ (Wood pallet fires).

Similar trend can be found in Figure 27. After around $8 \mathrm{~min}$, the $\mathrm{CO}$ production rate in the fire suppression test 19 is much higher than that in free-burn test 14.

In contrast, the $\mathrm{CO}$ production rates in the fire suppression tests 5 and 17 with earlier activation are always lower than those in the corresponding free-burn tests. This implies the importance of the activation time.

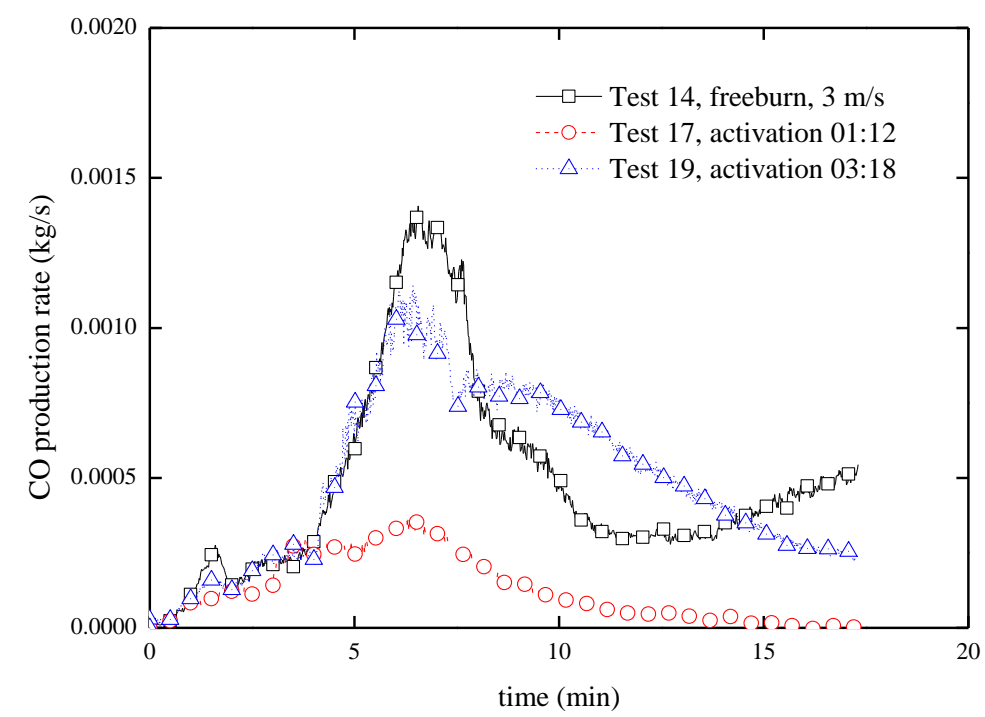

Figure 27 Comparison of $C O$ production rates in the free burn test and fire suppression tests for velocity of $3 \mathrm{~m} / \mathrm{s}$ (Wood pallet fires).

\subsubsection{CO yield}

Figure 28 and Figure 29 show comparisons of $\mathrm{CO}$ yields in the free burn tests and fire suppression tests with wood pallets for a velocity of $1.5 \mathrm{~m} / \mathrm{s}$ and $3 \mathrm{~m} / \mathrm{s}$, respectively. 
For small heat release rates in the growth period and in the decay period, the uncertainties in estimation of the heat release rates could be high, given that the $\mathrm{CO}$ yield is calculated based on the fuel mass burning rate. Further, the influence of ignition source on the results at the early stage decreases with the increasing heat release rate. Therefore data for heat release rates lower than around $30 \mathrm{~kW}$ (1 MW at full scale) are mostly ignored in the following figures.

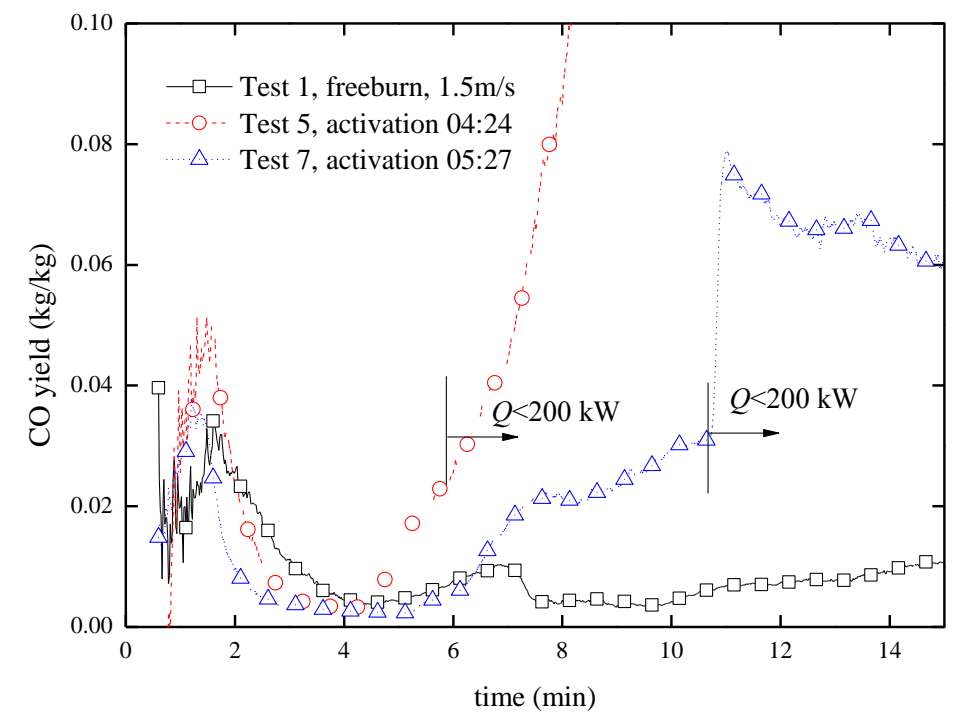

Figure 28 Comparison of $C O$ yield in the free burn test and fire suppression tests for velocity of $1.5 \mathrm{~m} / \mathrm{s}$ (Wood pallet fires).

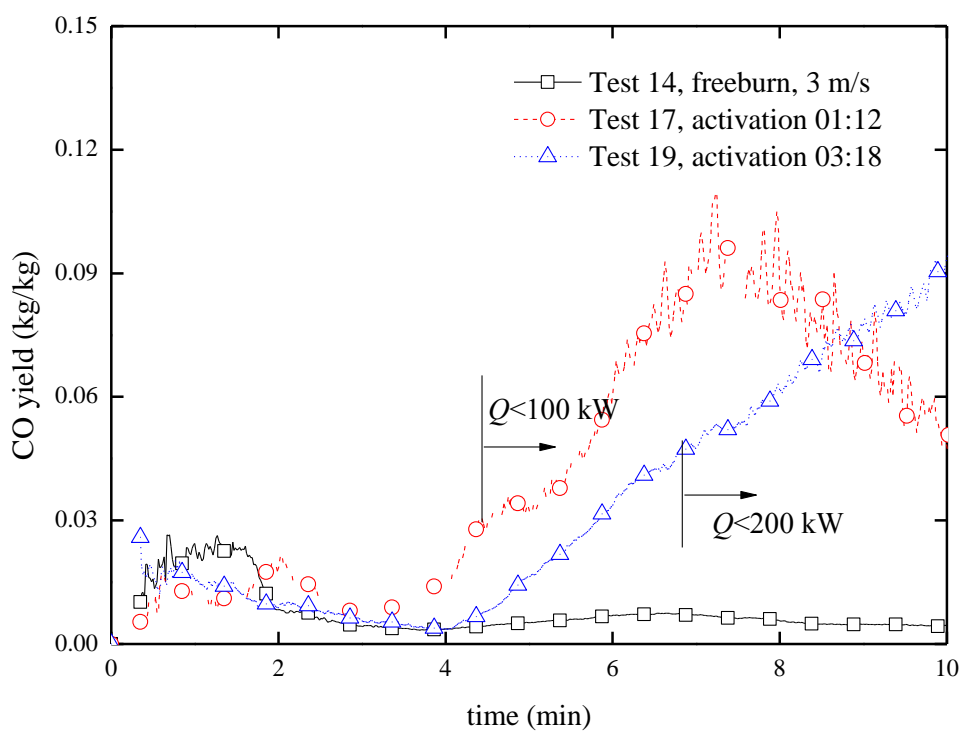

Figure 29 Comparison of $C O$ yield in the free burn test and fire suppression tests for velocity of $3 \mathrm{~m} / \mathrm{s}$ (Wood pallet fires).

It can be seen in Figure 28 and Figure 29 that in the free burn fire tests with wood pallets, the maximum CO yield is approximately 0.032 for a velocity of $1.5 \mathrm{~m} / \mathrm{s}$ and 0.025 for 3 
$\mathrm{m} / \mathrm{s}$. In these tests, the CO yield is higher at early stage and much lower after $2 \mathrm{~min}$. Some influence of the ignition source can be expected.

After activation the $\mathrm{CO}$ yield in the suppression tests starts to increase. It can also be observed that generally the $\mathrm{CO}$ yield increases with the decreasing heat release rate, and after the heat release rate is lower than around $100 \mathrm{~kW}$ to $200 \mathrm{~kW}$ (3 MW to $6 \mathrm{MW}$ at full scale) significant increase in $\mathrm{CO}$ yield can be found.

The CO yield in test 5 increases rapidly after suppression and reaches 0.1 at around 8 min, however, at this moment the heat release rate is around $30 \mathrm{~kW}$ close to extinguishment and therefore the results are not presented further after 8 min due to the large uncertainties. The $\mathrm{CO}$ yield in test 7 increases to around 0.033 at around $11 \mathrm{~min}$ and then ramps up to 0.08 . The $\mathrm{CO}$ yield in test 17 increases linearly after $3 \mathrm{~min}$ and reaches 0.10 at around $7 \mathrm{~min}$. In test 19 , the $\mathrm{CO}$ yield increases continuously to 0.09 at around 10 min. It can also be found that the maximum $\mathrm{CO}$ yield with suppression could be 3 to 4 times that in the free-burn tests.

The increase of $\mathrm{CO}$ yields indicate strong interaction between the water droplets, the produced water vapours and the combustion gases, which results in incomplete combustion and $\mathrm{CO}$ production.

An interesting finding is that the $\mathrm{CO}$ yield behaves very differently compared to the $\mathrm{CO}$ concentration at the mid-tunnel height. Note that the maximum $\mathrm{CO}$ concentration in the free burn test is still the highest, as shown in Figure 24 and Figure 25. Although the CO yield after activation of fire suppression is much higher, the heat release rate at this moment has been effectively suppressed in these tests, i.e. test 1 and test 14, and therefore the $\mathrm{CO}$ concentration at mid-tunnel height does not show an significant increase effect as the $\mathrm{CO}$ yield does.

Further, it can be expected that if the fire is not effectively suppressed after activation, the $\mathrm{CO}$ concentration could be much higher than that shown in Figure 24 and Figure 25. Note that in all these fire suppression tests, the maximum heat release rates are all lower than $40 \%$ of the maximum heat release rate in the free-burn test, that is, the fire sizes have been reduced to less than $40 \%$ of that in the free-burn test.

\subsubsection{Soot production in wood pallet fires}

\subsubsection{Soot production rate}

Soot production rate in most fire suppression tests is lower than in free-burn tests.

Soot yield before activation is at the same level. After activation the soot yield cannot be estimated, instead only upper limits could be known. The reason is that after activation a large amount of water droplets exist in the flow and behave as a light barrier and thus significantly affect the measurement of obscuration. These water droplets are produced both by nozzles and by condensation of water vapour. In case the deposition of the soot is negligible, the calculated soot production or soot yield could be used as the upper limits as the attenuation accounts for effects of both soot and water vapour. The contribution from the water droplets is difficult to estimate, and therefore the data is proposed to be regarded as the upper limit for soot until better methods or analysis can be carried out.

Figure 30 and Figure 31 shows comparisons of soot production rates in the free burn tests and fire suppression tests for a velocity of $1.5 \mathrm{~m} / \mathrm{s}$ and $3 \mathrm{~m} / \mathrm{s}$, respectively. For $3 \mathrm{~m} / \mathrm{s}$, the 
maximum soot production rate in the free burn test 14 is much higher than in the fire suppression tests. For $1.5 \mathrm{~m} / \mathrm{s}$, the maximum soot production rates in the free burn test 1 and the fire suppression test 5 approximately lie at the same level, and the value in test 7 is much lower. The results also show that after suppression the production rate in test 5 is much higher than the other two tests at $1.5 \mathrm{~m} / \mathrm{s}$. One reason could be a large amount of water droplets is produced after activation of fire suppression system. Another reason could be that large measurement error in test 5 is introduced as the laser measurement is very sensitive to deflection caused by, e.g. heat.

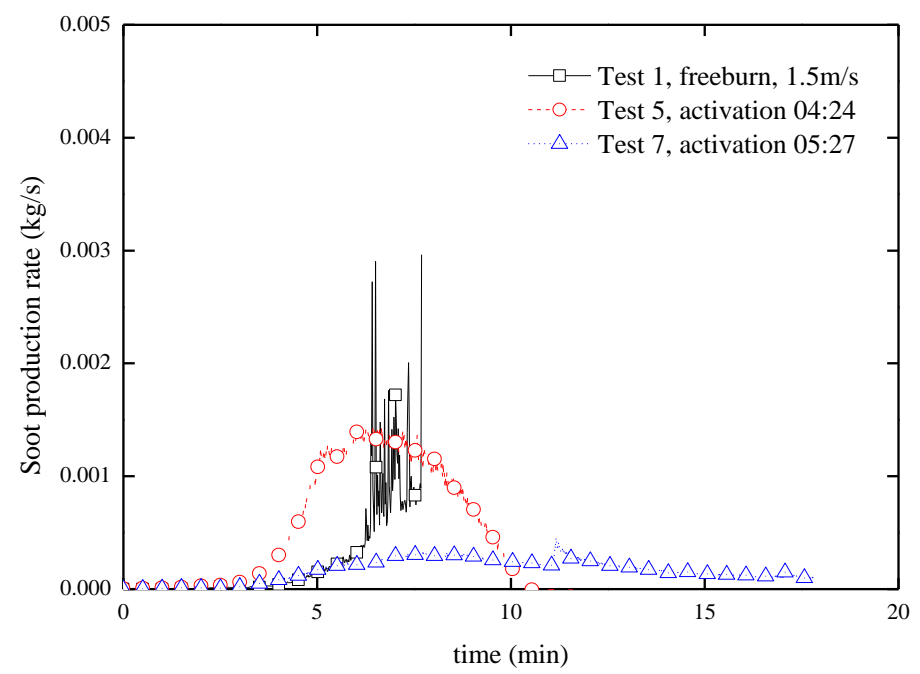

Figure 30 Comparison of soot production rates in the free burn test and fire suppression tests for velocity of $1.5 \mathrm{~m} / \mathrm{s}$ (Wood pallet fires). Laser in Test 1 failed after around $8 \mathrm{~min}$ and might also not work well before. Note that after activation the data are not really soot production rates but upper limits for them.

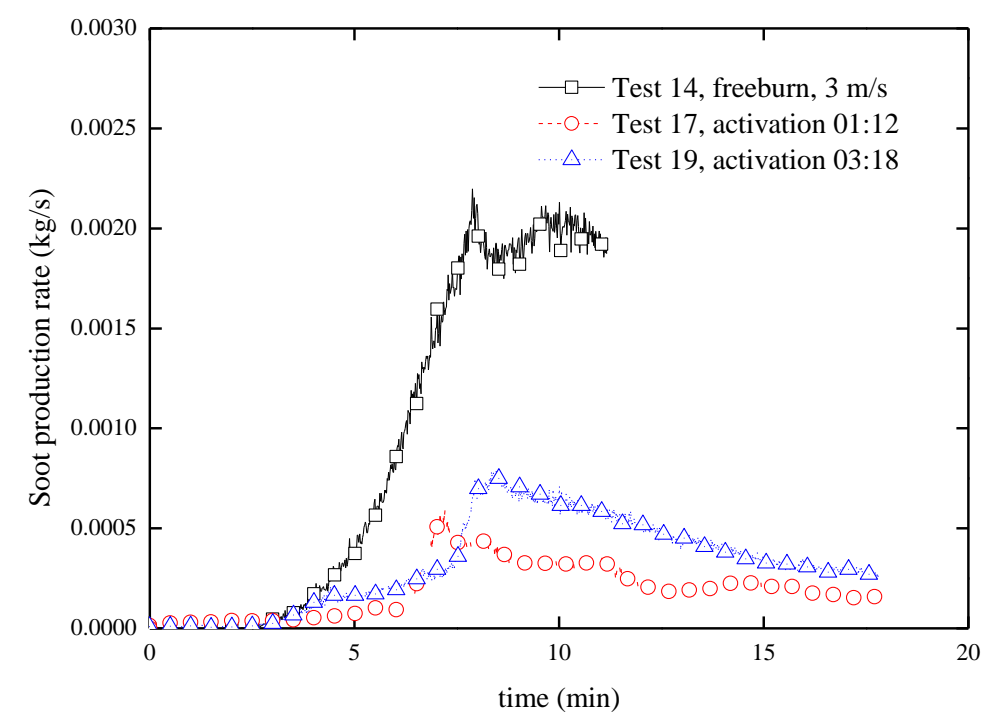

Figure 31 Comparison of soot production rates in the free burn test and fire suppression tests for velocity of $3 \mathrm{~m} / \mathrm{s}$ (Wood pallet fires). Laser in Test 14 failed after $11.2 \mathrm{~min}$. Note that after activation the data are not really soot production rates but upper limits for them. 


\subsubsection{Soot yield}

Figure 32 and Figure 33 show comparisons of soot yields in the free burn tests and fire suppression tests for a velocity of $1.5 \mathrm{~m} / \mathrm{s}$ and $3 \mathrm{~m} / \mathrm{s}$, respectively. The soot in the free burn test tends to increase with time. The soot yield in the free burn test and in suppression tests before activation is mainly in a range of 0.002-0.02. Note that the data from test 5 before activation as shown in Figure 32 are slightly higher than the others, which indicates possible large measurement error as mentioned earlier.

There is also a trend that after activation the soot yield increases. In test 5 the soot yield increases significantly with time after activation, while in test 7 only slight increase in soot yield could be observed. In test 17 the soot yield also increases significantly with time after activation while in test 19, the soot yield increases to 0.075 at around $8 \mathrm{~min}$ and keeps at this level till the end. Note that the maximum soot yield can be found to be as high as 0.22 .

It can also be observed that generally the soot yield increases with the decreasing heat release rate, and after the heat release rate is lower than around $200 \mathrm{~kW}$ significant increase in soot yield can be found.

Although during some period of a test with fire suppression the soot yield can be significantly higher than that in a free-burn test, the total production of soot particles in the free-burn test is still the highest as shown above.

However, as indicated earlier, it should be kept in mind that after activation, the soot measurement does not only measure soot but also water droplets. Therefore the data can only be considered as upper limit for the soot yield.

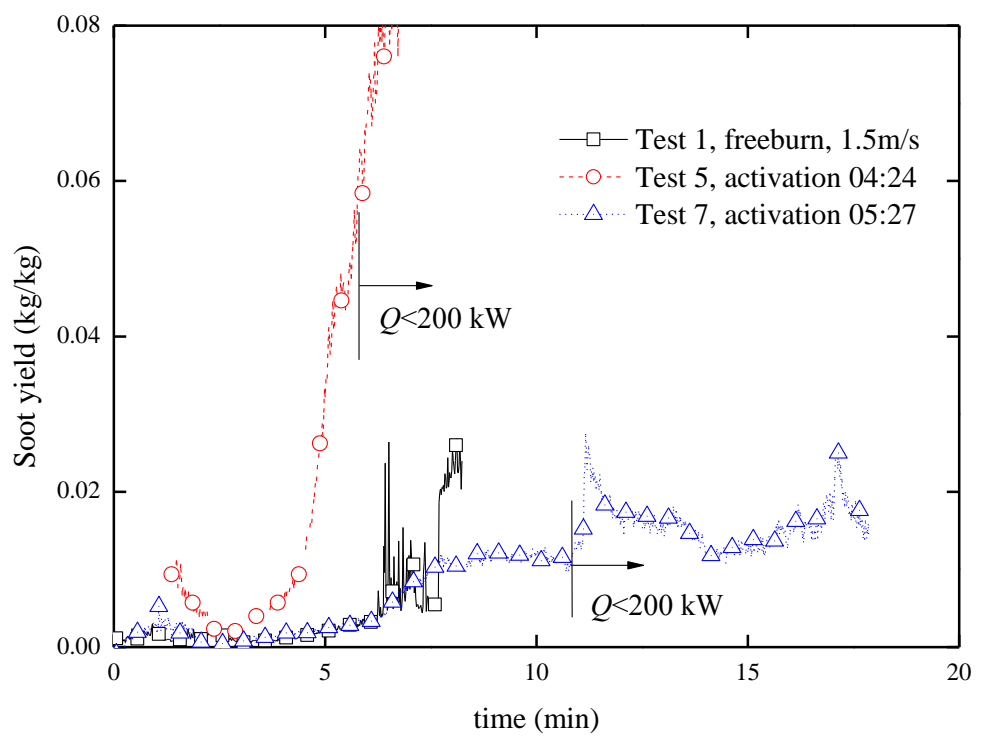

Figure 32 Comparison of soot yield in the free burn test and fire suppression tests for velocity of $1.5 \mathrm{~m} / \mathrm{s}$ (Wood pallet fires). Note that after activation the data are not really soot yield. 


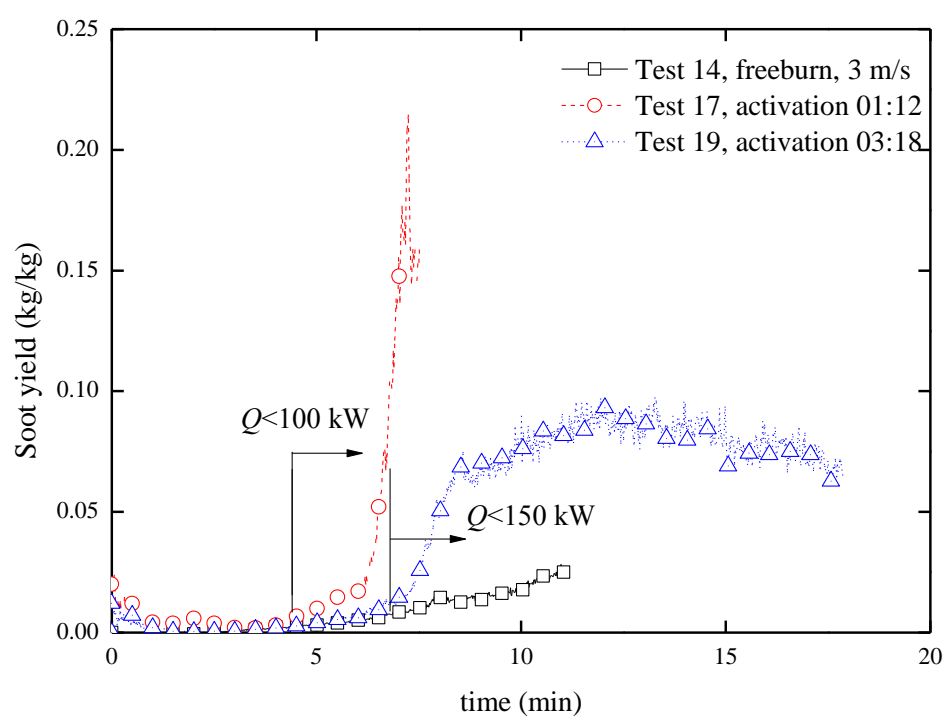

Figure 33 Comparison of soot yield in the free burn test and fire suppression tests for velocity of $3 \mathrm{~m} / \mathrm{s}$ (Wood pallet fires). Note that after activation the data are not really soot yield.

\subsubsection{Visibility at mid tunnel height in wood pallet fires}

Figure 34 and Figure 35 show comparisons of visibilities at mid tunnel height in the free burn tests and fire suppression tests for a velocity of $1.5 \mathrm{~m} / \mathrm{s}$ and $3 \mathrm{~m} / \mathrm{s}$, respectively. Note that the visibility in the free burn test is generally the smallest compared to fire suppression tests. The main reason is that the heat release rate decreased immediately after activation of the fire suppression system. According to the scaling theory presented in Section 2.1, the visibilities are the same in all scales.

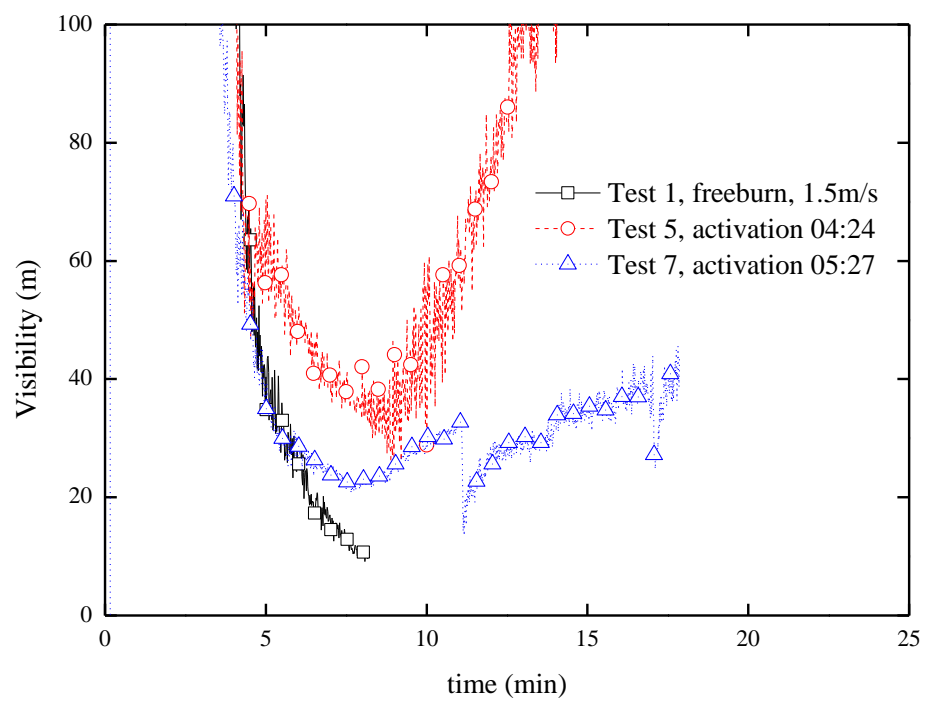

Figure 34 Comparison of visibility in the free burn test and fire suppression tests for velocity of $1.5 \mathrm{~m} / \mathrm{s}$ (Wood pallet fires). 


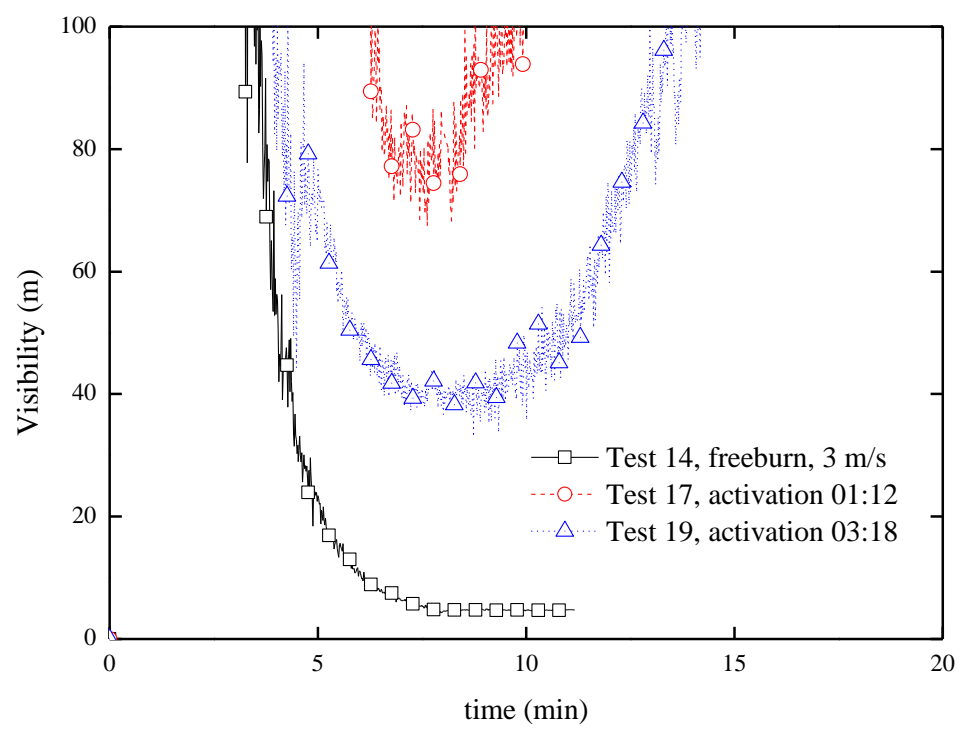

Figure 35 Comparison of visibility in the free burn test and fire suppression tests for velocity of $3 \mathrm{~m} / \mathrm{s}$ (Wood pallet fires).

\subsubsection{Discussion of wood pallet fires}

For wood pallet fires, the effect of ventilation velocity on the maximum heat release rate is insignificant. The fire growth rate is greater at higher ventilation velocity. For both 1.5 $\mathrm{m} / \mathrm{s}$ and $3 \mathrm{~m} / \mathrm{s}$, the wood crib fires was effectively suppressed under both velocities and the heat release rate decreased immediately after the fire suppression system was activated.

The CO concentration at mid tunnel height in the free burn test obtained the highest value for both velocities. The $\mathrm{CO}$ concentration curve in the free-burn test approximately follows the heat release rate curve. In the decay period the $\mathrm{CO}$ concentrations in a fire suppression test with late activation are higher than that in the free-burn test. Further, early activation reduces the $\mathrm{CO}$ concentration significantly and the $\mathrm{CO}$ concentrations can be much lower than that in the free-burn test.. The $\mathrm{CO}$ production rates show similar trend as the $\mathrm{CO}$ concentration at mid tunnel height.

In the free burn tests, the maximum CO yield is approximately 0.032 for a velocity of 1.5 $\mathrm{m} / \mathrm{s}$ and 0.025 for $3 \mathrm{~m} / \mathrm{s}$, and the CO yield is higher at early stage and much lower after 2 min. Generally the $\mathrm{CO}$ yield increases with the decreasing heat release rate. In tests with later activation, after the heat release rate decreases to around $100 \mathrm{~kW}$ to $200 \mathrm{~kW}$ (3 MW to $6 \mathrm{MW}$ at full scale), significant increase in $\mathrm{CO}$ yield is observed. However in most tests with suppression, the contribution of the high $\mathrm{CO}$ yield to the $\mathrm{CO}$ production rate after suppression is limited as the corresponding heat release rates are at a low level. Given that the maximum $\mathrm{CO}$ concentration in the free burn test is still the highest, the free burn tests could still represent the worst scenario from the point of view of $\mathrm{CO}$ concentration and evacuation.

For $3 \mathrm{~m} / \mathrm{s}$, the maximum soot production rate in the free burn test is much higher than in the fire suppression tests. For $1.5 \mathrm{~m} / \mathrm{s}$, the maximum soot production rates in the free burn test 1 and the fire suppression test 5 approximately lie at the same level, and the value in test 7 is much lower. After activation the same trend as the $\mathrm{CO}$ yield can be found. The soot yield increases with the decreasing heat release rate, and after the heat release rate is 
lower than around $100 \mathrm{~kW}$ to $200 \mathrm{~kW}$ (3 MW to $6 \mathrm{MW}$ at full scale) significant increase in soot yield is observed. In reality the estimated soot production or soot yield after activation of fire suppression become higher than real values and could be used as indications of upper limits as the attenuation accounts for effects of both soot and water droplets.

The visibility in the free burn test is generally the smallest compared to fire suppression tests due to that the heat release rate decreased immediately after activation of the fire suppression system.

Note that data of $\mathrm{CO}$ and visibility are reliable but not for data of soot. Test results of the $\mathrm{CO}$ concentration at the early stage indicate that the free burn test corresponds to the worst scenario despite the fact that in the decay period of a fire with late activation the $\mathrm{CO}$ concentration could be higher. Test results of visibility also show that the free burn test corresponds to the minimum value.

\subsection{PE crib fires in tunnel tests}

\subsubsection{Heat release rates in PE crib fires}

\subsubsection{Effect of ventilation velocity in PE crib fires}

Figure 36 shows the effect of ventilation velocity on heat release rate in the free-burn tunnel fire tests with PE crib fires. The heat release rate in test with $1.5 \mathrm{~m} / \mathrm{s}$ is slightly lower than that with $3 \mathrm{~m} / \mathrm{s}$ and the highest value is registered in test with $0.75 \mathrm{~m} / \mathrm{s}$. Although the influence of ventilation velocity is different to what has been found for wood crib fires, it is still clearly shown that the effect of ventilation velocity on the heat release rate curve is insignificant. It can also be found that the fire growth rate does not show a monotonous increase with the ventilation velocity. The reason could be that the crib is of a cube shape and longitudinal flame spread (leaning inside the fuel) does not dominates. For such types of fuel of short length in longitudinal direction, transverse flame spread is as important as longitudinal flame spread.

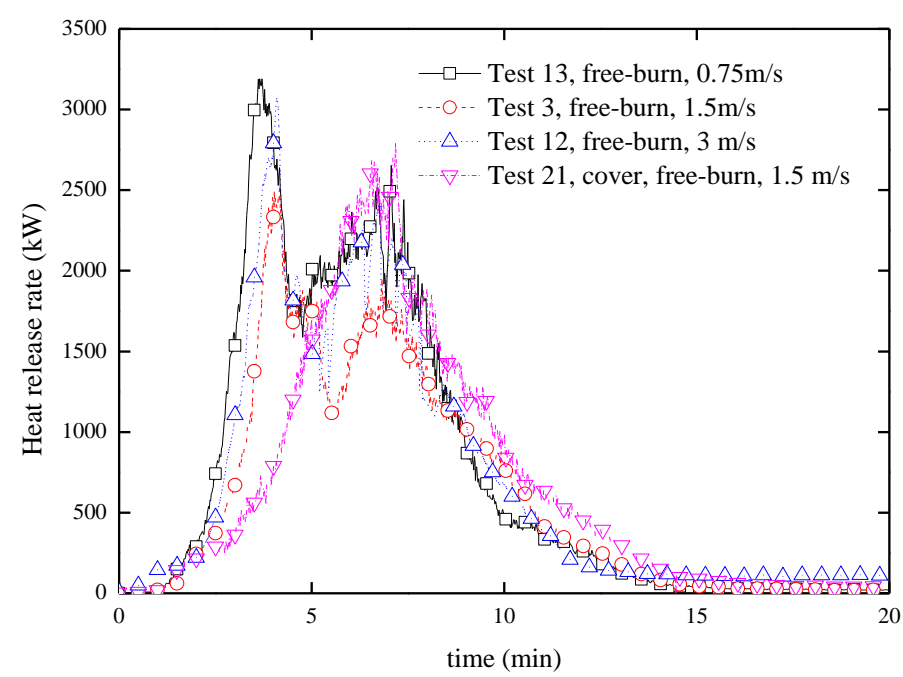

Figure 36 Heat release rate in the free-burn tests at different velocities (PE crib fires). 
The fire with coverage in test 21 develops much more slowly as the wind cannot directly blow into the fuel. However, the maximum heat release rate is approximately at the same level as the fires without coverage.

\subsubsection{Effect of fire suppression}

Figure 37, Figure 38 and Figure 39 show comparisons of heat release rates in the free burn tests and fire suppression tests for a velocity of $0.75 \mathrm{~m} / \mathrm{s}, 1.5 \mathrm{~m} / \mathrm{s}$ and $3 \mathrm{~m} / \mathrm{s}$, respectively. In all the tests the fires without coverage are suppressed immediately after activation of the fire suppression system, even the fire size at activation is close to the maximum size in a free-burn test. Note that the heat release rate curve in test 26 slightly deviates from the others. This should be due to the influence of ignition source. The same trend can be found for test 8 .

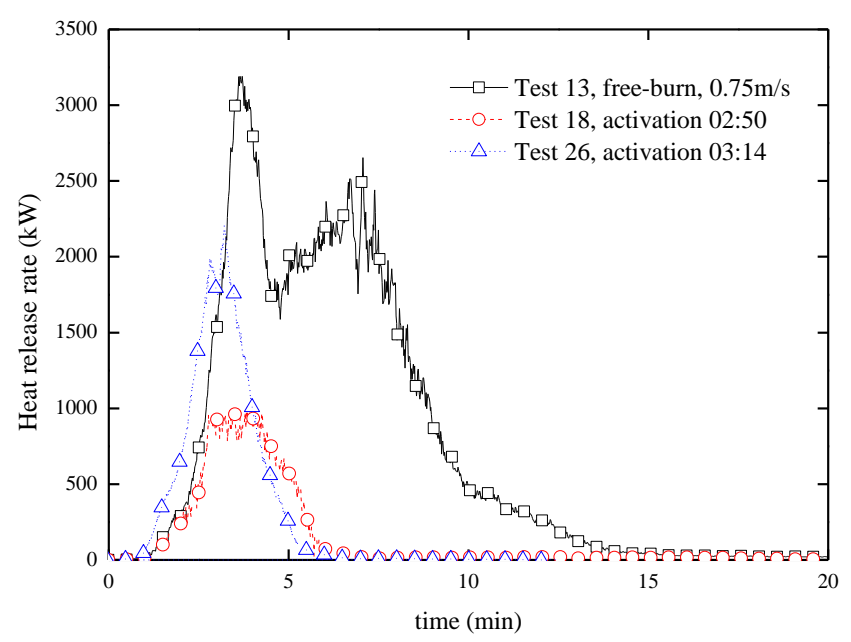

Figure 37 Comparison of heat release rates in the free burn test and fire suppression tests for velocity of $0.75 \mathrm{~m} / \mathrm{s}$ (PE crib fires).

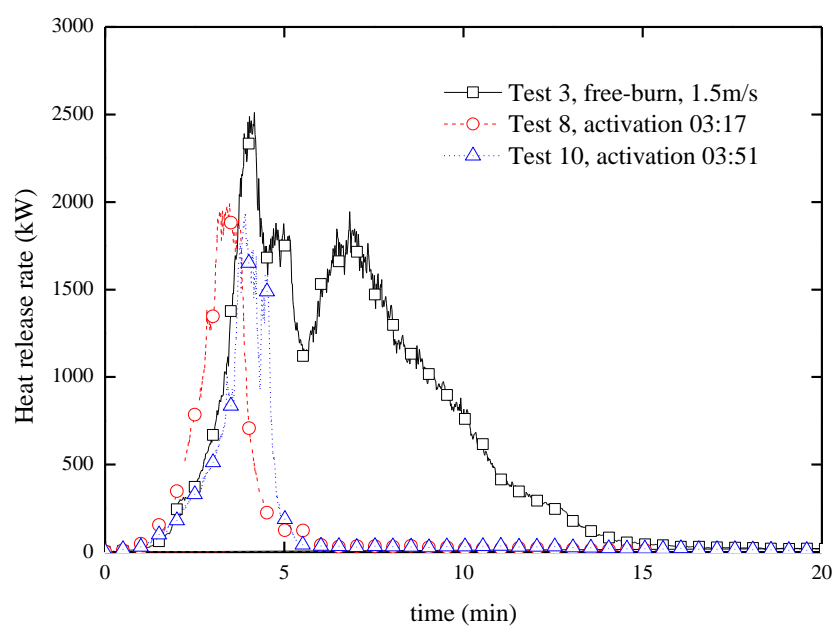

Figure 38 Comparison of heat release rates in the free burn test and fire suppression tests for velocity of $1.5 \mathrm{~m} / \mathrm{s}$ (PE crib fires). 


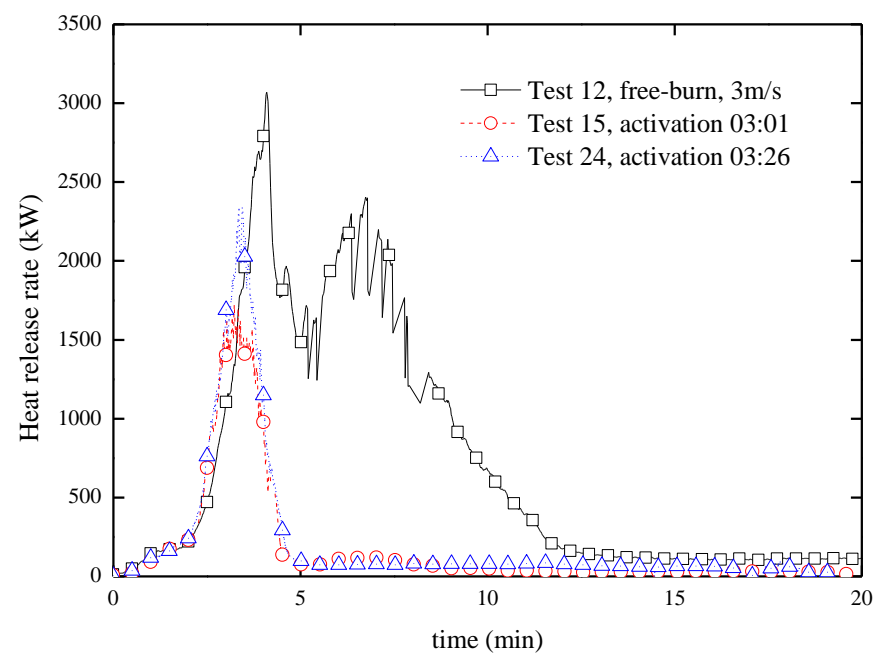

Figure 39 Comparison of heat release rates in the free burn test and fire suppression tests for velocity of $3 \mathrm{~m} / \mathrm{s}$ (PE crib fires).

Figure 40 shows the heat release rates for a velocity of $1.5 \mathrm{~m} / \mathrm{s}$ and fuel with coverage. The fire with coverage in test 25 is also suppressed immediately after activation of fire suppression while the decay period is much longer. It is shown in that the heat release rates in test 21 and test 25 show a deviation. This could be due to the fire with coverage is very sensitive to the placement of the ignition source.

Comparing the PE fires without coverage to the wood pallet fires shows that all the fires are suppressed effectively but the extinguishment takes much more time for the wood pallet fires.

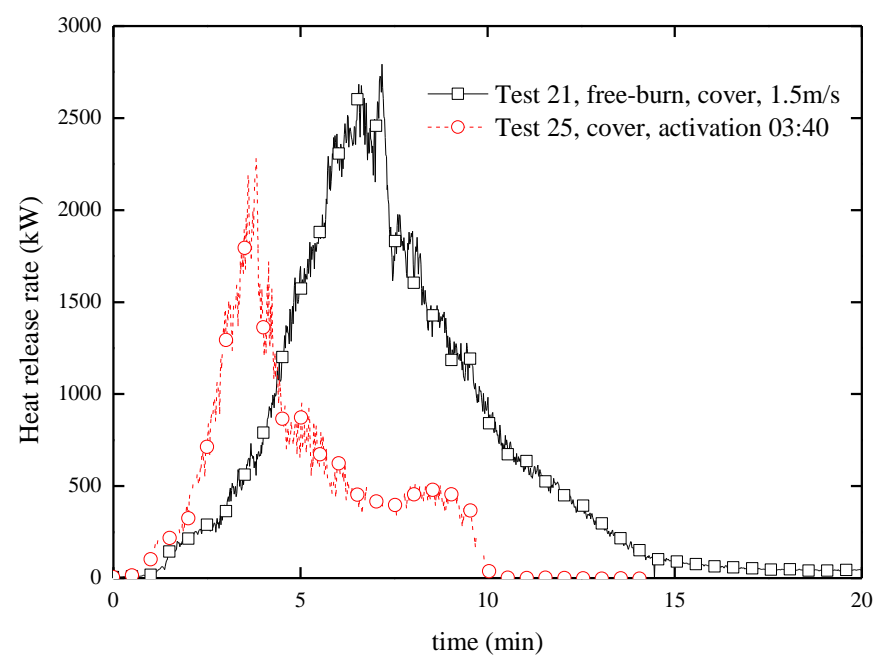

Figure 40 Comparison of heat release rates in the free burn test and fire suppression tests with coverage for velocity of $1.5 \mathrm{~m} / \mathrm{s}$ (PE crib fires). 


\subsubsection{CO production in PE crib fires}

\subsubsection{CO concentration at mid tunnel height}

Figure 41,Figure 42 and Figure 43 show comparisons of $\mathrm{CO}$ concentrations at mid tunnel height in the free burn test and fire suppression tests for velocity of $0.75 \mathrm{~m} / \mathrm{s}, 1.5 \mathrm{~m} / \mathrm{s}$ and $3 \mathrm{~m} / \mathrm{s}$. Cleary, the results show that after activation, the CO concentration at mid-tunnel height decreases immediately, following the same trend as shown in the heat release rate curves. In test 8 , the $\mathrm{CO}$ concentration in the growth period also slightly deviates from the others, as the corresponding heat release rate curve does.

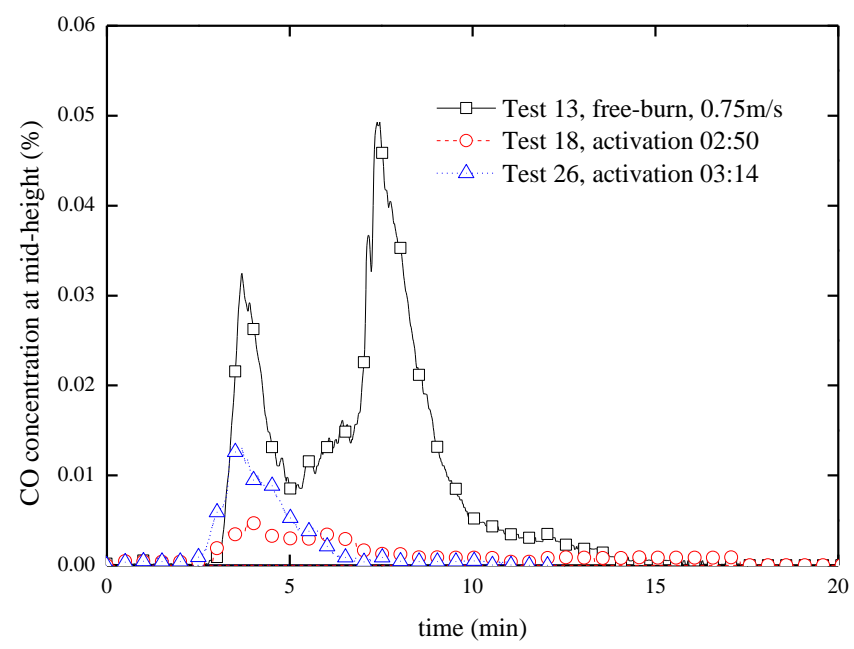

Figure 41 Comparison of $C O$ concentration at mid-height in the free burn test and fire suppression tests for velocity of $0.75 \mathrm{~m} / \mathrm{s}$ (PE crib fires).

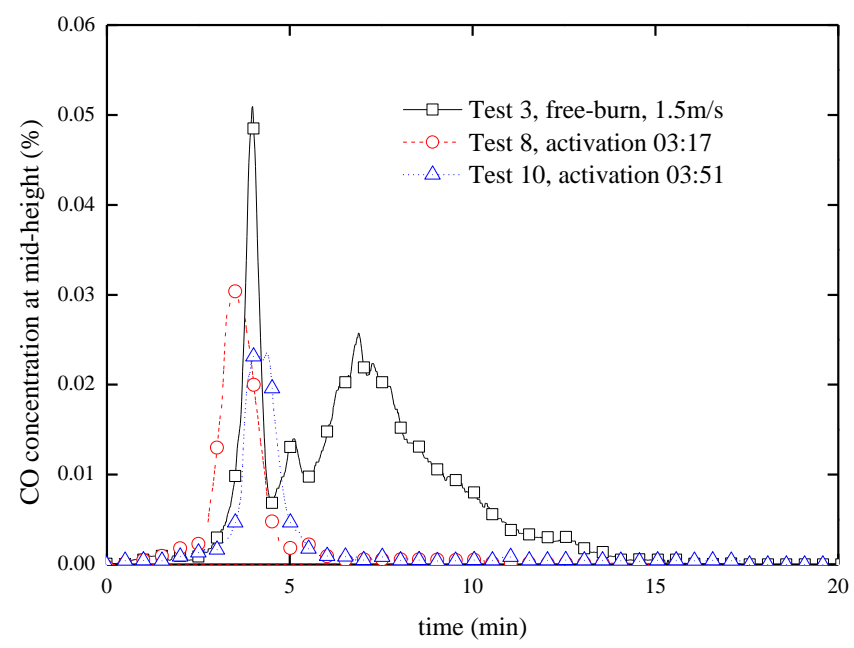

Figure 42 Comparison of $\mathrm{CO}$ concentration at mid-height in the free burn test and fire suppression tests for velocity of $1.5 \mathrm{~m} / \mathrm{s}$ (PE crib fires). 


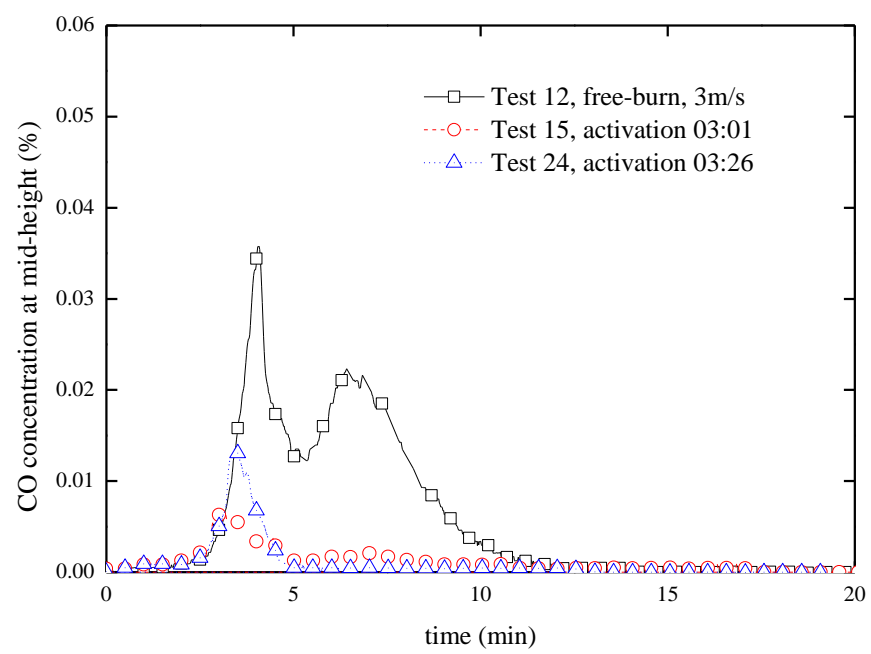

Figure 43 Comparison of $\mathrm{CO}$ concentration at mid-height in the free burn test and fire suppression tests for velocity of $3 \mathrm{~m} / \mathrm{s}$ (PE crib fires).

Figure 44 shows the results for a velocity of $1.5 \mathrm{~m} / \mathrm{s}$ and fuel with coverage. The CO concentration reaches its peak value much earlier. Comparing the two $\mathrm{CO}$ curves with the corresponding heat release rate curves in Figure 40 shows the same trend. Therefore it does not mean that the suppression increases the $\mathrm{CO}$ production. Instead, the $\mathrm{CO}$ concentration is approximately proportional to the heat release rate.

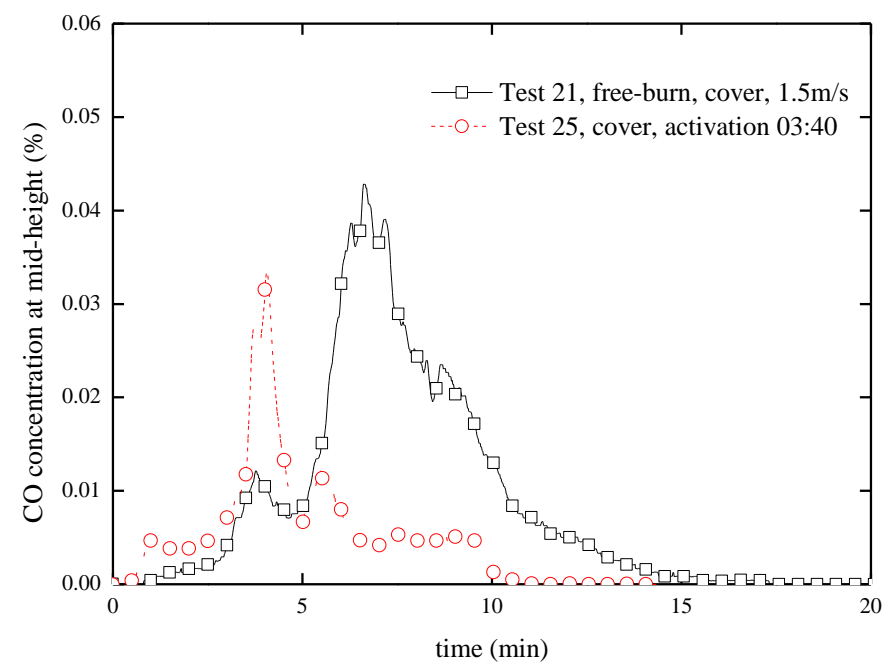

Figure 44 Comparison of $\mathrm{CO}$ concentration at mid-height in the free burn test and fire suppression tests with coverage for a velocity of $1.5 \mathrm{~m} / \mathrm{s}$ (PE crib fires).

\subsubsection{CO production rate}

Figure 45, Figure 46 and Figure 47 show comparisons of $\mathrm{CO}$ production rates in the free burn tests and fire suppression tests for velocity of $0.75 \mathrm{~m} / \mathrm{s}, 1.5 \mathrm{~m} / \mathrm{s}$ and $3 \mathrm{~m} / \mathrm{s}$. Similar trend as shown for $\mathrm{CO}$ concentration can be found. 


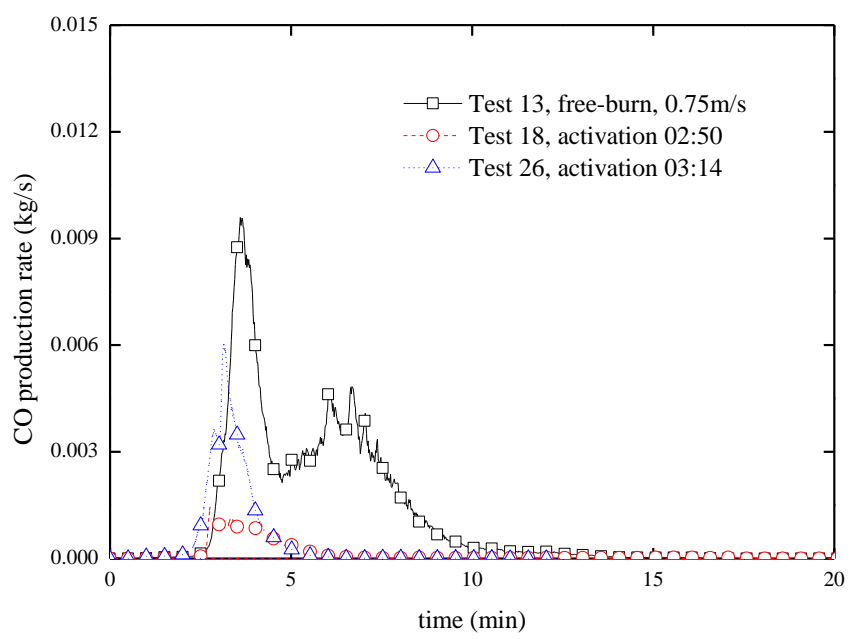

Figure 45 Comparison of $C O$ production rate in the free burn test and fire suppression tests for velocity of $0.75 \mathrm{~m} / \mathrm{s}$ (PE crib fires).

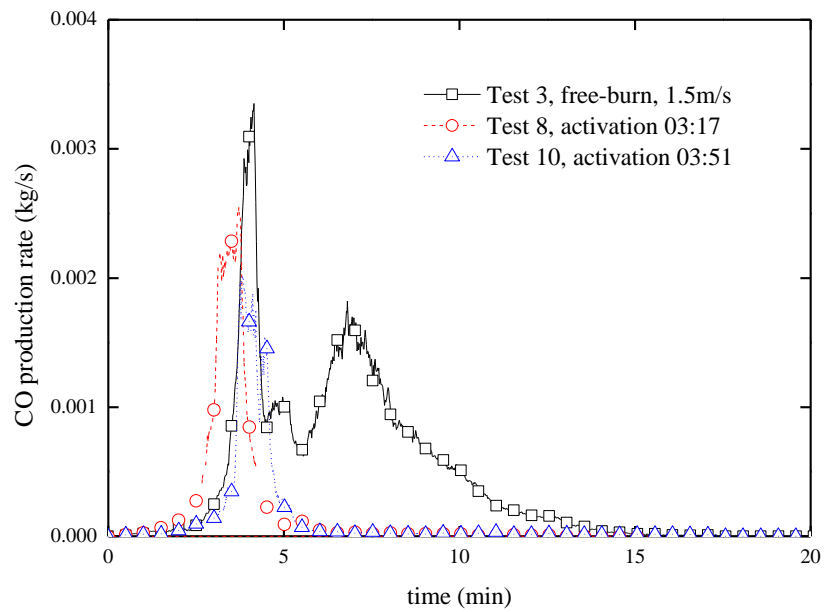

Figure 46 Comparison of $C O$ production rate in the free burn test and fire suppression tests for velocity of $1.5 \mathrm{~m} / \mathrm{s}$.

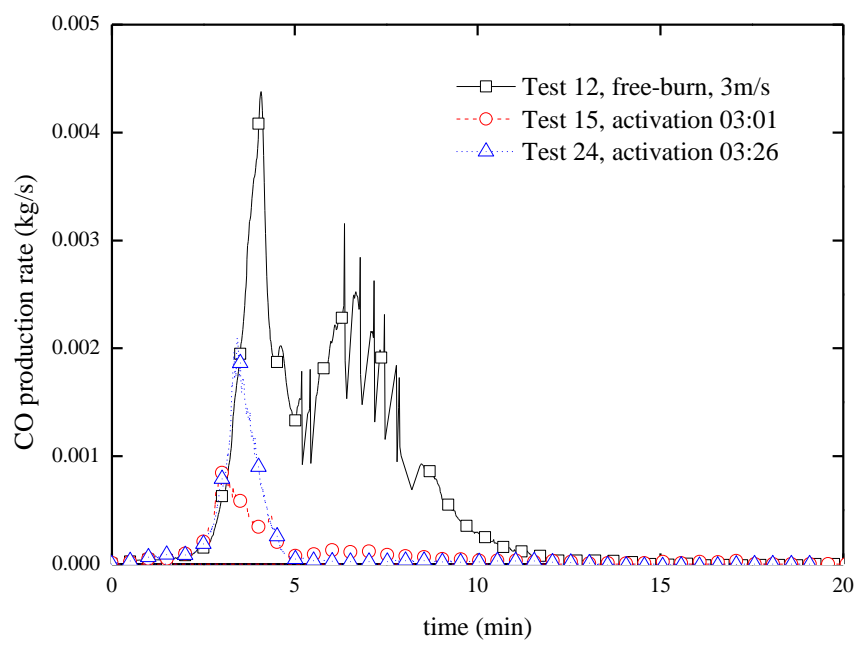

Figure 47 Comparison of CO production rate in the free burn test and fire suppression tests for velocity of $3 \mathrm{~m} / \mathrm{s}$ (PE crib fires). 
Figure 48 shows the results for a velocity of $1.5 \mathrm{~m} / \mathrm{s}$ and fuel with coverage. Compared the $\mathrm{CO}$ production rate curves to the heat release rate curves shows that more $\mathrm{CO}$ is produced after activation in the test with cover. This trend can be seen more clearly in terms of $\mathrm{CO}$ yield which will be discussed in the following.

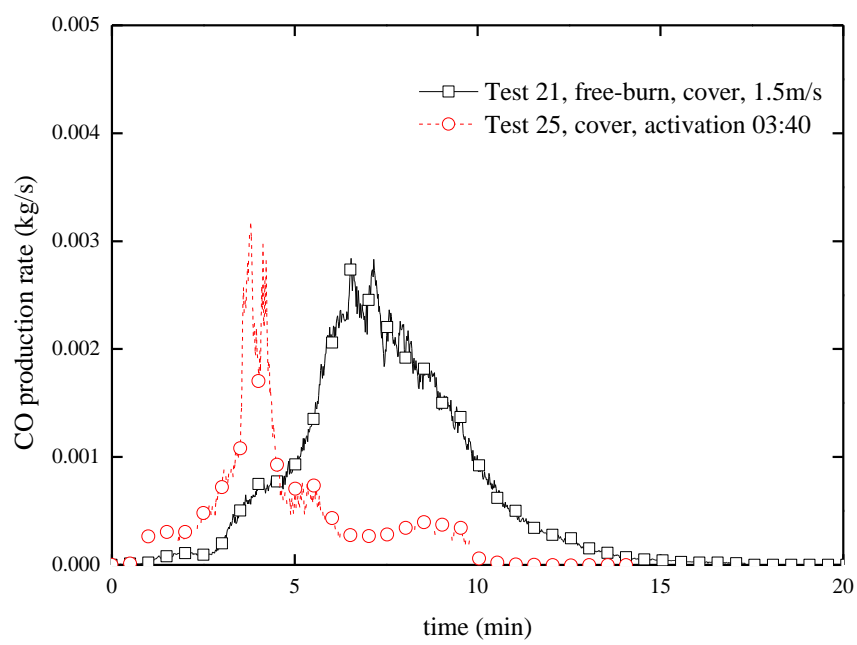

Figure 48 Comparison of $C O$ production rate in the free burn test and fire suppression tests with coverage for a velocity of $1.5 \mathrm{~m} / \mathrm{s}$ (PE crib fires).

\subsubsection{CO yield}

Figure 49, Figure 50 and Figure 51 show comparisons of $\mathrm{CO}$ yields in the free burn test and fire suppression tests for velocity of $0.75 \mathrm{~m} / \mathrm{s}, 1.5 \mathrm{~m} / \mathrm{s}$ and $3 \mathrm{~m} / \mathrm{s}$ respectively. It is shown that the CO yield is mainly in a range of 0.015 to 0.12 for $0.75 \mathrm{~m} / \mathrm{s}, 0.01$ to 0.08 for $1.5 \mathrm{~m} / \mathrm{s}$, and 0.01 to 0.06 for $3 \mathrm{~m} / \mathrm{s}$. This indicates that the CO yield decreases with ventilation velocity. Moreover, the difference in CO yield between $1.5 \mathrm{~m} / \mathrm{s}$ and $3 \mathrm{~m} / \mathrm{s}$ is much smaller than that between $0.75 \mathrm{~m} / \mathrm{s}$ and $1.5 \mathrm{~m} / \mathrm{s}$, that is, the influence of ventilation velocity on $\mathrm{CO}$ yield decreases with increasing velocity.

After activation of fire suppression, the $\mathrm{CO}$ yield is approximately at the same level as in the free-burn test. In tests with suppression, the CO yield increases slightly in the decay period, i.e. when the heat release rate is lower than $100 \mathrm{~kW}-200 \mathrm{~kW}$. 


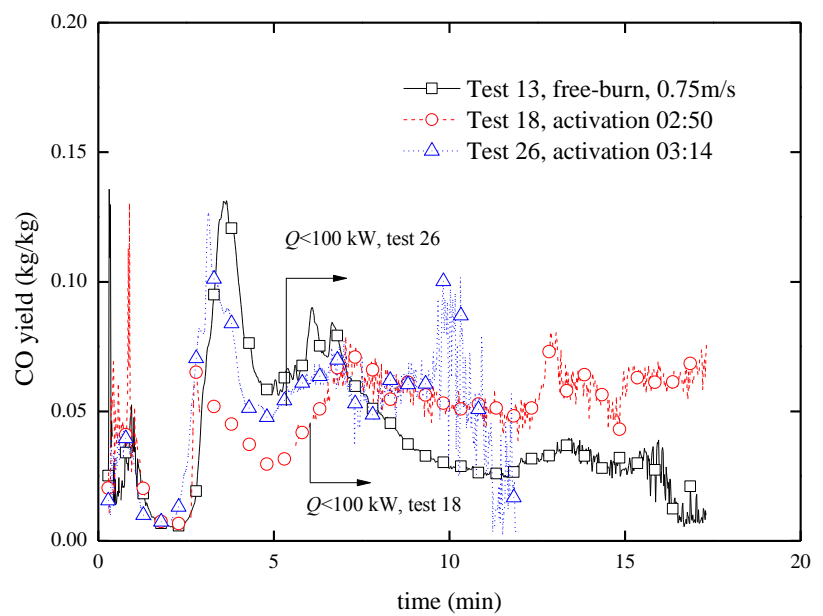

Figure 49 Comparison of $C O$ yield in the free burn test and fire suppression tests for velocity of $0.75 \mathrm{~m} / \mathrm{s}$ (PE crib fires).

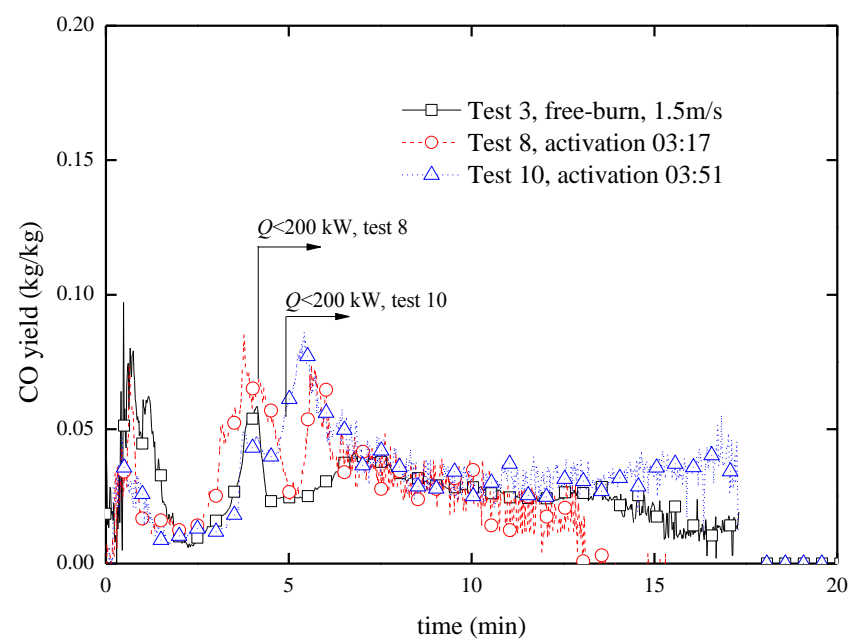

Figure 50 Comparison of $C O$ yield in the free burn test and fire suppression tests for velocity of $1.5 \mathrm{~m} / \mathrm{s}$ (PE crib fires).

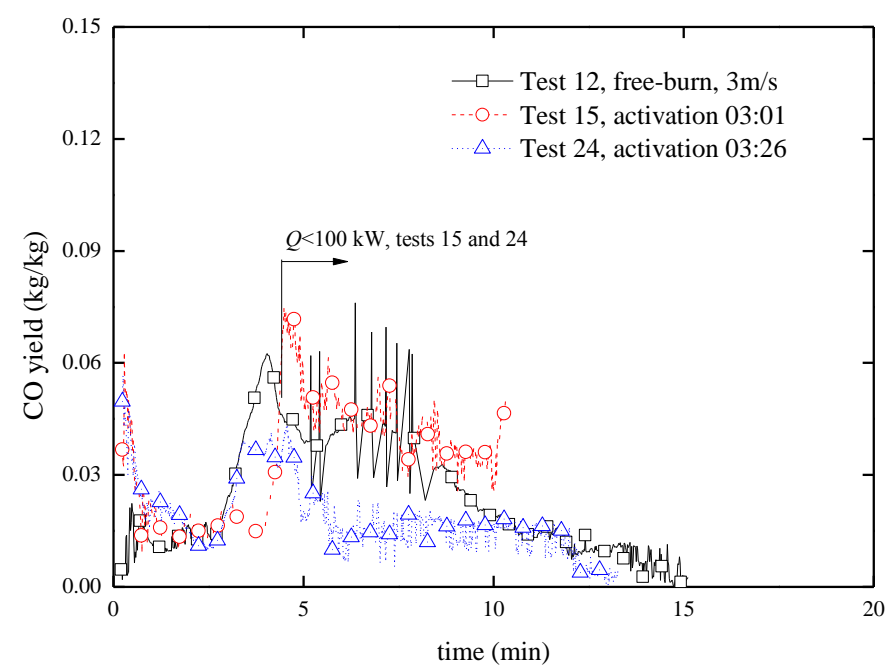

Figure 51 Comparison of $C O$ yield in the free burn test and fire suppression tests for velocity of $3 \mathrm{~m} / \mathrm{s}$ (PE crib fires). 
Figure 52 shows the results for a velocity of $1.5 \mathrm{~m} / \mathrm{s}$ and fuel with coverage. In test 25 before activation of suppression, the $\mathrm{CO}$ yield is higher than that in the free-burn test. This could be due to that at early stage when the heat release rate is small, the error in estimation of $\mathrm{CO}$ yield is large. After activation the $\mathrm{CO}$ yield in test 25 increases rapidly but lasts for a very short period during which the fire was extinguished. This rapid increase could also be mainly or partly due to the error in estimation of $\mathrm{CO}$ yield for low heat release rates.

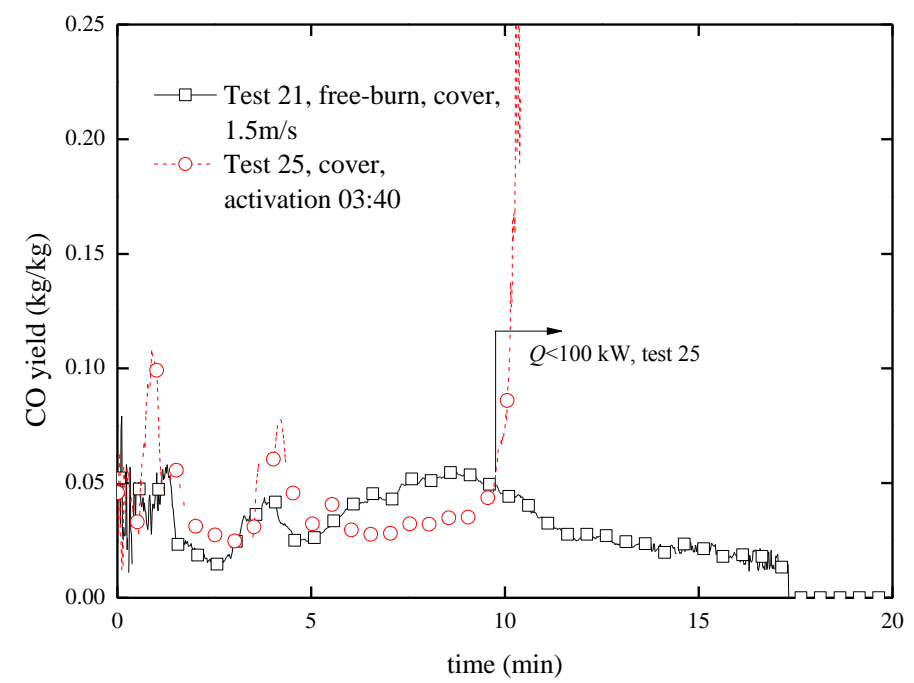

Figure 52 Comparison of $\mathrm{CO}$ yield in the free burn test and fire suppression tests with coverage for a velocity of $1.5 \mathrm{~m} / \mathrm{s}$ (PE crib fires).

In summary, the influence of fire suppression on $\mathrm{CO}$ yield is insignificant although in some tests the $\mathrm{CO}$ yield after suppression increases slightly.

Comparing the results of the PE crib fires and the wood pallet fires show that they behave very differently with regard to production of $\mathrm{CO}$. In the PE crib fires with fire suppression, the $\mathrm{CO}$ concentration is generally lower than that in the free-burn test and the $\mathrm{CO}$ yield increases slightly after fire suppression. In contrast, in the wood crib tests with late activation, the $\mathrm{CO}$ concentration in the decay period is slightly higher than that in the free-burn test. The difference in the $\mathrm{CO}$ yield of the wood pallet fires is, however, much larger, and the CO yield after activation rises continually to around $0.10 \mathrm{~kg} / \mathrm{kg}, 3.5$ to 4.5 times that in a free-burn wood pallet test. This indicates stronger interaction between the water droplets, the produced water vapours and the combustion gases for wood pallet fires, which results in incomplete combustion. There could be two reasons for this. One reason could be that the cellulose materials, e.g. wood, absorb water into the material, which to some extent behaves as a water sink. During fire suppression, the unburnt fuels can be pre-wetted while part of the fuels could be extinguished and then absorbs water. During the fire, a large amount of water vapours could be produced from these extra water sources and interact strongly with the combustion gases. Another reason could be that for a same maximum heat release rate, a wood pallet corresponds to a larger exposed fuel surface area that indicates more fuel surfaces could be pre-wetted. 


\subsubsection{Soot production in PE crib fires}

\subsubsection{Soot production rate}

Figure 53, Figure 54 and Figure 55 show comparisons of soot production rate in the free burn test and fire suppression tests for velocity of $0.75 \mathrm{~m} / \mathrm{s}, 1.5 \mathrm{~m} / \mathrm{s}$ and $3 \mathrm{~m} / \mathrm{s}$. Note that soot production rate after suppression does not mean real soot production rate but approximately represents its upper limit as both soot and water droplets affects the soot measurement. Despite this, in all the tests the maximum soot production rate in the freeburn test is the highest. In test 8 , the soot production rate at the early stage is higher than that in the free-burn test. However, this correlates well with the heat release rate curve in test 8 which shows the fire develops more rapidly in the growth period.

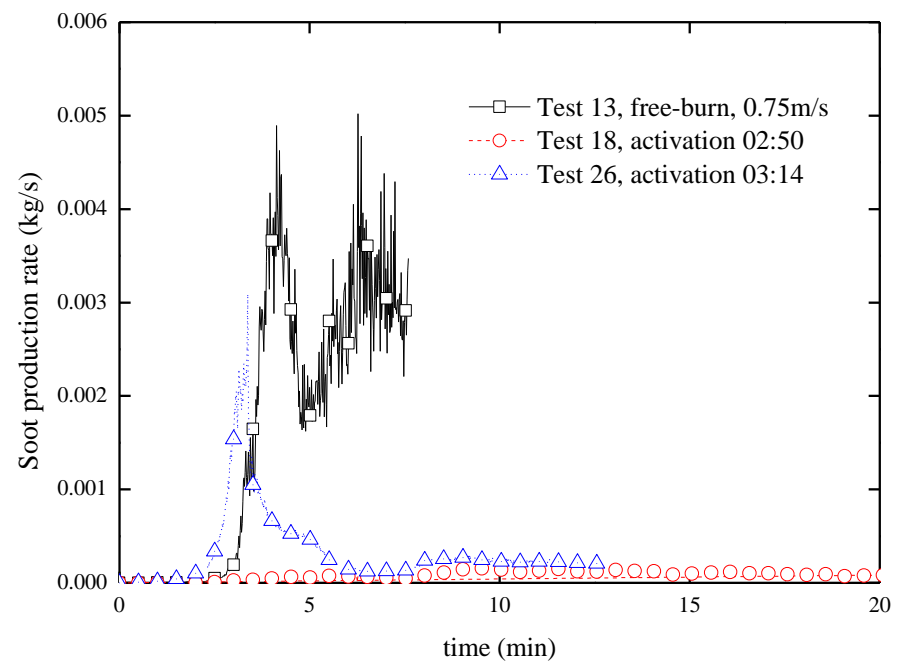

Figure 53 Comparison of soot production rate in the free burn test and fire suppression tests for velocity of $0.75 \mathrm{~m} / \mathrm{s}$ (PE crib fires).

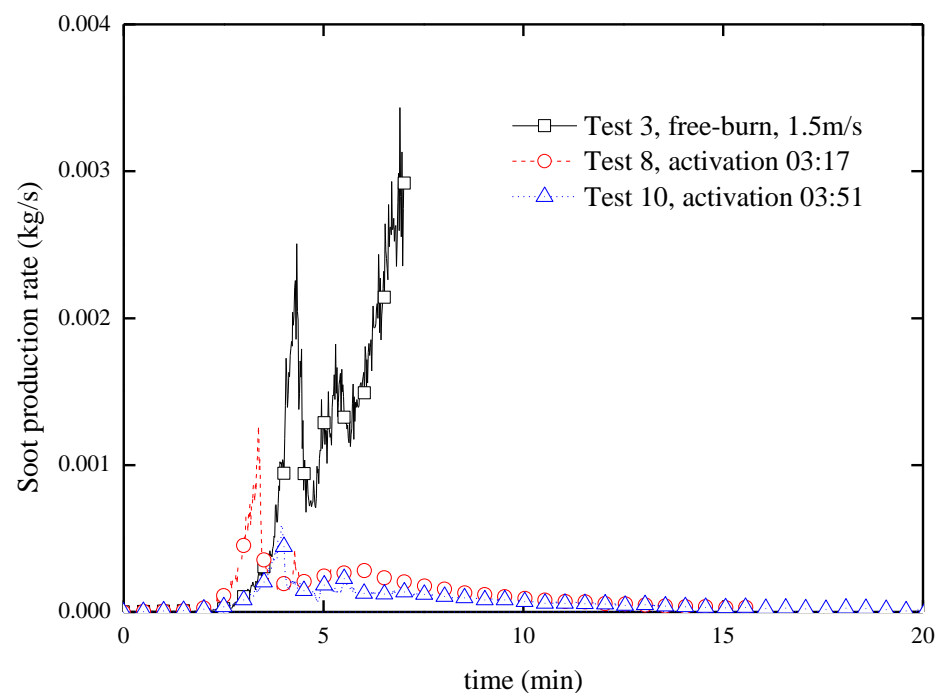

Figure 54 Comparison of soot production rate in the free burn test and fire suppression tests for velocity of $1.5 \mathrm{~m} / \mathrm{s}$ (PE crib fires). 


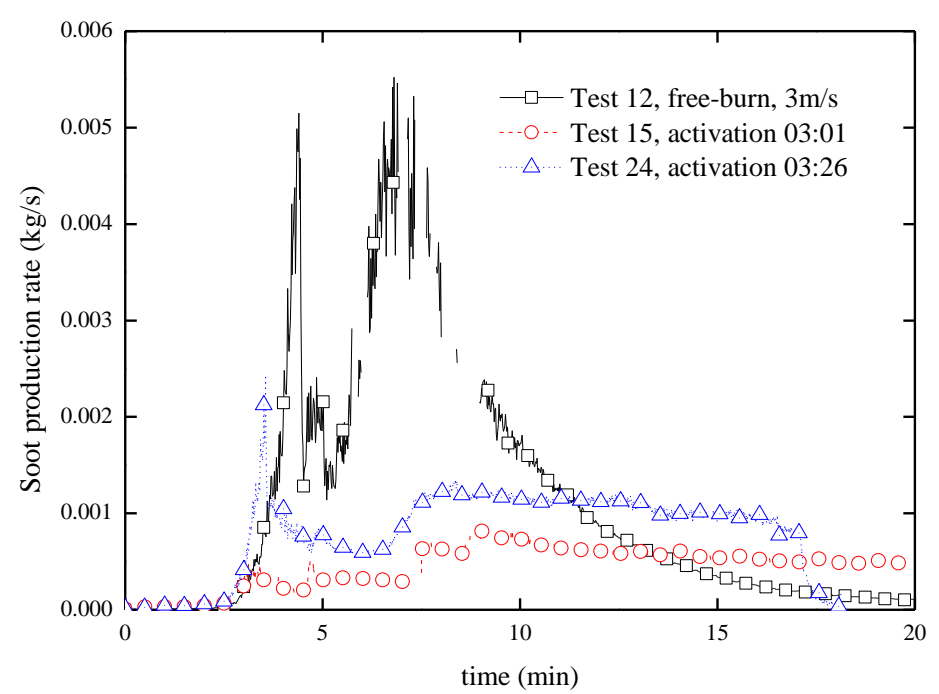

Figure 55 Comparison of soot production rate in the free burn test and fire suppression tests for velocity of $3 \mathrm{~m} / \mathrm{s}$ (PE crib fires).

Figure 56 shows the results for a velocity of $1.5 \mathrm{~m} / \mathrm{s}$ and fuel with coverage. The maximum soot production rate in the free-burn test 21 is much higher than that in test 25 with suppression. However, immediately after activation in test 25 the soot production rate is higher. The reason could be that both soot and water droplets affect the soot measurement after activation.

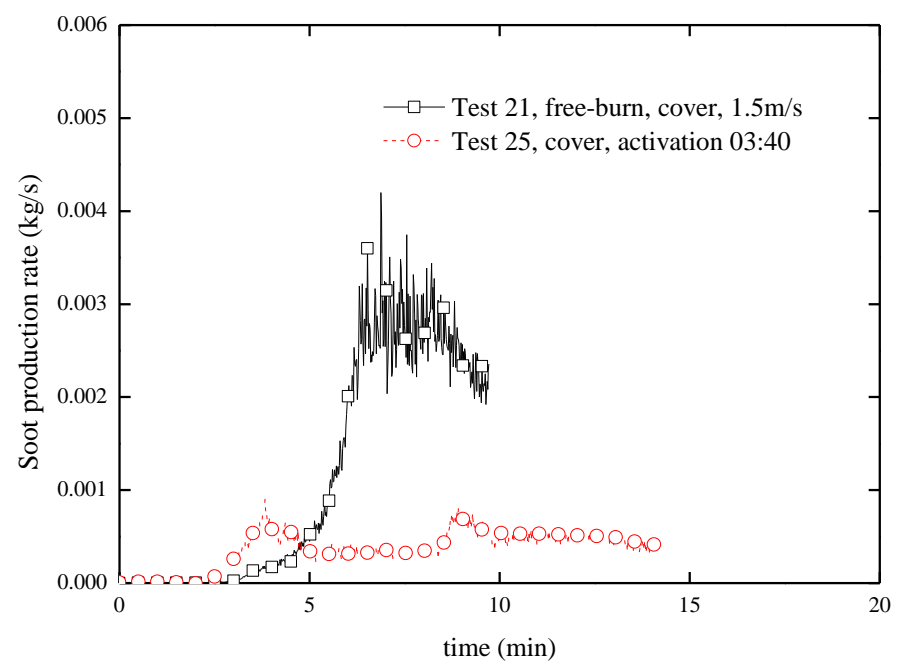

Figure 56 Comparison of soot production rate in the free burn test and fire suppression tests for velocity of $1.5 \mathrm{~m} / \mathrm{s}$ (PE crib fires).

\subsubsection{Soot yield}

Figure 57, Figure 58 and Figure 59 show comparisons of soot yields in the free burn test and fire suppression tests for velocity of $0.75 \mathrm{~m} / \mathrm{s}, 1.5 \mathrm{~m} / \mathrm{s}$ and $3 \mathrm{~m} / \mathrm{s}$, respectively. Clearly, the soot yield in the free burn test tends to increase with time.

The soot yield in the free-burn test 13 at $0.75 \mathrm{~m} / \mathrm{s}$ increases to around 0.06 at approximately $1 \mathrm{~min}$ (partly due to contribution from the ignition source) and decays 
immediately to 0.002 . It rises up again to approximately 0.07 after $4.5 \mathrm{~min}$. Similar trend can be found in test 3 at $1.5 \mathrm{~m} / \mathrm{s}$ while the first peak value is approximately 0.04 compared to 0.06 in test 13 .

The soot yield in the fire suppression tests is generally at the same level as in the freeburn test. However, when the heat release rate is lower than a certain value, e.g. $150 \mathrm{~kW}$ $-200 \mathrm{~kW}$, the soot yield increases significantly with time. Fortunately this period is very short and also corresponds to very small heat release rates. Therefore the contribution to the smoke production rate is limited even if the soot yield is high.

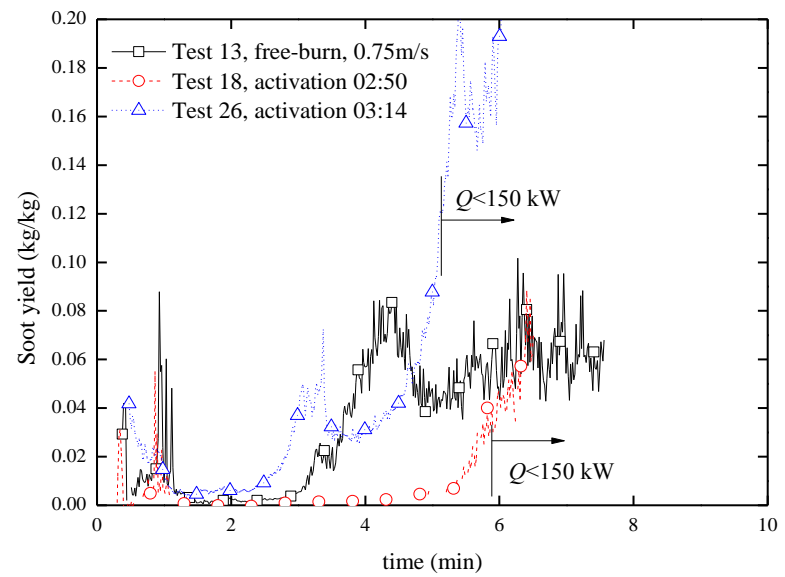

Figure 57 Comparison of soot yield in the free burn test and fire suppression tests for velocity of $0.75 \mathrm{~m} / \mathrm{s}$ (PE crib fires).

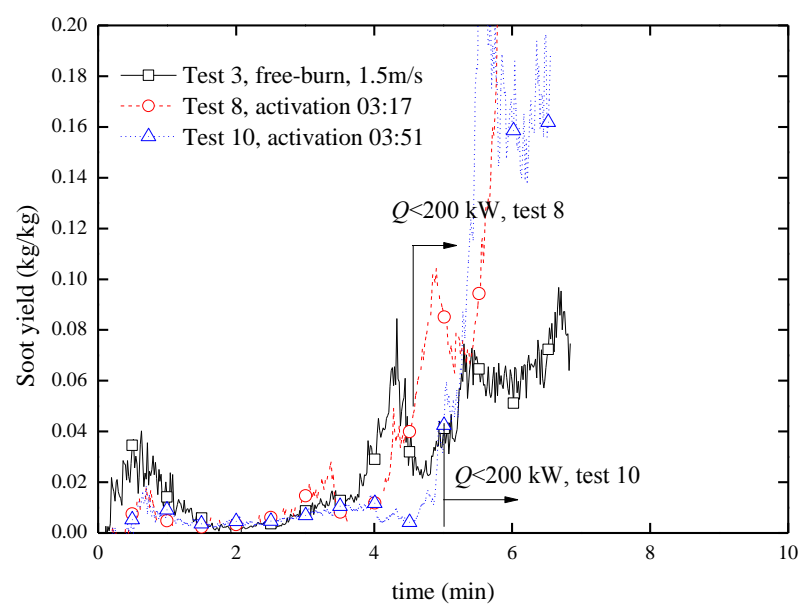

Figure 58 Comparison of soot yield in the free burn test and fire suppression tests for velocity of $1.5 \mathrm{~m} / \mathrm{s}$ (PE crib fires). 


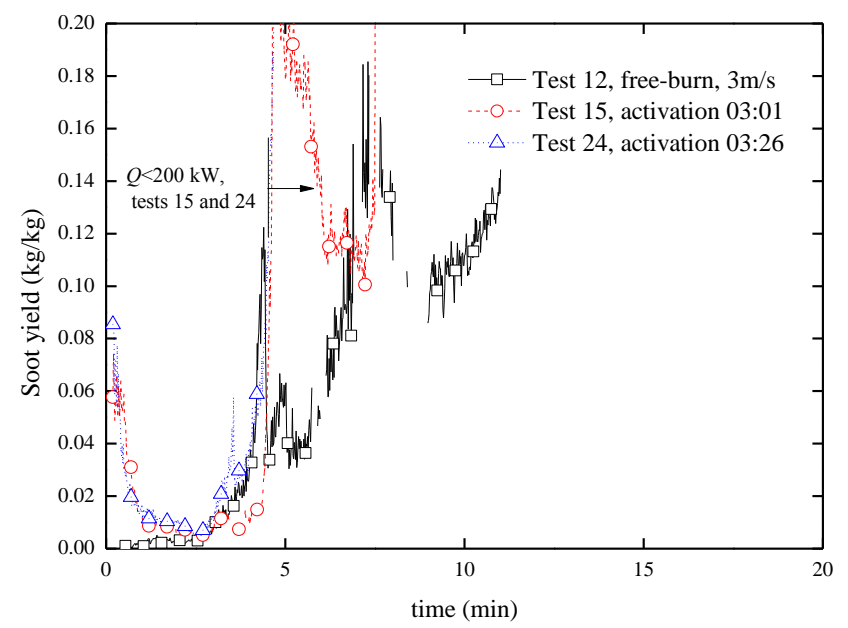

Figure 59 Comparison of soot yield in the free burn test and fire suppression tests for velocity of $3 \mathrm{~m} / \mathrm{s}$ (PE crib fires).

Figure 60 shows the results for a velocity of $1.5 \mathrm{~m} / \mathrm{s}$ and fuel with coverage. Clearly, the soot yield in the fire suppression tests with coverage is also at the same level as in the free-burn test. The soot yield in test 25 increases significantly after around $9.5 \mathrm{~min}$ when the heat release rate is around $200 \mathrm{~kW}$. It can be seen in Figure 40 that during this period, the fire was extinguished.

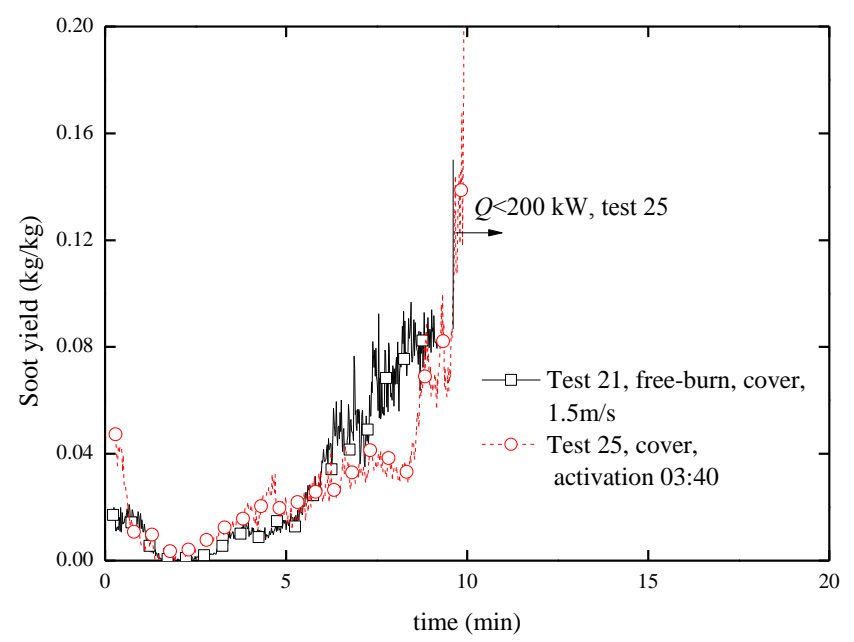

Figure 60 Comparison of soot yield in the free burn test and fire suppression tests with coverage for a velocity of $1.5 \mathrm{~m} / \mathrm{s}$ (PE crib fires).

Again, it should be kept in mind that after activation, the soot measurement does not only measure soot but also water droplets. Therefore the data can only be considered as upper limit for the soot yield.

\subsubsection{Visibility at mid tunnel height in PE crib fires}

Figure 61, Figure 62, Figure 63 show comparisons of visibilities at mid tunnel height in the free burn test and fire suppression tests for velocity of $0.75 \mathrm{~m} / \mathrm{s}, 1.5 \mathrm{~m} / \mathrm{s}$ and $3 \mathrm{~m} / \mathrm{s}$. The minimum visibility in the free-burn test is the lowest. The deviation in visibility 
between the free-burn test 13 and test 26 in Figure 61 and the deviation in visibility between the free-burn test 3 and test 8 in Figure 62 at the early stage correlate well with the deviations in the heat release rate curves. Therefore during the whole period, it can be concluded that the free-burn test is the worst case.

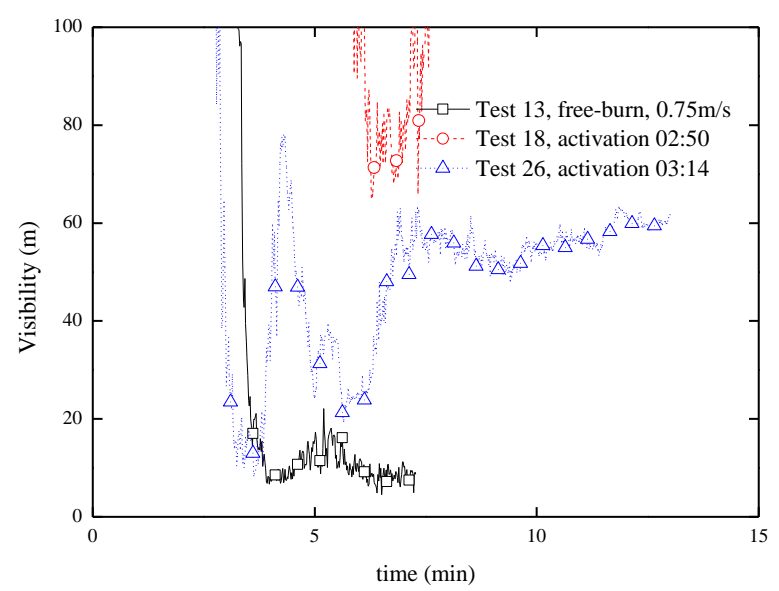

Figure 61 Comparison of visibility in the free burn test and fire suppression tests for velocity of $0.75 \mathrm{~m} / \mathrm{s}$ (PE crib fires).

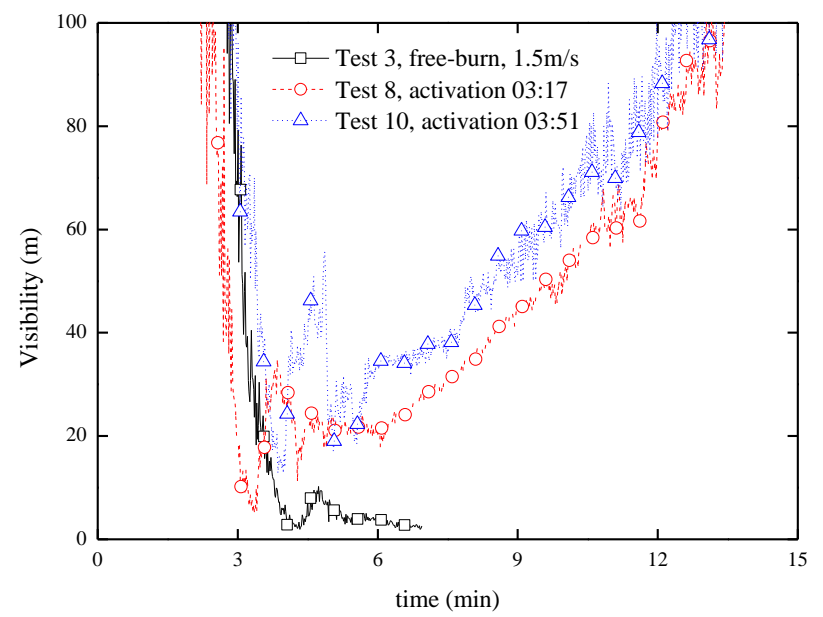

Figure 62 Comparison of visibility in the free burn test and fire suppression tests for velocity of $1.5 \mathrm{~m} / \mathrm{s}$ (PE crib fires). 


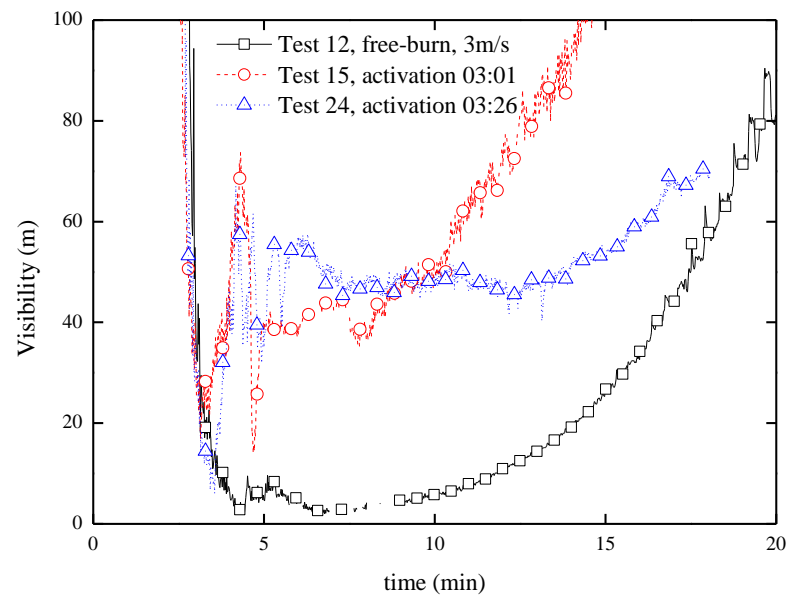

Figure 63 Comparison of visibility in the free burn test and fire suppression tests for velocity of $3 \mathrm{~m} / \mathrm{s}$ (PE crib fires).

Figure 64 shows the visibilities for a velocity of $1.5 \mathrm{~m} / \mathrm{s}$ and fuel with coverage. The deviation in visibility between the tests correlate well with the deviations in the heat release rate curves.

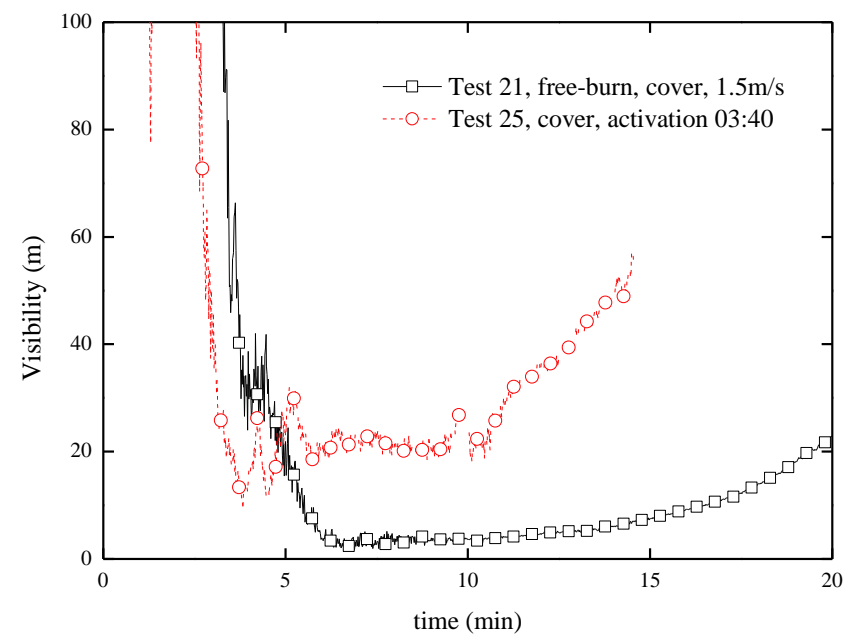

Figure 64 Comparison of visibility in the free burn test and fire suppression tests for velocity of $1.5 \mathrm{~m} / \mathrm{s}$ (PE crib fires).

\subsubsection{Discussion of PE crib fires}

For PE crib fires, the effect of ventilation velocity on the heat release rate curve is also insignificant, similar to the case with wood pallets. The fire with coverage develops slowly as the wind cannot directly blow into the fuel while the maximum heat release rate is approximately at the same level as the fires without coverage. The PE crib fires are very effectively suppressed and the fire with coverage decays more slowly.

The $\mathrm{CO}$ yield decreases slightly with ventilation velocity. After activation of fire suppression, the $\mathrm{CO}$ yield is approximately at the same level, or slightly higher, as in the free-burn test. However in most tests with suppression, the increase of $\mathrm{CO}$ yield after 
suppression is limited. The $\mathrm{CO}$ concentration at mid-tunnel height in all the fire suppression tests with PE cribs is generally lower than that in the corresponding free-burn test.

The soot yield in the free burn test tends to increase with time. The soot yield in the fire suppression tests is generally at the same level as in the free-burn test. However, when the heat release rate is lower than a certain value, e.g. $150 \mathrm{~kW}-200 \mathrm{~kW}$, the soot yield increases significantly with time. Fortunately this period is very short and also corresponds to very small heat release rates. Therefore the contribution to the smoke production rate is limited even if the soot yield is high. In all the tests the maximum soot production rate in the free-burn test is the highest. Consequently, during the whole period, it can be concluded that the free-burn test can be considered as the worst case in terms of visibility.

Note that data of $\mathrm{CO}$ and visibility are reliable but not for data of soot. Test results show that the $\mathrm{CO}$ concentration at mid-tunnel height in the fire suppression tests is generally lower than that in the corresponding free-burn tests. Test results of visibility also show that that the free burn test corresponds to the minimum value.

\subsection{PUR crib fires in tunnel tests}

\subsubsection{Heat release rate in PUR crib fires}

\subsubsection{Effect of ventilation velocity in free-burn tests}

Figure 65 shows the effect of ventilation velocity on heat release rate in the free-burn tunnel fire tests. Test 4 is a repeat test of test 2 , and the heat release rate curves correlates with each other quite well. Clearly it shows that the effect of ventilation velocity on the maximum heat release rate is insignificant (the difference between $1.5 \mathrm{~m} / \mathrm{s}$ and $3 \mathrm{~m} / \mathrm{s}$ is less than $10 \%$ ). It also shows that the fire growth rate is slightly greater for $3 \mathrm{~m} / \mathrm{s}$.

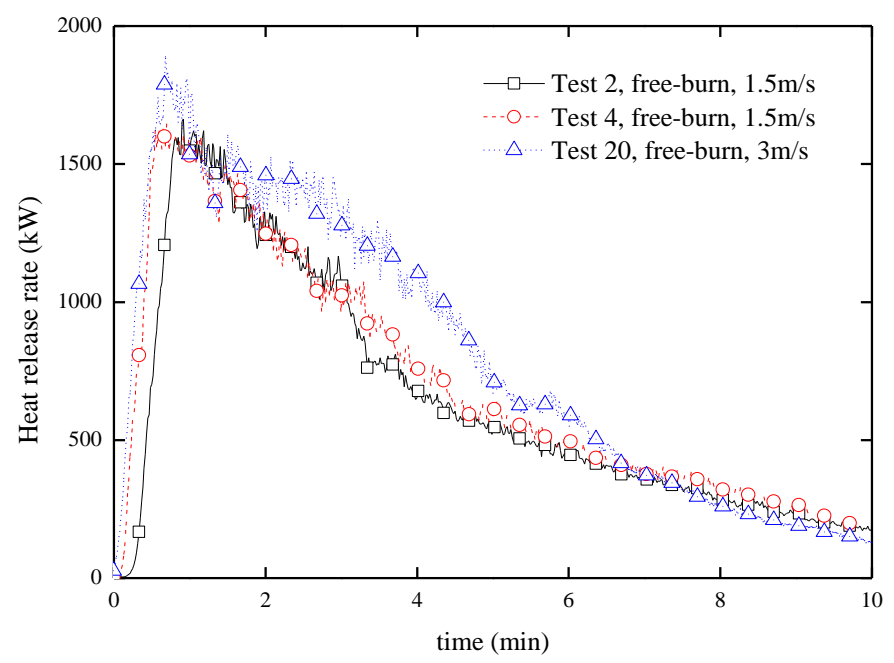

Figure 65 Heat release rate in the free-burn tests at different velocities (PUR crib fires). 


\subsubsection{Effect of fire suppression}

Figure 66 and Figure 67 show comparisons of heat release rates in the free burn test and fire suppression tests for velocity of $1.5 \mathrm{~m} / \mathrm{s}$ and $3 \mathrm{~m} / \mathrm{s}$ respectively.

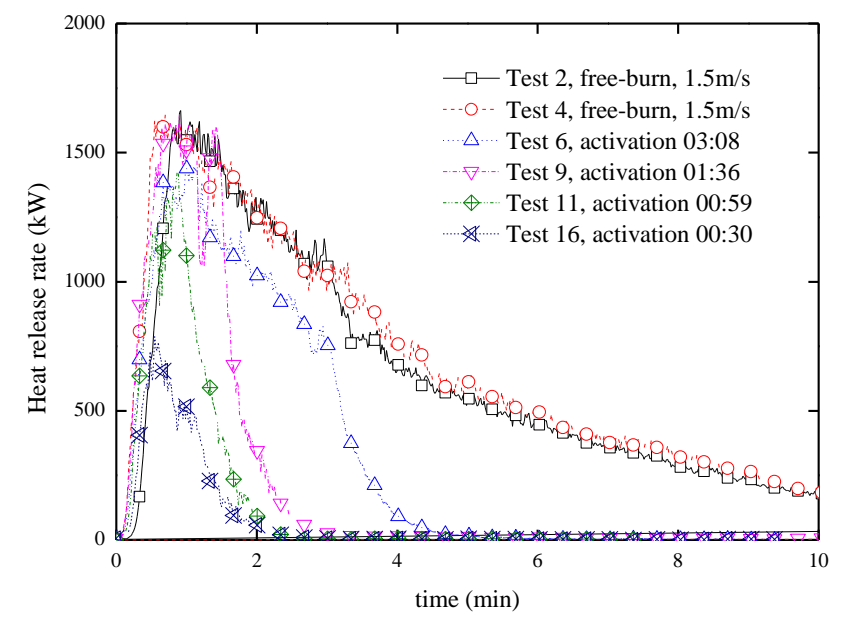

Figure 66 Comparison of heat release rates in the free burn test and fire suppression tests for velocity of $1.5 \mathrm{~m} / \mathrm{s}$ (PUR crib fires).

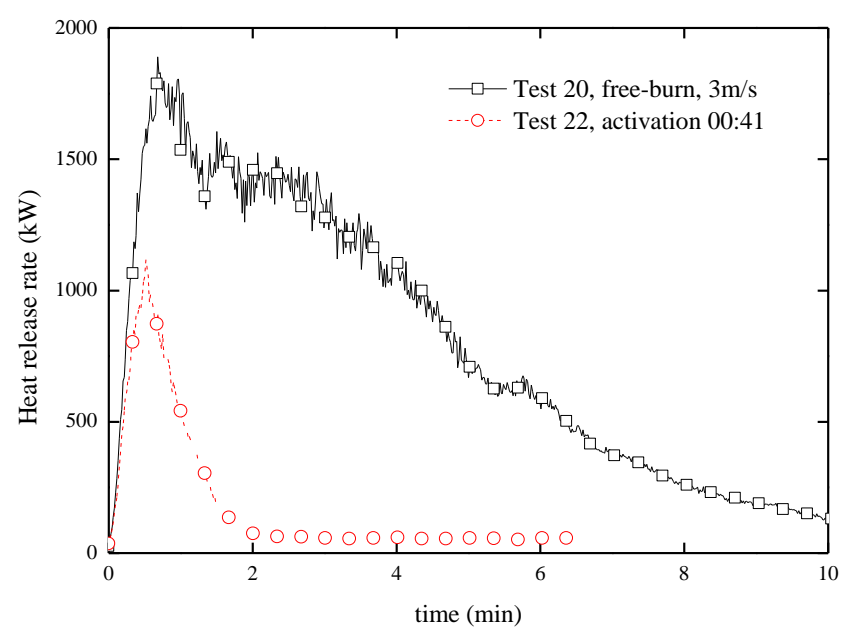

Figure 67 Comparison of heat release rates in the free burn test and fire suppression tests for velocity of $3 \mathrm{~m} / \mathrm{s}$.

\subsubsection{CO production in PUR crib fires}

\subsubsection{CO concentration at mid tunnel height}

Figure 68 and Figure 69 show comparisons of CO concentration at mid tunnel height in the free burn tests and fire suppression tests for velocity of $1.5 \mathrm{~m} / \mathrm{s}$ and $3 \mathrm{~m} / \mathrm{s}$ respectively. It is shown that the $\mathrm{CO}$ concentration at mid-tunnel height in the fire suppression tests is lower than that in the corresponding free-burn test 2. Note that during $1 \mathrm{~min}$ to $3 \mathrm{~min}$ the $\mathrm{CO}$ concentration in the free-burn test 4 is lower than that in test 2, which might be due to slight difference in placement of the fuels. 


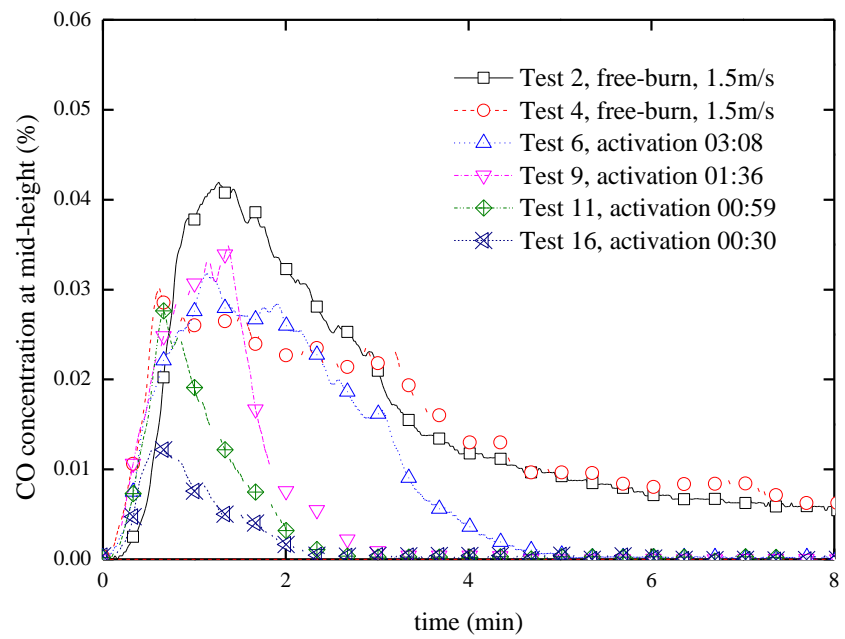

Figure 68 Comparison of $C O$ concentration at mid tunnel height in the free burn test and fire suppression tests for velocity of $1.5 \mathrm{~m} / \mathrm{s}$ (PUR crib fires).

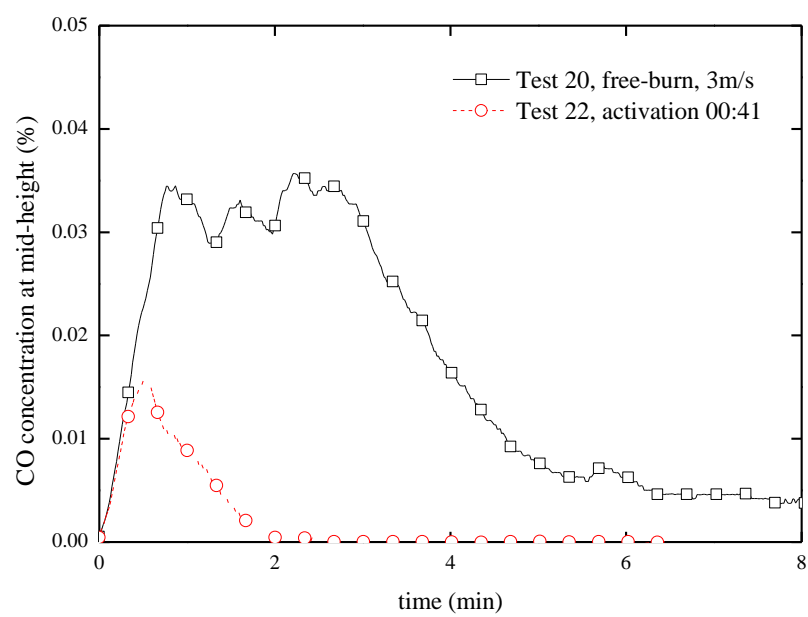

Figure 69 Comparison of $C O$ concentration in the free burn test and fire suppression tests for velocity of $3 \mathrm{~m} / \mathrm{s}$.

\subsubsection{CO production rate}

Figure 70 and Figure 71 show comparisons of $\mathrm{CO}$ production rates in the free burn tests and fire suppression tests for velocity of $1.5 \mathrm{~m} / \mathrm{s}$ and $3 \mathrm{~m} / \mathrm{s}$ respectively. It is shown that the $\mathrm{CO}$ production rates in the fire suppression tests is lower than that in the corresponding free-burn tests with the exception of that in test 9 the $\mathrm{CO}$ production rate is slightly higher during a short period. 


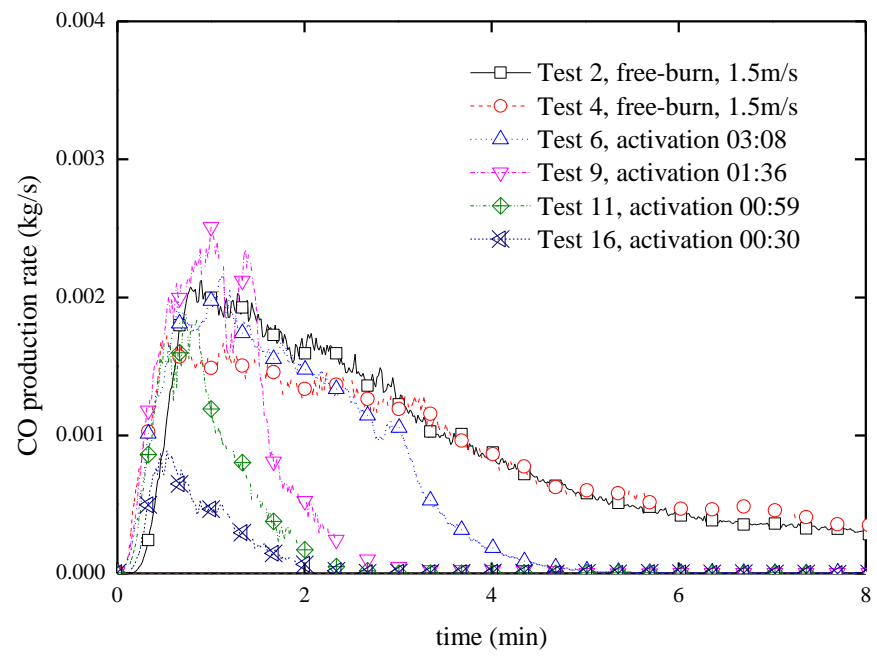

Figure 70 Comparison of $C O$ production rates in the free burn test and fire suppression tests for velocity of $1.5 \mathrm{~m} / \mathrm{s}$ (PUR crib fires).

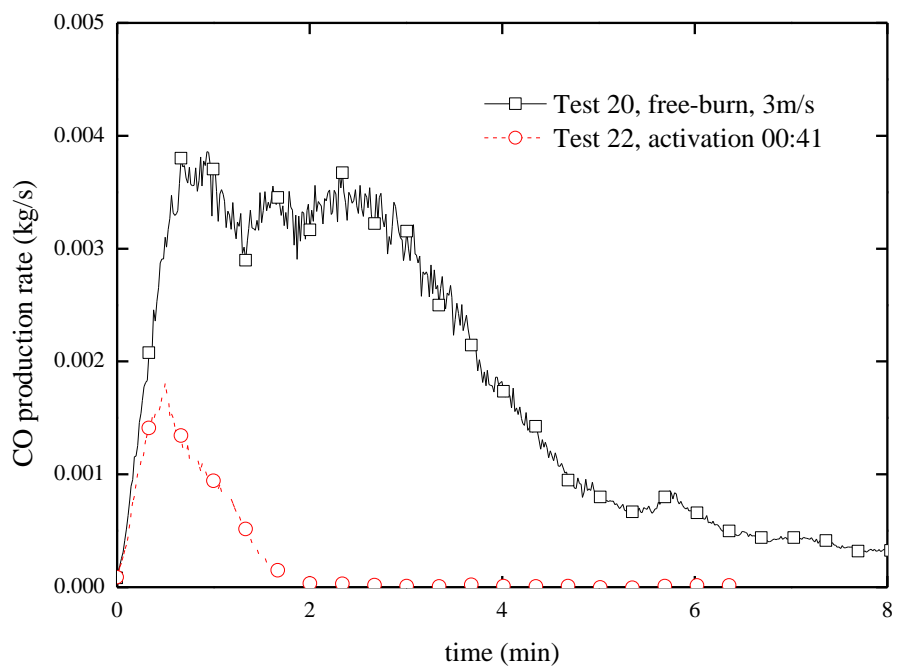

Figure 71 Comparison of $C O$ production rates in the free burn test and fire suppression tests for velocity of $3 \mathrm{~m} / \mathrm{s}$ (PUR crib fires).

\subsubsection{CO yield}

Figure 72 shows comparisons of $\mathrm{CO}$ yields in the free burn tests and fire suppression tests for velocity of $1.5 \mathrm{~m} /$. It is shown in Figure 72 that the CO yields in the tests with $1.5 \mathrm{~m} / \mathrm{s}$ are mostly at the same level, around $0.03 \mathrm{~kg} / \mathrm{kg}$ to $0.035 \mathrm{~kg} / \mathrm{kg}$. However in some tests with fire suppression, the $\mathrm{CO}$ yield increases significantly after the heat release rate decreases to around $200 \mathrm{~kW}$. Especially in test 11, the CO yield increases to around 0.10 $\mathrm{kg} / \mathrm{kg}$ at around $2.6 \mathrm{~min}$ (around three times that in the free-burn test), however, the corresponding heat release rate is as low as $92 \mathrm{~kW}$ at $2 \mathrm{~min}$ and therefore the $\mathrm{CO}$ production rate is expected to be low as shown in Figure 70. 


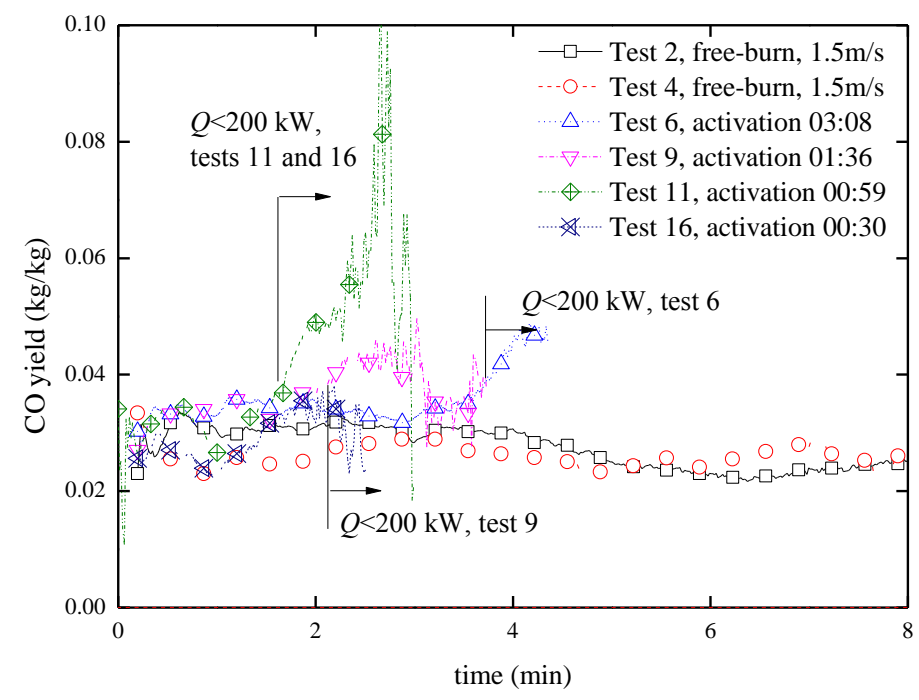

Figure 72 Comparison of $C O$ yield in the free burn test and fire suppression tests for velocity of $1.5 \mathrm{~m} / \mathrm{s}$ (PUR crib fires).

Figure 73 shows comparisons of $\mathrm{CO}$ yields in the free burn tests and fire suppression tests for velocity of $3 \mathrm{~m} / \mathrm{s}$. The CO yield in the free-burn test is in a range of $0.025 \mathrm{~kg} / \mathrm{kg}$ to $0.06 \mathrm{~kg} / \mathrm{kg}$. In test 22, the CO yield decreases after around $1.2 \mathrm{~min}$. From Figure 67 it can be seen that the fire was effectively suppressed and the heat release rate is around $75 \mathrm{~kW}$ at $2 \mathrm{~min}$. This indicate that although in some tests with late activation the $\mathrm{CO}$ yield could increase significantly or slightly but with early activation the $\mathrm{CO}$ yield could be even lower.

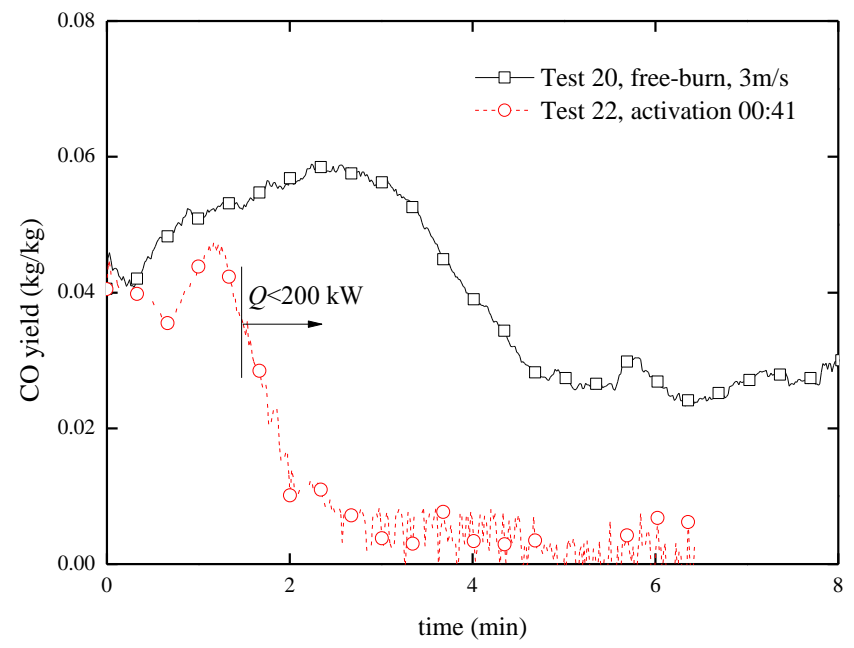

Figure 73 Comparison of $C O$ yield in the free burn test and fire suppression tests for velocity of $3 \mathrm{~m} / \mathrm{s}$ (PUR crib fires). 


\subsubsection{Soot production in PUR crib fires \\ 5.4.3.1 Soot production rate}

Figure 74 and Figure 75 show comparisons of soot production rates in the free burn tests and fire suppression tests for velocity of $1.5 \mathrm{~m} / \mathrm{s}$ and $3 \mathrm{~m} / \mathrm{s}$ respectively. The soot production rates in the free-burn tests are higher than those in the fire suppression tests.

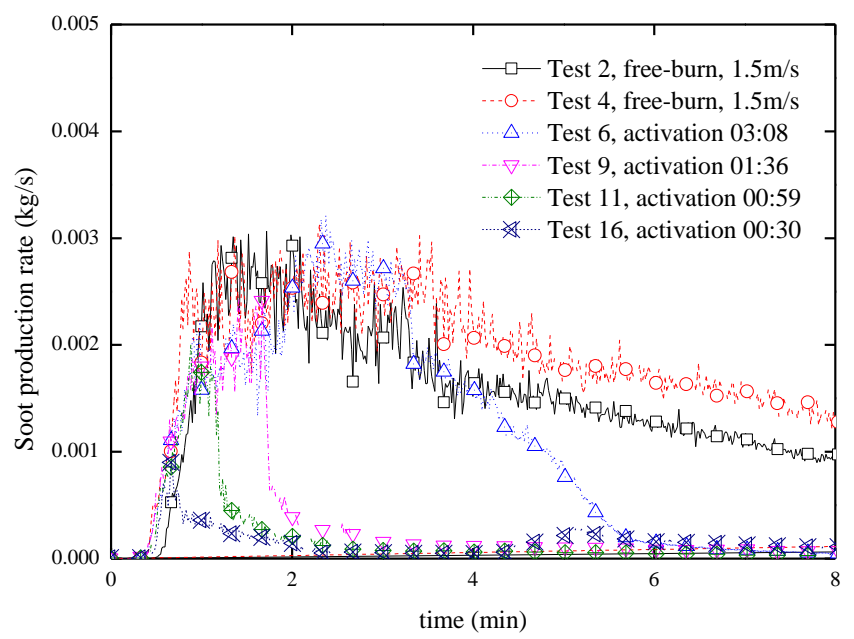

Figure 74 Comparison of soot production rates in the free burn test and fire suppression tests for velocity of $1.5 \mathrm{~m} / \mathrm{s}$. Note that after activation the data are not really soot production rates but upper limits for them.

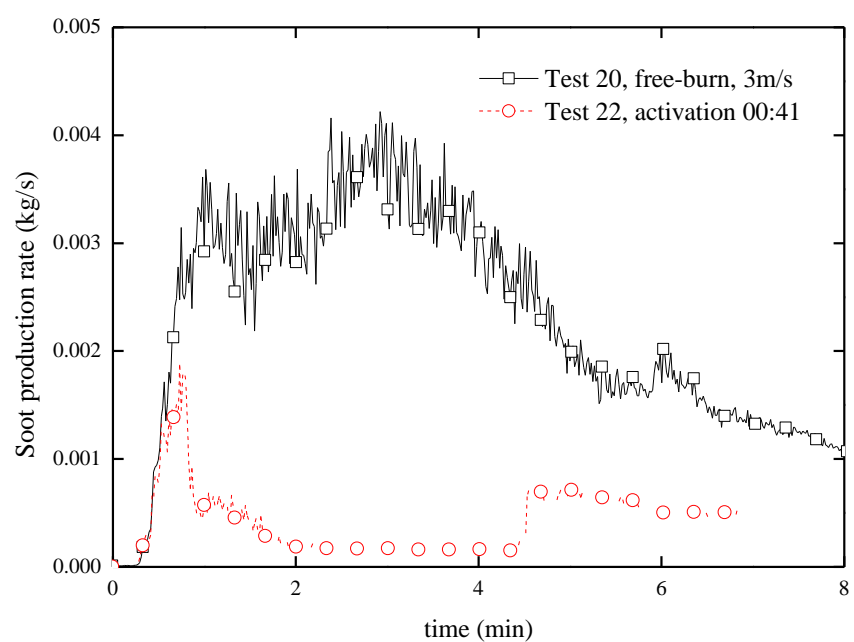

Figure 75 Comparison of soot production rates in the free burn test and fire suppression tests for velocity of $3 \mathrm{~m} / \mathrm{s}$ (PUR crib fires). Note that after activation the data are not really soot production rates but upper limits for them. 


\subsubsection{Soot yield}

Figure 76 shows comparisons of soot yields in the free-burn tests and fire suppression tests for velocity of $1.5 \mathrm{~m} / \mathrm{s}$. The soot yield in the free-burn test tends to increase with time and is mainly in a range of $0.05 \mathrm{~kg} / \mathrm{kg}$ to $0.10 \mathrm{~kg} / \mathrm{kg}$. The soot yields in fire suppression tests are approximately at the same level as in the free burn tests before 2 min. However, generally it increases significantly after suppression. The maximum value is even over $0.25 \mathrm{~kg} / \mathrm{kg}$. Again, note that in fire suppression tests the soot yield after activation in fact represents the upper limit for the soot yield. Further the error in the soot yield could increase significantly in the decay period of the fire.

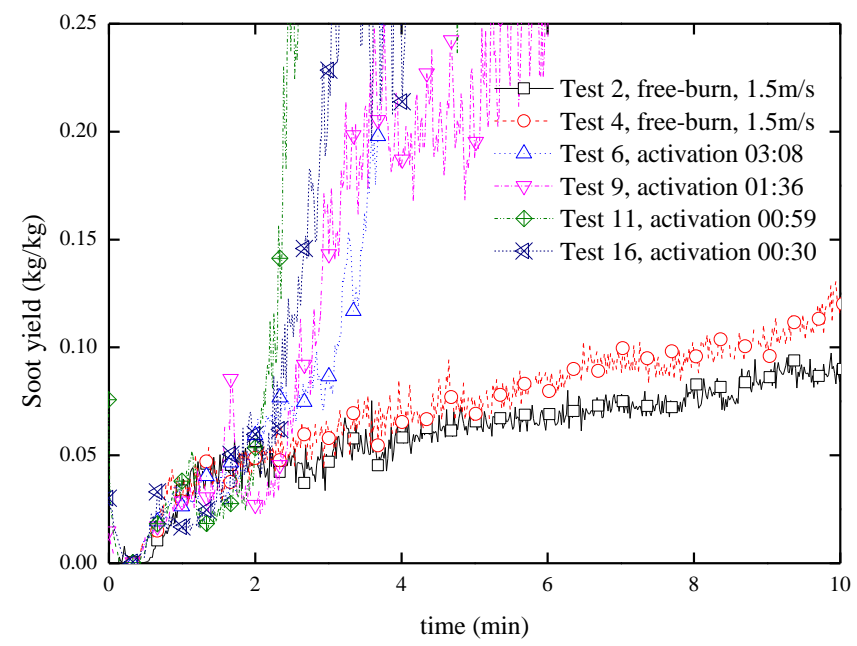

Figure 76 Comparison of soot yield in the free burn test and fire suppression tests for velocity of $1.5 \mathrm{~m} / \mathrm{s}$ (PUR crib fires). Note that after activation the data are not really soot yield.

Figure 77 shows comparisons of soot yields in the free-burn tests and fire suppression tests for velocity of $3 \mathrm{~m} / \mathrm{s}$. Clearly, the soot yields in the fire suppression test are approximately at the same level as in the free burn test. No significant increase is observed. Note that this test corresponds to very early activation and effective suppression.

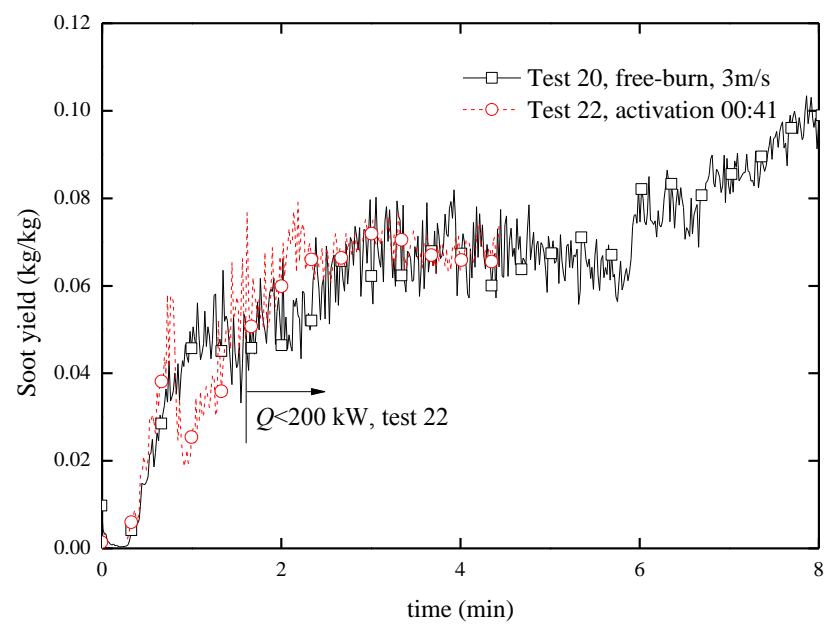

Figure 77 Comparison of soot yield in the free burn test and fire suppression tests for velocity of $3 \mathrm{~m} / \mathrm{s}$. Note that after activation the data are not really soot yield. 


\subsubsection{Visibility at mid tunnel height in PUR crib fires}

Figure 78 and Figure 79 show comparisons of visibilities at mid tunnel height in the free burn tests and fire suppression tests for velocity of $1.5 \mathrm{~m} / \mathrm{s}$ and $3 \mathrm{~m} / \mathrm{s}$ respectively. The minimum visibility in the free-burn test is the lowest. After activation of fire suppression, the visibility increases immediately even though the measurement of visibility account for both effect of soot and water vapour.

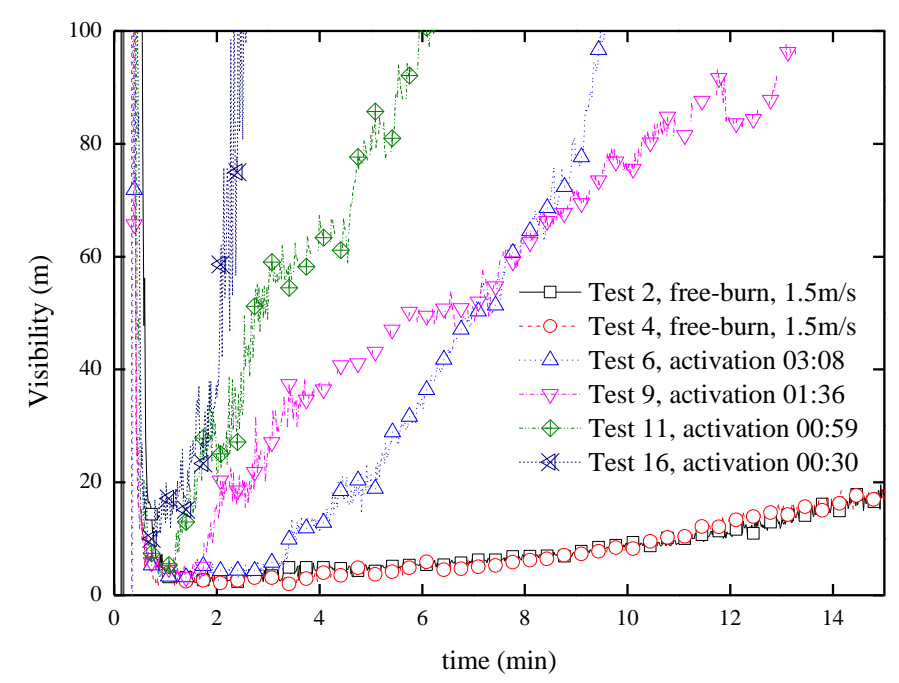

Figure 78 Comparison of visibility in the free burn test and fire suppression tests for velocity of $1.5 \mathrm{~m} / \mathrm{s}$ (PUR crib fires).

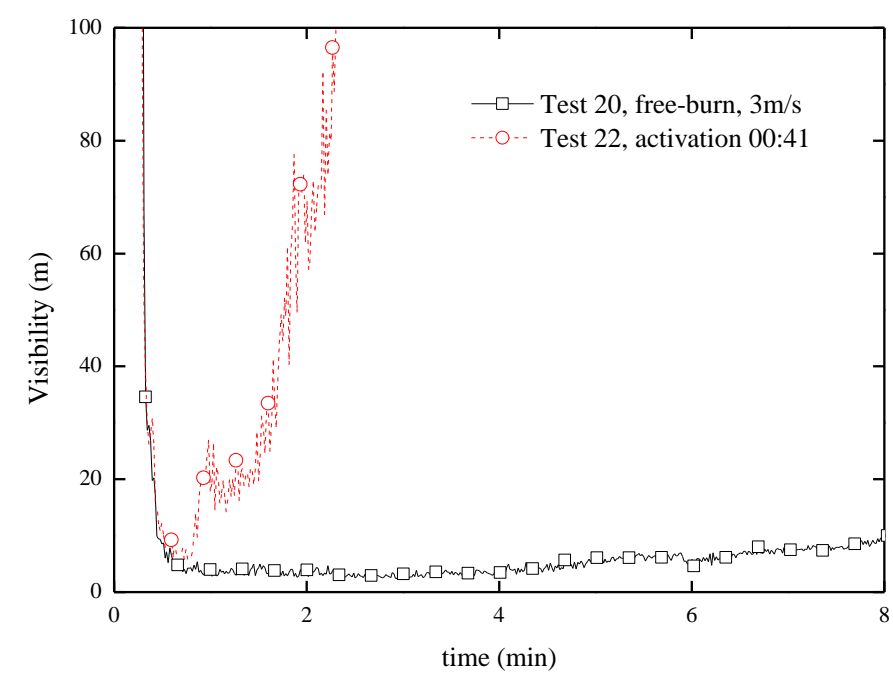

Figure 79 Comparison of visibility in the free burn test and fire suppression tests for velocity of $3 \mathrm{~m} / \mathrm{s}$ (PUR crib fires).

\subsubsection{Discussion of PUR crib fires}

For PUR crib fires, the effect of ventilation velocity on the maximum heat release rate is insignificant. The PUR crib fires are very effectively suppressed under both $1.5 \mathrm{~m} / \mathrm{s}$ and 3 $\mathrm{m} / \mathrm{s}$. 
In some tests with fire suppression, the $\mathrm{CO}$ yield increases significantly after the heat release rate decreases to around $200 \mathrm{~kW}$. However, the $\mathrm{CO}$ concentration at mid-tunnel height in the fire suppression tests is generally lower than that in the corresponding freeburn tests.

The soot yields in fire suppression tests are approximately at the same level as in the free burn tests. After activation the soot yield increases. However, the soot production rates in the free-burn tests are higher than those in the fire suppression tests.

The minimum visibility in the free-burn test is the lowest. After activation of fire suppression, the visibility increases immediately even though the measurement of visibility account for both effect of soot and water droplets.

Note that data of $\mathrm{CO}$ and visibility are reliable but not for data of soot. Test results show that for PUR crib fires, the CO concentration at mid-tunnel height in the fire suppression tests is generally lower than that in the corresponding free-burn tests. Test results of visibility also show that that the free burn test corresponds to the minimum value.

\subsection{HCN production in tunnel tests}

HCN concentration was also measured in the tunnel tests. However, the uncertainty in the measurement is so high that the repeatability of the tests were found to be unsatisfactory. Therefore comparison of results from tests with and without fire suppression is not presented here, , only a short summary is given. From the data obtained from the tests, the measured $\mathrm{HCN}$ is mostly in a range of $2 \mathrm{ppm}$ to $6 \mathrm{ppm}$ in the measurement duct of the industry calorimeter. In the tests with fire suppression, it is observed that the production of $\mathrm{HCN}$ decreases after activation of fire suppression.

\subsection{Summary of test data}

Test data concerning yields of combustion products, i.e. $\mathrm{CO}$ yield and soot yield is summarized in Table 5. Note that the soot yields in tests with fire suppression are indicative values, or to be more precise a upper limits. The range of free burn values presented in Table 5 from these tests are comparable to the values presented in Table 2.

Table 5 Summary of yields of combustion products.

\begin{tabular}{|c|c|c|c|}
\hline Fuel type & test & $\mathrm{Y}_{\mathrm{CO}}$ & $\mathrm{Y}_{\text {soot }}$ \\
\hline & & $\mathrm{kg} / \mathrm{kg}$ & $\mathrm{kg} / \mathrm{kg}$ \\
\hline \multirow{3}{*}{ Tyre } & Pre-test calorimeter (No suppression) & $0.04-0.08$ & $0.05-0.08$ \\
\hline \multirow{3}{*}{ Wood } & Pre-test calorimeter (No suppression) & $0.001-0.02$ & - \\
\cline { 2 - 4 } & Free-burn tunnel & $0.005-0.025$ & $0.002-0.03$ \\
\cline { 2 - 4 } & Suppression tunnel & $0.025-0.11$ & $0.03-0.22^{*}$ \\
\cline { 2 - 4 } & Pre-test calorimeter & $0.02-0.06$ & $0.04-0.11$ \\
\cline { 2 - 4 } & Free-burn tunnel & $0.03-0.12$ & $0.01-0.14$ \\
\cline { 2 - 4 } & Suppression tunnel & $0.04-0.08$ & $0.20^{*}$ \\
\hline \multirow{3}{*}{ PUR } & Pre-test calorimeter & $0.06-0.10$ & $0.03-0.06$ \\
\cline { 2 - 4 } & Free-burn tunnel & $0.02-0.06$ & $0.002-0.08$ \\
\cline { 2 - 5 } & Suppression tunnel & $0.04-0.10$ & $0.15-0.25^{*}$ \\
\hline
\end{tabular}

* The soot yield is upper limit for the soot yield as effect of water vapour has been considered. 


\section{$6 \quad$ Summary and conclusions}

A series of pre-tests under calorimeter and a series of model scale tunnel fire tests with and without fire suppression were carried out to investigate the effect of fire suppression on production of key combustion products. The key parameters accounted for in the tests include fuel type, ventilation velocity and activation time.

\section{- Pre-tests}

For the tyre fire, the soot yield is mainly in a range of 0.05 to 0.08 and it is as high as 0.16 at the ignition stage, and the $\mathrm{CO}$ yield is in a range of 0.04 to 0.08 . For wood pallet fires, the soot yield in the free burn test increases with time up to approximately 0.02 before 2.5 min after ignition and decreases to approx. 0.001 after $5 \mathrm{~min}$. For PE slab fires, the CO yield is mainly in a range of 0.02 to 0.06 , and the soot yield in the free-burn test increases continuously to around 0.11 at $13 \mathrm{~min}$. For PUR slab fires, the CO yield is around 0.08 during most of the burning period and the soot yields in both tests are in a range of 0.03 to 0.06 .

The fires were not effectively suppressed except the PE slab fire. The effect of fire suppression on the $\mathrm{CO}$ yield and soot yield is not significant with the only exception of that they may rise during a short period. However, it should be kept in mind that the water flow rate delivered by the nozzle was only around $1.5 \mathrm{~mm} / \mathrm{min}$ at the floor level, much lower than the one used in tunnel fire tests, as the main objective of the pre-tests was to obtain burning rates of the fuels planned for use in the tunnel fire tests.

\section{- Tunnel fire tests}

For the fires of all the three types of fuel, i.e. wood pallet, PE crib and PUR crib, the effect of ventilation velocity on the maximum heat release rate is insignificant. The fire appears to grow more rapidly at a higher ventilation velocity. After activation of the fire suppression system with a water density of $5 \mathrm{~mm} / \mathrm{min}(10 \mathrm{~mm} / \mathrm{min}$ at full scale), the fires were effectively suppressed under all the velocities tested, with or without coverage. The wood crib fires take slightly longer time to decay compared to the plastic fires. The fire with coverage both develops and decays more slowly but the maximum heat release rate is approximately the same.

The CO yields in the free burn tests tend to decrease slightly with the ventilation velocity and the time. In tests with fire suppression, the $\mathrm{CO}$ yields generally increase with the decreasing heat release rates. In tests with later activation after the heat release rate decreases to around $100 \mathrm{~kW}$ to $200 \mathrm{~kW}$ ( $3 \mathrm{MW}$ to $6 \mathrm{MW}$ at full scale), significant increase (3.5 to 4.5 times increase) in CO yield could be observed, especially for wood pallet fires. Note that without activation of the water spray system the fires could develop up to $1800 \mathrm{~kW}(57 \mathrm{MW})$ to $3200 \mathrm{~kW}(100 \mathrm{MW})$. In other words, production of CO mainly occurs when the fire is close to the extinguishment. However in most tests with suppression, the contribution of the high $\mathrm{CO}$ yield to the $\mathrm{CO}$ production rate is limited as the corresponding heat release rates are at a low level. Given that the maximum $\mathrm{CO}$ concentration at mid tunnel height (10.6 m downstream, corresponding to $42 \mathrm{~m}$ at full scale) in the free burn test is still the highest for all the fuels and velocities tested, the free burn tests could still represent the worst scenarios from the point of view of $\mathrm{CO}$ concentration and evacuation. Further, early activation reduces the $\mathrm{CO}$ concentration significantly.

Concerning soot it should be kept in mind that the estimated soot production or soot yield after activation of fire suppression become higher than real values and can only be used 
as indications of upper limits. The reason for this is that the attenuation of light intensity accounts for effects of both soot and water droplets. The soot yields in the free burn test tend to decrease with the ventilation velocity and increase with time. The soot yields in free burn tests and fire suppression tests approximately lie at the same level but after activation when the heat release rate is lower than a certain value, e.g. $150 \mathrm{~kW}-200 \mathrm{~kW}$, the soot yields increase significantly with time. Fortunately this period is very short and also corresponds to very small heat release rates. Therefore the contribution to the smoke production rate is limited even if the soot yield is high. In all the tests the maximum soot production rate in the free-burn test is the highest. Consequently, during the whole period, it can be concluded that the free-burn test can be considered as the worst case in terms of visibility.

The visibility in the free burn tests for all the fuels is generally the lowest compared to fire suppression tests due to that the heat release rate decreased immediately after activation of the fire suppression system.

Note that data of $\mathrm{CO}$ and visibility are reliable but not for data of the soot. In summary, test results of $\mathrm{CO}$ concentration at the early stage indicate that in most cases, the free burn test corresponds to the worst scenario despite that in the decay period of a fire with late activation the $\mathrm{CO}$ concentration could be higher. Further, test results of visibility show that that the free burn test corresponds to the minimum value.

It is observed that wood pallet fires behave differently compared to the plastic crib fires. In the wood crib tests with late activation, the $\mathrm{CO}$ concentration in the decay period is slightly higher than that in the free-burn test. The difference in the $\mathrm{CO}$ yield is, however, much larger. The $\mathrm{CO}$ yield of a wood pallet fire after fire suppression is generally 3.5 to 4.5 times that in a free-burn test while generally the $\mathrm{CO}$ yield in the plastic fires increases slightly after suppression and only in tests 11 and 25 significant increase is observed. The high $\mathrm{CO}$ yield for wood pallet fires after suppression indicates strong interaction between the water droplets, the produced water vapours and the combustion gases for wood pallet fires, which results in incomplete combustion. There could be two reasons for this. One reason could be that the cellulose materials, e.g. wood, absorb water into the material, which to some extent behaves as a water sink. During fire suppression, the unburnt fuels can be pre-wetted while part of the fuels could be extinguished and then absorbs water. During the fire, a large amount of water vapours could be produced from these extra water sources and interact strongly with the combustion gases. Another reason could be that for a same maximum heat release rate, a wood pallet fire corresponds to a larger exposed fuel surface area and more fuel surfaces could be pre-wetted, compared to a plastic crib fire.

Based on the test data and the above analysis, it can be concluded for the fires tested that low-pressure fire suppression does not cause significant adverse effect in case that the fire can be effectively suppressed after activation, that is, the fire size has been reduced to less than $40 \%$ of that in the free-burn test. To achieve this goal, early activation and high water density is required. In case that the fire is not effectively suppressed, e.g. when the water density is too low or activation is too late, the $\mathrm{CO}$ concentration and visibility could be much worse than in the free-burn test.

Therefore, from the point of view of production of combustion products, only fire suppression systems with sufficient capability and early activation are recommended to be used in tunnels. 
1. Ingason, H., G. Appel, and Y.Z. Li, Large scale fire tests with fixed fire fighting system in Runehamar tunnel, 2014, SP Report 2014:32, SP Technical Research Institute of Sweden: Borås, Sweden.

2. Ingason, H. and Y.Z. Li., TECHNICAL TRADE-OFFS USING FIXED FIRE FIGHTING SYSTEMS, in 7thInternational Conference 'Tunnel Safety and Ventilation2014: Graz.

3. Gehandler, J., The transportation of water reactive substances through road tunnels equipped with sprinkler system: A literature review, 2014, SP Technical Research Institute of Sweden, SP Report 2014:37.

4. Lemaire, T. and Y. Kenyon, Large Scale Fire Tests in the Second Benelux Tunnel. Fire Technology, 2006. 42: p. 329-350.

5. Development of new innovative technologies, 2006, UPTUN Work Package 2.

6. Tuomisaari, M. Full Scale fire testing for raod tunnel applications - evaluation of acceptable fire protection performance. in Third International Symposium on Tunnel Safety and Security. 2008. Stockholm.

7. Mawhinney, J.R. Evaluating the performance of water mist systems in road tunnels. in IV Congreso Bienal Apci Ingenieria de Pci 2007. Madrid.

8. Lemaire, A.D. and V.J.A. Meeussen, Effects of water mist on real large tunnel fires: Experimental determination of BLEVE-risk and tenability during growth and suppression, 2008, Efectis Nederland BV.

9. Kratzmeir, S. and M. Lakkonen. Road Tunnel Protection by water mist systems Implementation of full scale fire test results into a real project. in Third International Symposium on Tunnel Safety and Security. 2008. Stockholm: SP

10. Cheong, M.K., et al., Heat Release Rates of Heavy Goods Vehicle Fire in Tunnels with Fire Suppression System. Fire Technology, 2014. 50: p. 249-266.

11. Cheong, M.K., et al. Heat release rates of heavy goods vehicle fires in tunnels. in 15th International Symposium on Aerodynamics, Ventilation \& Fire in Tunnels. 2013. Barcelona, Spain: BHR Group.

12. Ingason, H., et al. Large scale fire tests with a Fixed Fire Fighting System (FFFS). in ISTSS 6th International Symposium on Tunnel Safety and Security. 2014. Marseille.

13. Li, Y.Z., et al., Model scale tunnel fire tests with water-based fire suppression systems, 2014, SP Report 2014:02, SP Technical Research Institute of Sweden: Borås, Sweden.

14. Li, Y.Z. and H. Ingason, Model scale tunnel fire tests with automatic sprinkler. Fire Safety Journal, 2013. 61: p. 298-313.

15. Li, Y.Z. and H. Ingason, The maximum ceiling gas temperature in a large tunnel fire. Fire Safety Journal, 2012. 48: p. 38-48.

16. Li, Y.Z., H. Ingason, and A. Lönnermark, Correlations between different scales of metro carriage fire tests, 2013, SP Report 2013:13, SP Technical Research Institute of Sweden: Borås.

17. Li, Y.Z. and H. Ingason. The fire growth rate in a ventilated tunnel fire. in 10th International Symposium on Fire Safety Science (IAFSS). 2011. Maryland, USA.

18. Li, Y.Z., B. Lei, and H. Ingason, Study of critical velocity and backlayering length in longitudinally ventilated tunnel fires. Fire Safety Journal, 2010. 45: p. 361-370.

19. Ingason, H. and Y.Z. Li, Model scale tunnel fire tests with longitudinal ventilation. Fire Safety Journal, 2010. 45(6-8): p. 371-384.

20. Li, Y.Z., H. Ingason, and A. Lönnermark. Fire development in different scales of train carriages. in 11th International Symposium on Fire Safety Science. 2014. Christchurch, New Zealand. 
21. Li, Y.Z. and H. Ingason, Scaling of wood pallet fires, 2014, SP Report 2014:57, SP Technical Research Institute of Sweden: Borås, Sweden.

22. Hägglund, B. and K. Jöred, Simulating the Smoke Filling in a Two-compartment Structure, 1991, National Defence Research Establishment: Sundbyberg, Sweden.

23. Janssens, M. and W.J. Parker, Oxygen Consumption Calorimetry, in Heat Release in Fires, V. Babrauskas and T.J. Grayson, Editors. 1995, E \& FN Spon: London, UK. p. 31-59.

24. Ingason, H., Fire Dynamics in Tunnels, in In The Handbook of Tunnel Fire Safety, 2nd Edtion A.N. Beard and R.O. Carvel, Editors. 2012, ICE Publishing: London. p. 273-304.

25. Lönnermark, A. and P. Blomqvist, Emissions from Tyre Fires, 2005, SP Swedish National Testing and Research Institute: Borås, Sweden.

26. Tewarson, A., Generation of Heat and Chemical Compounds in Fires, in SFPE Handbook of Fire Protection Engineering, P.J. DiNenno, et al., Editors. 1988, NFPA. p. 1-179 -- 1-199.

27. Dahlberg, M., The SP Industry Calorimeter: For rate of heat release measurements up to $10 \mathrm{MW}, 1993$, SP Swedish National Testing and Research Institute: Borås, Sweden. 


\section{SP Technical Research Institute of Sweden}

Our work is concentrated on innovation and the development of value-adding technology. Using Sweden's most extensive and advanced resources for technical evaluation, measurement technology, research and development, we make an important contribution to the competitiveness and sustainable development of industry. Research is carried out in close conjunction with universities and institutes of technology, to the benefit of a customer base of about 9000 organisations, ranging from start-up companies developing new technologies or new ideas to international groups.

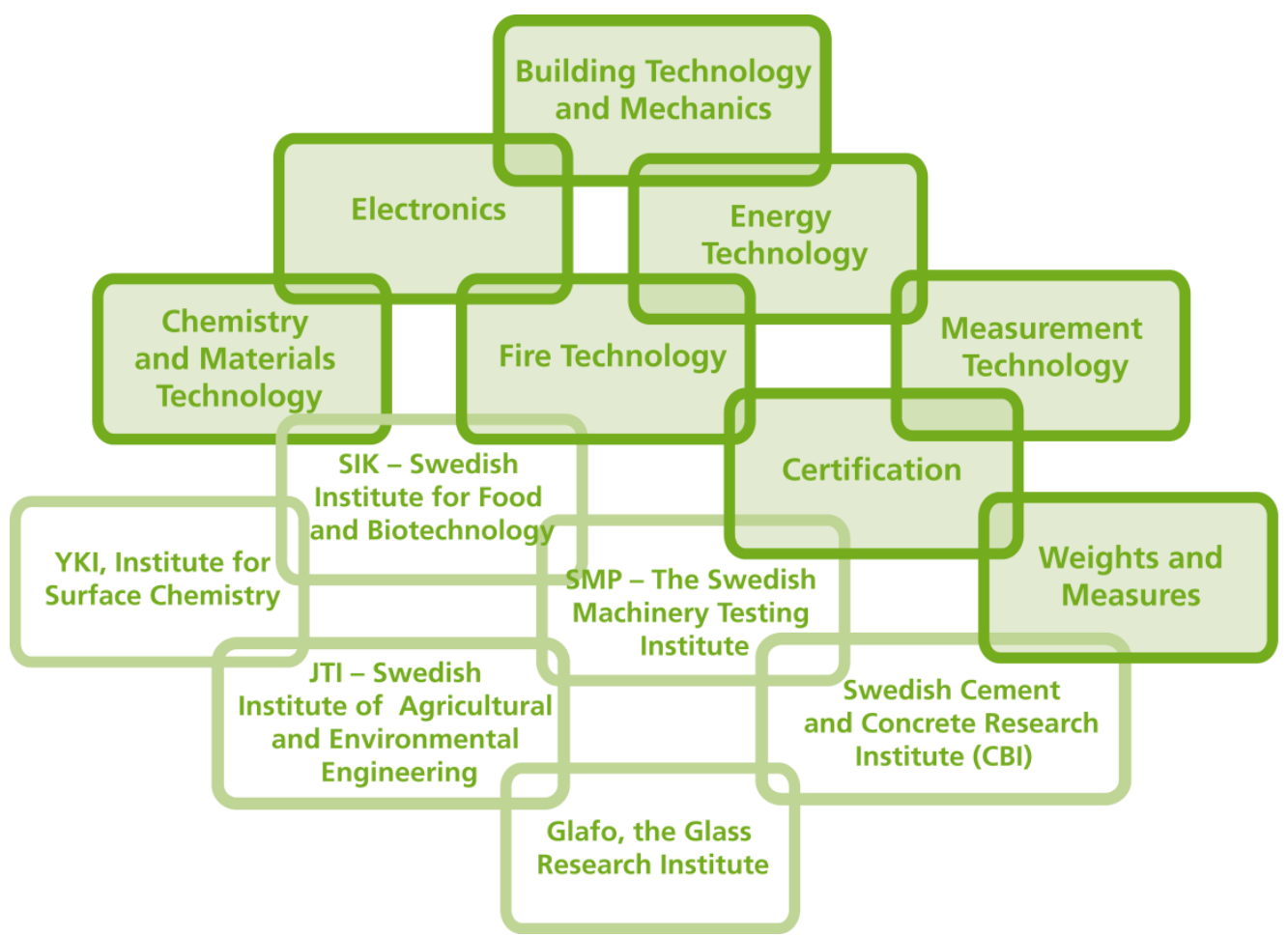

SP Technical Research Institute of Sweden Box 857, SE-501 15 BORÅS, SWEDEN

Telephone: +46 1051650 00, Telefax: +46 33135502

E-mail: info@sp.se, Internet: www.sp.se

www.sp.se
Fire Research

SP Report 2015:09

ISBN 978-91-88001-39-9

ISSN 0284-5172

More information about publications published by SP: www.sp.se/publ 